Check for updates

Cite this: RSC Adv., 2018, 8, 12232

Received 10th January 2018 Accepted 2nd March 2018

DOI: $10.1039 / c 8 r a 00283 e$

rsc.li/rsc-advances

\section{Computational investigations of click-derived 1,2,3-triazoles as keystone ligands for complexation with transition metals: a review $\dagger$}

\author{
Tayebeh Hosseinnejad, (D) * Fatemeh Ebrahimpour-Malmir and Bahareh Fattahi
}

In recent years, metal complexes of organo 1,2,3-triazole click-derived ligands have attracted significant attention as catalysts in many chemical transformations and also as biological and pharmaceutical active agents. Regarding the important applications of these metal-organo 1,2,3-triazole-based complexes, in this review, we focused on the recently reported investigations of the structural, electronic, and spectroscopic aspects of the complexation process in transition metal complexes of 1,2,3-triazole-based click ligands. In line with this, the coordination properties of these triazole-based click ligands with transition metals were studied via several quantum chemistry calculations. Moreover, considering the complexation process, we have presented comparative discussions between the computational results and the available experimental data.

\section{Introduction}

1,3-Dipolar cycloaddition is a chemical reaction between a 1,3dipole and a dipolarophile to afford a five-membered ring. Mechanistic study and the synthetic application of this

Department of Chemistry, Faculty of Physics \& Chemistry, Alzahra University, Vanak, Tehran, Iran. E-mail: tayebeh.hosseinnejad@alzahra.ac.ir; Fax: +98-21-8804-1344; Tel: $+98-9124775800$

$\dagger$ Dedicated to the unique essence of a great teacher, Professor Majid M. Heravi, who is the realization of simorgh in the form of a scientist. important reaction were investigated initially via Rolf Huisgen's study reported in the 1960s..$^{1,2}$

Although this reaction is often referred to as a 1,3-dipolar cycloaddition reaction, it is worth noting that the specific reaction is actually between an organic azide and an alkyne to construct a common and useful heterocyclic system of 1,2,3triazoles, as initially realized by Rolf Huisgen ${ }^{1,2}$ (Scheme 1). It was the American chemist K. Barry Sharpless who referred to this cycloaddition as "the cream of the crop" of click chemistry. Click chemistry reactions are usually high yielding and wide in scope and also generate only by-products that can be removed

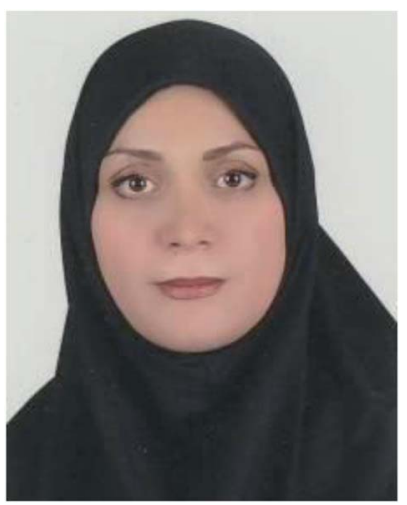

Tayebeh Hosseinnejad was born in 1979 in Tehran, Iran. She received her $B S c, M S c$, and $P h D$ degrees from the University of Tehran in 2001, 2003, and 2007, respectively. She completed her doctoral thesis under the supervision of Prof. Hassan Behnejad in the field of nonequilibrium statistical thermodynamics. She currently works as an assistant professor in Alzahra University, Tehran, Iran. Her research interests focus on computational organic and organometallic chemistry and statistical thermodynamics. She has published more than 31 papers in reputed journals and has been recently serving as the guest editor of the thematic issue inCurrent Organic Chemistry.

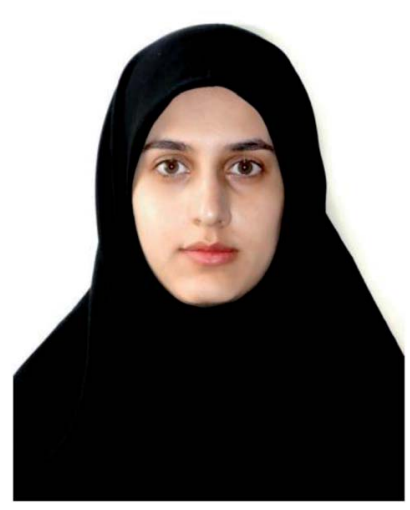

Fatemeh Ebrahimpour-Malamir was born in Tehran, Iran in 1990. She received her B.Sc. degree in Applied Chemistry from Sharif University of Technology, Tehran, Iran (2014) and her M.Sc. degree in Organic Chemistry at Alzahra University, Tehran, Iran (2016) under the supervision of Prof. Majid M. Heravi and the advision of $\mathrm{Dr}$ Tayebeh Hosseinnejad. Her researches are concentrated on the catalyzed click reactions from the combined experimental and computational viewpoints. 


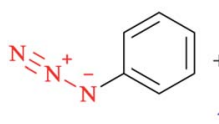

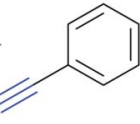

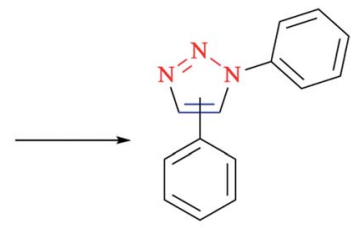

3
Scheme 1 Synthesis of a mixture of 1,4- and 1,5-triazoles via an azide-alkyne cycloaddition reaction.

easily with no chromatography required. Click reactions are regioselective and stereospecific, simple to conduct and can be also performed in easily removable or benign solvents. ${ }^{3}$

An outstanding variant of the Huisgen 1,3-dipolar cycloaddition is the copper(I)-catalyzed cycloaddition click reaction, in which organic azides and terminal alkynes are reacted to afford 1,4-regioisomers of 1,2,3-triazoles as the only products under mild reaction conditions and in a much shorter reaction time.

After the discovery of the regioselective copper(I)-catalyzed azide-alkyne cycloaddition (CuAAC) reaction, so-called click reaction, ${ }^{4,5}$ the synthesis of click ligands (the archetypal example of click chemistry) attracted significant attention due to its reliability, simplicity, and mild reaction conditions.

It should be mentioned that the mild-functional-grouptolerant click synthesis of 1,2,3-triazole species led to their widespread applications as building blocks throughout synthetic chemistry. The application of the CuAAC click reaction in the synthesis of 1,2,3-triazoles as a stable linkage between chemical or biological components and coordinating agent with metal ions and also their potential in catalytic systems were assessed, subsequently, increasing their impact far beyond the initial purpose of click chemistry. ${ }^{6-10}$

As a matter of fact, part of the special interest and focus on this type of reaction is due to the significant and diverse biological activities shown by 1,2,3-triazoles. ${ }^{11-15}$ These compounds can act as rigid linking units and can mimic the atom placement and electronic properties of a peptide bond, but with no hydrolytic cleavage effect. It is important to note that 1,2,3-

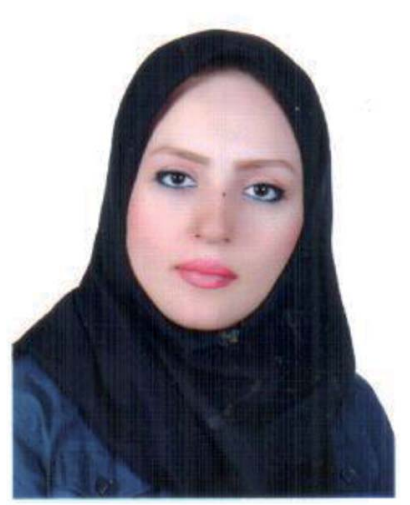

Bahareh Fattahi was born in Tehran, Iran in 1988. She received her B.Sc. in Applied Chemistry from Islamic Azad University, Tehran, Iran (2010) and her M.Sc. degree in Organic Chemistry at Alzahra University, Tehran, Iran (2016) under supervision of Professor Majid M. Heravi. She has also trained and investigated in the field of computational chemistry by the supervision of Dr Tayebeh Hosseinnejad. Her researches are focused on heterocyclic chemistry, catalysis, click reactions and computational chemistry. triazoles have the following structural and electronic features, which have a significant high impact on their biological pharmaceutical applications. The dipole moment of triazoles is much stronger than that of an amide bond, which leads to increasing the hydrogen bond donor and acceptor properties of triazoles, subsequently enhancing the peptide bond mimicry. ${ }^{15,16}$

Due to the aforementioned potential of 1,2,3-triazoles to mimic the peptide bond role, several biological activities have been screened for 1,2,3-triazoles, including anti-HIV activity, ${ }^{17}$ selective $\beta_{3}$ adrenergic receptor inhibition, ${ }^{\mathbf{1 8}}$ anti-bacterial activity, ${ }^{19}$ and potent anti-histamine activity. ${ }^{20}$ It is important to note that 1,2,3-triazole click compounds have anticancer potency, which can be subsequently increased upon complexation with transition metal ions. ${ }^{\text {21-23 }}$

On the other hand, based on the solid-phase click chemistry, switching from the solution-phase to solid-phase chemistry provides a playground for the application of triazoles to act as linkers to attach other functionalities to solid-phase resins ${ }^{24}$ as well as being able to functionalize metal surfaces for modification of their properties ${ }^{25}$ and to enable prompt adhesion. ${ }^{26}$

Recently, the promise of metal complexes of organo 1,2,3triazole-based ligands has been demonstrated in the catalysis of some chemical transformations, ${ }^{27,28}$ such as hydroformylation and intramolecular hydroamination. ${ }^{29-36}$

It was shown that the catalytic efficiency of these complexes essentially depends on the appropriate electron-donating ability of atoms in 1,2,3-triazole moieties. Precisely speaking, the 1,2,3triazole unit in the click ligand has an N-donor coordinating role to play through two types of nitrogen atoms: $\mathrm{N}(2)$ and $\mathrm{N}(3) \cdot{ }^{37}$ From a mechanistic viewpoint, such a set of donor groups may stabilize intermediate species via coordination and increase reactivity and can also reduce the energy of transition states by partial dissociation to consequently improve the catalytic efficiency of the complex.

To the best of our knowledge, a few research studies have reported on the synthesis of 1,2,3-triazole organo-based ligands and the applications of their metal complexes as catalysts. ${ }^{38-42}$

In addition to their catalysis applications, some transition metal complexes of 1,2,3-triazole-based ligands have attracted interest for their luminescent properties and consequent applications as radiopharmaceutical agents in bioimaging techniques. $^{43-45}$

Envisaging the importance of such complexes and their several applications, the structural, electronic, and spectroscopic features of these metal complexes with 1,2,3-triazolebased ligands have been widely investigated from experimental and computational viewpoints.

In line with this, several spectroscopic techniques have been used to assess the structural and electronic properties of these complexes. On the other hand, the veracity of computational methods was ascertained by comparison of the calculated results with experimental observations. However, the calculated geometrical parameters of these complexes could be compared with the available X-ray crystal structure and also the frequency calculations can be attributed to FT-Raman spectra. It should be mentioned that Raman spectroscopy can probe the nature of 
electronic transitions and also provide an insight into the structural character of the donor and acceptor MOs. ${ }^{46}$ Clearly speaking, the resonance effect enhances the Raman spectra bands corresponding to the structural changes associated with the photoexcitation. ${ }^{47-52}$ So, the pattern of band enhancements can be combined and interpreted with a computational analysis of the vibration normal modes.

On the other hand, the HOMO (highest occupied molecular orbital) and LUMO (lowest unoccupied molecular orbital) energy gap of a complex can be correlated to its chemical reactivity and this information can be applied to interpret the catalytic role of these transition metal complexes of 1,2,3triazole-based ligands.

In this route, the structural and electronic aspects of coordination in a series of mono and multinuclear transition metal complexes containing nitrogen-donating triazole ligands were investigated computationally through structural optimization calculations via density functional theory (DFT) ${ }^{53,54}$ and ligand field analysis. ${ }^{55}$ Moreover, the conformational fluxionality of flexible triazole-based click ligands in coordination with metal ion centers was assessed in the formation of trans or anti-trans conformers of six-membered metallacycles, and the isomerization mechanism was also studied to obtain the activation and entropy of the reactions via DFT computations. ${ }^{56,57}$

Moreover, the structural aspects of complexation between 1,2,3-triazole-based organochalcogen ligands and metal ions were studied via DFT computations and crystallographical methods and showed a disposition of donor atoms around the metal center with several coordination modes through the triazole skeleton. ${ }^{38-41}$

The functionalization effect on the structural and photophysical properties of the complexation of triazole-based ligands with transition metal ions have been studied and reviewed..$^{58-62}$

In this respect, the relation between the energy adsorption band of the electronic spectra and metal-to-ligand charge transfer (MLCT) for all the complexes were modeled via DFT approaches. ${ }^{61,63-65}$

The coordination and electronic features of functionalized triazaphosphole click ligands and their substitution pattern were studied in comparison with triazole-based click ligands using quantum chemical computations, and the results were verified by crystallographical data. ${ }^{60}$

We recently investigated the synthesis and characterization of various heterogeneous nanocatalysts and their applications in various organic reactions, especially in the regioselective synthesis of 1,2,3-triazoles via a click reaction. ${ }^{67-75}$ We also recently focused on combining experimental and

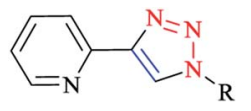

4

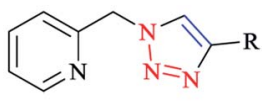

5
Scheme 2 Bidentate $\mathrm{N}^{\wedge} \mathrm{N}$ chelators: 2-(1-R-1H-1,2,3-triazol-4-yl) pyridines (4) and [(4-R-1H-1,2,3-triazol-1-yl)methyl]pyridines (5).

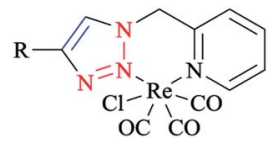

Scheme 3 fac- $\operatorname{Re}(\mathrm{CO})_{3} \mathrm{Cl} \cdot 2-(1-\mathrm{R}-1 \mathrm{H}-1,2,3$-triazol-4-yl)pyridine (6) complexes.

computational studies to provide a deeper insight into this important reaction. We reviewed the mechanistical aspects of the 1,3-dipolar Huisgen cycloaddition reactions and the regioselective behavior of metal-catalyzed click reactions using computational chemistry.,76

Armed with these experiences, herein, we show that mild one-pot click methods can be used to readily and rapidly synthesize a family of functionalized multi-dentate 1,2,3-triazole ligand scaffolds, containing electrochemically, photochemically, and biologically active functional groups in a reliable yield. Overall, in this review, we present the experimental and computational features of the synthesis and properties of functionalized click ligands and their complexes with transition metal cations. The structural, photochemical, and biological properties of the complexes will be discussed via the spectroscopic and computational analysis.

\section{1,2,3-Triazole-containing chelators: click synthetic vision}

Click ligands are generally prepared using the functional-grouptolerant $\mathrm{Cu}(\mathrm{I})$-catalyzed 1,3-dipolar cycloaddition of organic azides with terminal alkynes (CuAAC reaction), ${ }^{10,77,78}$ which leads to the rapid generation of a wide range of functionalized ligands in association with the mild reaction conditions.

The 2-(1-R-1H-1,2,3-triazol-4-yl)pyridine 4 and [(4-R-1H-1,2,3triazol-1-yl)methyl]pyridine 5 (Scheme 2) click ligands have emerged as readily modified bipy and phen surrogates. ${ }^{\mathbf{8 , 7 9 0}}$

These bidentate click ligands form rhenium(I) complexes with a $1: 1$ metal : ligand ratio. The complexes of these ligands have wide applications in electronic ${ }^{81,82}$ and luminescent ${ }^{29,83-89}$ materials, catalysts, ${ }^{{ }^{90-92}}$ and in metallo-pharmaceuticals. ${ }^{93-95}$

Moreover, with the goal of the development of novel rhenium(I) complexes as luminescent and pharmaceutical agents, rhenium(I) complexes from mono-functionalized 2-pyridyl1,2,3-triazole derivatives (pyta) were synthesized as alternative ligands to $2,2^{\prime}$-bipyridines. ${ }^{63}$ Nevertheless, only a few of them possessed a tethering group for further coupling to a biomolecule. ${ }^{63,96}$

In short, the synthesis of novel pyta derivative grafted onto a bioactive pharmacophore was reported by considering the advantages of trendy click chemistry. Moreover, the

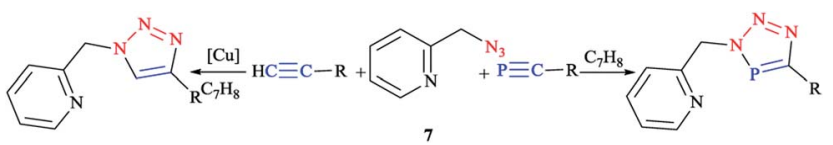

Scheme 4 Syntheses of 2-pyridylmethyl-functionalized triazoles (left) and 2-pyridylmethyl-functionalized triazaphospholes (right). 


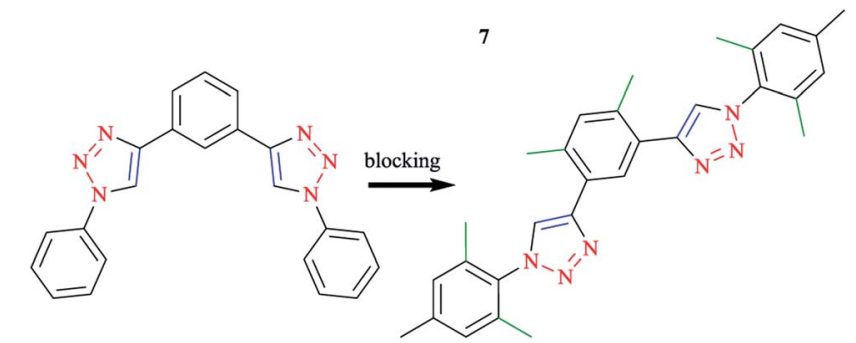

Scheme 5 Optimization process, alternative coordination modes (left), and desired coordination mode (right). corresponding rhenium complexes were synthesized and characterized in the solid and solution states. ${ }^{63,97}$

In another research, a family of electronically tuned fac$\mathrm{Re}(\mathrm{CO})_{3} \mathrm{Cl} \cdot 2-(1-\mathrm{R}-1 H-1,2,3$-triazol-4-yl)pyridine 6 complexes (Scheme 3) was generated using efficient click reactions.

These safe one-pot CuAAC click methodologies produced a series of electronically modified 2-pyridyl-1,2,3-triazole ligand architectures, which were readily converted into the corresponding family of $f a c$ - $\left[\mathrm{Re}(\mathrm{CO})_{3} \mathrm{Cl}\right]$ complexes.

Elemental analysis demonstrated that the isolated powders were pure and showed that the bidentate ligands generated rhenium(I) complexes in a $1: 1$ metal/ligand ratio. ${ }^{64}$

The coordination chemistry of analogous donorfunctionalized triazoles has been widely investigated over the

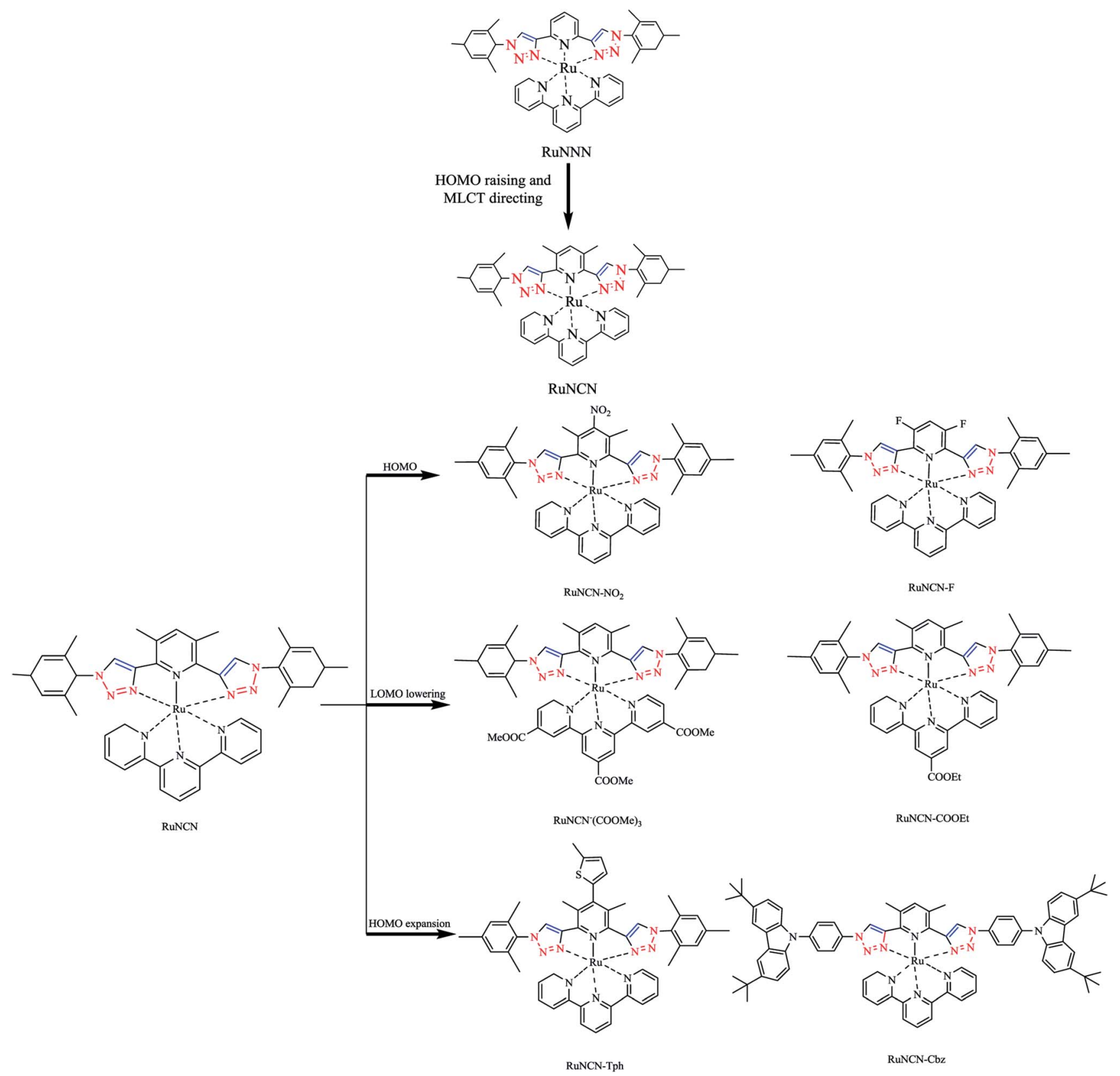

Scheme 6 Synthesis procedures of ruthenium(II) complexes. 


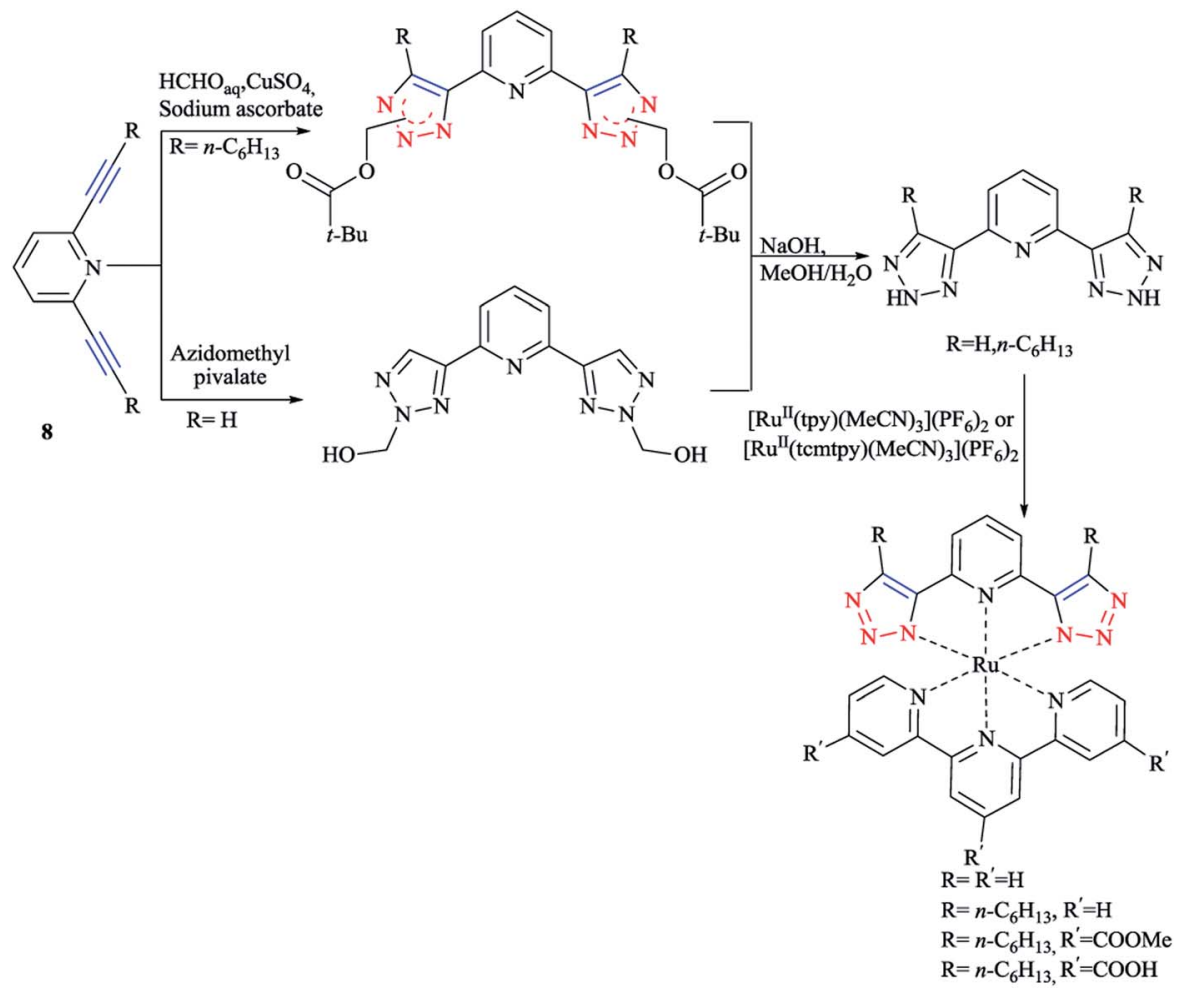

Scheme 7 Synthesis of bis(tridentate)ruthenium(॥) complexes.

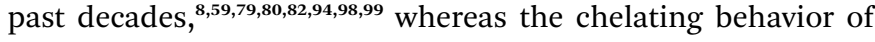
donor-functionalized $3 H$-1,2,3,4-triaza-phosphole derivatives is still practically uncharted. ${ }^{\mathbf{1 0 0 - 1 0 2}}$ Clearly speaking, the click reaction between donor-functionalized azides and phosphaalkynes enables access to polydentate ligands, so that we can adjust the stereoelectronic properties based on the additional phosphorus heteroatom and the nature of the substituents. However, few investigations have been performed on the influence of an additional heteroatom on the properties of triazole derivatives. So far, only one example of such a species was assessed and characterized crystallographically, namely a tridentate ligand, tripodaltris (triazaphosphole), coordinated toward a $\mathrm{Pt}(0)$ center via $\mathrm{P}$ dentate, as reported by Jones et al. ${ }^{\mathbf{1 0 3}}$ In the next research studies, the click reaction between 2-(azidomethyl)pyridine ${ }^{104} 7$ with $t \mathrm{Bu}-\mathrm{C} \equiv \mathrm{P}^{\mathbf{1 0 5}}$ and $\mathrm{TMS}-\mathrm{C} \equiv \mathrm{P}^{\mathbf{1 0 6}}$ (trimethylsilyl is denoted as TMS) was reported according to the standard literature processes. Furthermore, the reaction between equimolar amounts of the azide and tertbutylphospha-ethyne was carried out at room temperature in toluene via a click methodology. Interestingly, it has been also reported that trimethylsilylphospha-ethyne reacts straightforwardly with 2-(azidomethyl)pyridine 7 and proceeds to give the TMS-substituted triazaphosphole derivatives (Scheme 4). ${ }^{\mathbf{6 6}}$

Click-derived ${ }^{3,107}$ ligands have been introduced as analogs of polypyridyl ligands, in particular of terpyridine (tpy), ${ }^{\mathbf{9 6 , 1 0 8 - 1 1 1}}$ and successfully used to produce tridentate cyclometalating polypyridyl ligands, namely 1,3-dipyridylbenzene. In this respect, aryl azides react with diethynylbenzene building blocks, in good yields using a standard click procedure. ${ }^{112-114}$ With the purpose of blocking alternatives, methyl groups were placed at strategic positions when possible and reasonable. ${ }^{115}$ Therefore, $o$-xylene was selected as the central ring and mesityl species were selected for the clicked-on functionalities (Scheme 5). It should be mentioned that mesityl was kept as the reference moiety in all the other experiments to discuss the important influences of substituents directly attached to the cyclometalating phenyl ring or the opposing ligand (Scheme 6).<smiles></smiles>

bipy

9<smiles></smiles>

11<smiles></smiles>

Rpytri

10<smiles></smiles>

Rtripy
Scheme 8 Structures of the 2,2'-bipyridine (bipy) (9) metal complex,

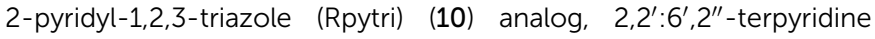
(terpy) (11) metal complex, and 2,6-pyridyl-bis(1,2,3-triazole) (Rtripy) (12) analog. 
a)

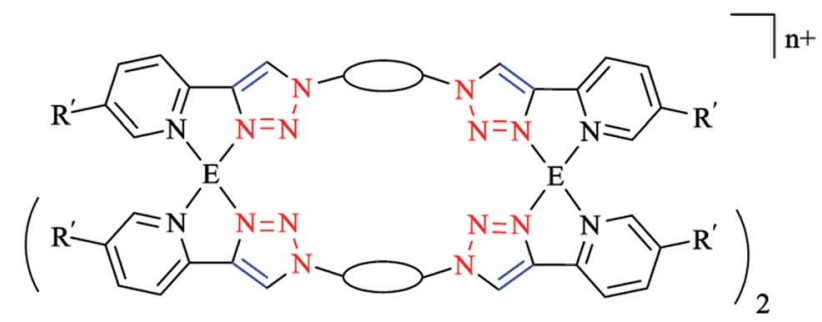

b)

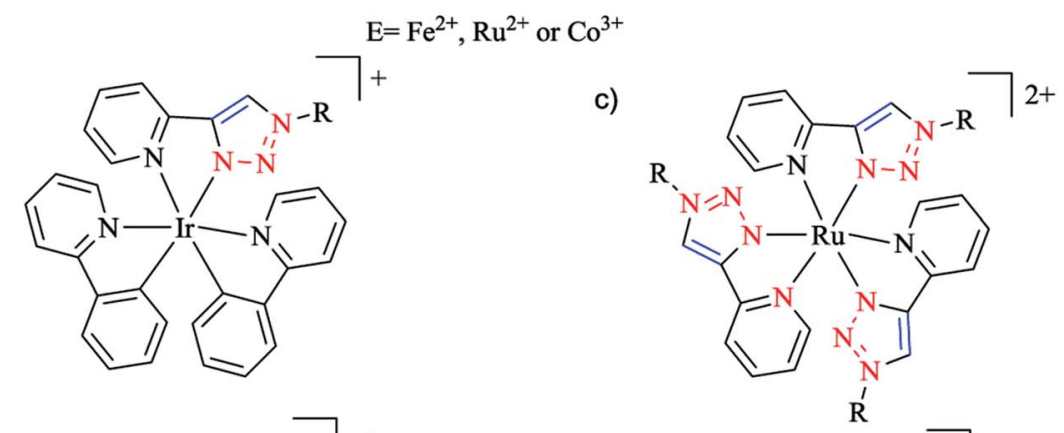

d)<smiles></smiles>

e)<smiles></smiles>

$$
\begin{gathered}
\mathrm{E}=\mathrm{Pt}^{2+}, \mathrm{Pd}^{2+} \text { or } \mathrm{Ru}^{2+} \\
\mathrm{L}=\mathrm{L}^{\prime}=\mathrm{Cl}^{-} \text {or } \mathrm{L}=\mathrm{Cp} \mathrm{L} \mathrm{L}^{\prime}=\mathrm{PPh}_{3}
\end{gathered}
$$

f)

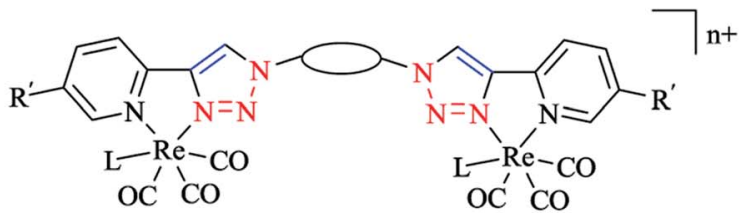

Scheme 9 Structures of biologically active click Rpytri complexes.

In this context, a new and systematic series of click-derived tridentate cyclometalated $\mathrm{Ru}(\mathrm{II})$ complexes was considered to assess their potential for dye-sensitized solar-cell applications. ${ }^{\mathbf{8 5}}$ These combined theoretical photophysical studies as well as electrochemical experiments led to a consistent and emergent explanatory picture of the new dyes. ${ }^{116}$

In another research, the synthesis of 2,6-bis(1,2,3-triazol-4-yl) pyridine 8 ligands were performed via the $\mathrm{Cu}(\mathrm{I})$-catalyzed cycloaddition reaction of hydroxyl methylazide followed by a base-induced cleavage of formaldehyde. It could also be synthesized via a thermal azide-alkyne cycloaddition with azidomethyl pivalate and an internal alkyne. In this azide-alkyne cycloaddition, a mixture of adducts was produced and after cleavage and reprotonation, and free $\mathrm{NH}$-triazole was obtained. $^{7}$

As illustrated in Scheme 7, the corresponding ruthenium(II) complexes were synthesized in good yields using $\left[\mathrm{Ru}^{\mathrm{II}}\right.$ (tpy) $\left.(\mathrm{MeCN})_{3}\right]\left(\mathrm{PF}_{6}\right)_{2} \quad$ (tpy $=2,2^{\prime}: 6^{\prime}, 2^{\prime \prime}$-terpyridine) or $\left.\left[\mathrm{Ru}^{\mathrm{II}} \text { (tcmtpy)(MeCN}\right)_{3}\right]\left(\mathrm{PF}_{6}\right)_{2}$ (tcmtpy $=4,4^{\prime}, 4^{\prime \prime}$-tricarboxymethyl$2,2^{\prime}: 6^{\prime}, 2^{\prime \prime}$-terpyridine) as precursors. ${ }^{116}$ The solubilities of the charge-neutral complexes were measured and it was shown that the alkyl chains increases the solubility, allowing the investigation of the photophysical and electrochemical properties (vide infra). ${ }^{\mathbf{1 1 7}}$

The synthesis and biological activity of $\mathrm{Fe}, \mathrm{Ru}, \mathrm{Co}, \mathrm{Pt}$, and $\mathrm{Pd}$ complexes of 2-pyridyl-1,2,3-triazole (Rpytri) $\mathbf{1 0}$ bidentate and 2,6-pyridylbis(1,2,3-triazole) (Rtripy) 12 tridentate click ligands (Scheme 8) were investigated. It is important to mention that Rpytri and Rtripy click ligands are commonly considered as analogs of the 2,2'-bipyridine (bipy) 9 and $2,2^{\prime}: 6^{\prime}, 2^{\prime \prime}$-terpyridine (terpy) 11 ligand systems (Scheme 8). ${ }^{\mathbf{8}, 79}$

In this vein, the CuAAC click reaction was exploited to synthesize a series of iron(II), ${ }^{118}$ ruthenium(II), ${ }^{119}$ and cobalt(III) ${ }^{120}$ bis-2-pyridyl-1,2,3-triazole (bis-Rpytri) ligands (Scheme 9). It was demonstrated that iron(II) bis-Rpytri complexes have no biological activity and are rapidly decomposed under biological

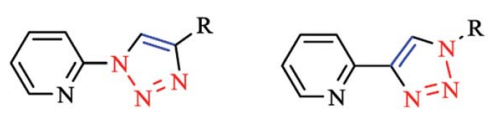

Scheme 10 Structures of inverse-Rpytri (left) and regular-Rpytri (right) isomers. 


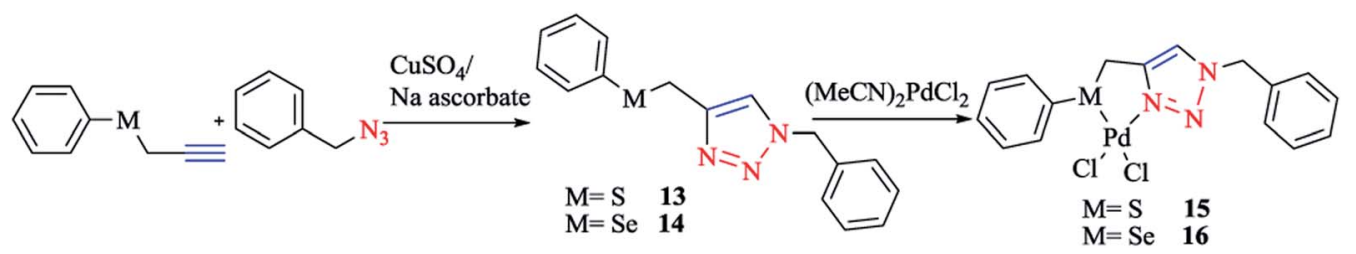

Scheme 11 Synthesis of palladium(॥) complexes based on the 1,2,3-triazole organosulfur/selenium ligand.

conditions, while the more inert ruthenium(II) and cobalt(III) bisRpytri complexes showed biological stability. The same authors also produced a family of mono- and di-fac-rhenium(I) tricarbonyl complexes using the Rpytri and bis-Rpytri ligands with aliphatic and aromatic substituents and linkers (Schemes 9e and f). These showed modest biological activity, attributed to the low charge on the rhenium centers as well as their molecular shape. ${ }^{121}$

Moreover, Henderson and coworkers synthesized complexes of iridium(II) with Rpytri ligands including aromatic substituents and assessed their biological potency (Scheme 9b). ${ }^{23}$

In another work, Aldrich-Wright and coworkers generated a set of six heteroleptic platinum(II) complexes bearing chiral diaminocyclohexane and either aliphatic or aromatic Rpytri ligands (Scheme 9d). ${ }^{122}$

Pyridyl-substituted $\left[\mathrm{Pd}(\mathrm{Rpytri}) \mathrm{Cl}_{2}\right]$ complexes were also synthesized by Sangtrirutnugul and coworkers. The regular Rpytri complex demonstrated a significant catalytic activity in the Suzuki reaction under aerobic conditions without catalyst degradation, indicating it was more resilient than the inverse Rpytri complex (Scheme 10)..$^{22,123}$

According to the procedure illustrated in Scheme 11, complexes 15 and 16 were synthesized as yellow solids by reacting $\left[(\mathrm{MeCN})_{2} \mathrm{PdCl}_{2}\right]$ with 13 and 14 , respectively, in a $1: 1$ molar ratio, in THF solution at room temperature, leading to $90 \%$ and $85 \%$ yields for complexes 15 and $\mathbf{1 6}$, respectively. The two air- and moisture-insensitive complexes $\mathbf{1 5}$ and $\mathbf{1 6}$ were moderately soluble in $\mathrm{CHCl}_{3}, \mathrm{CH}_{2} \mathrm{Cl}_{2}$, and $\mathrm{CH}_{3} \mathrm{OH}$, but had good solubility in $\mathrm{CH}_{3} \mathrm{CN}$ and DMSO. 13 and $\mathbf{1 4}$ and their Pd complexes 15 and 16 were characterized with ${ }^{1} \mathrm{H},{ }^{13} \mathrm{C}\{1 \mathrm{H}\}$ and ${ }^{77} \mathrm{Se}\{1 \mathrm{H}\}$ NMR, HR-MS, and IR spectra, and the results were found to be in good confirmation with those reported earlier. ${ }^{37,124}$

In another work, $\left[\mathrm{Pd}(\text { Rpytri })_{2}\right]^{2+}$ complexes were synthesized from the ligands in a head-to-tail arrangement avoiding steric clashes and leading to favorable interligand hydrogen bonding. ${ }^{56,125}$ Furthermore, related platinum Rpytri compounds are known, including [Pt-(Rpytri) $)_{2} \mathrm{Cl}_{2}$ ] complexes, ${ }^{82,125-129}$ heteroleptic $\left[\mathrm{Pt}(\text { Rpytri })_{2}(\mathrm{~L})_{2}\right]^{2+}$ complexes, where $\mathrm{L}=$ phenylpyridine $^{130,131}$ or diaminocyclohexane, ${ }^{122}$ and bis-pyridyltriazolato complexes. ${ }^{132}$ Two bis-2-pyridyl-1,2,3-triazole ligands (L) with methylene spacers were also synthesized, which had the shortest possible "regular" pyridyl-triazole linkage, with the fewest possible degrees of freedom of any "hinged" bis-pyridyl1,2,3-triazole. Then, theses ligands were used to produce bispyridyl-triazole $\left[\mathrm{Pt}(\mathrm{L})_{2}\right]^{4+}$ complexes, which were assembled exclusively in a head-to-tail conformation. These Pt(II) metalloligands had vacant peripheral binding sites that could then be employed in the generation of heterometallic complexes. Mixed $\mathrm{Pd}(\mathrm{II}) / \mathrm{Pt}(\mathrm{II})$ macrocycles were synthesized in a concentrationdependent manner, while a mixed metal $\mathrm{Cu}(\mathrm{I}) / \mathrm{Pt}(\mathrm{II})$ was prepared independent of the concentration (Scheme 12).

While a wide range of bispyridyltriazole ligands ${ }^{133-135}$ are known, the previously unreported methylene-linked ligands

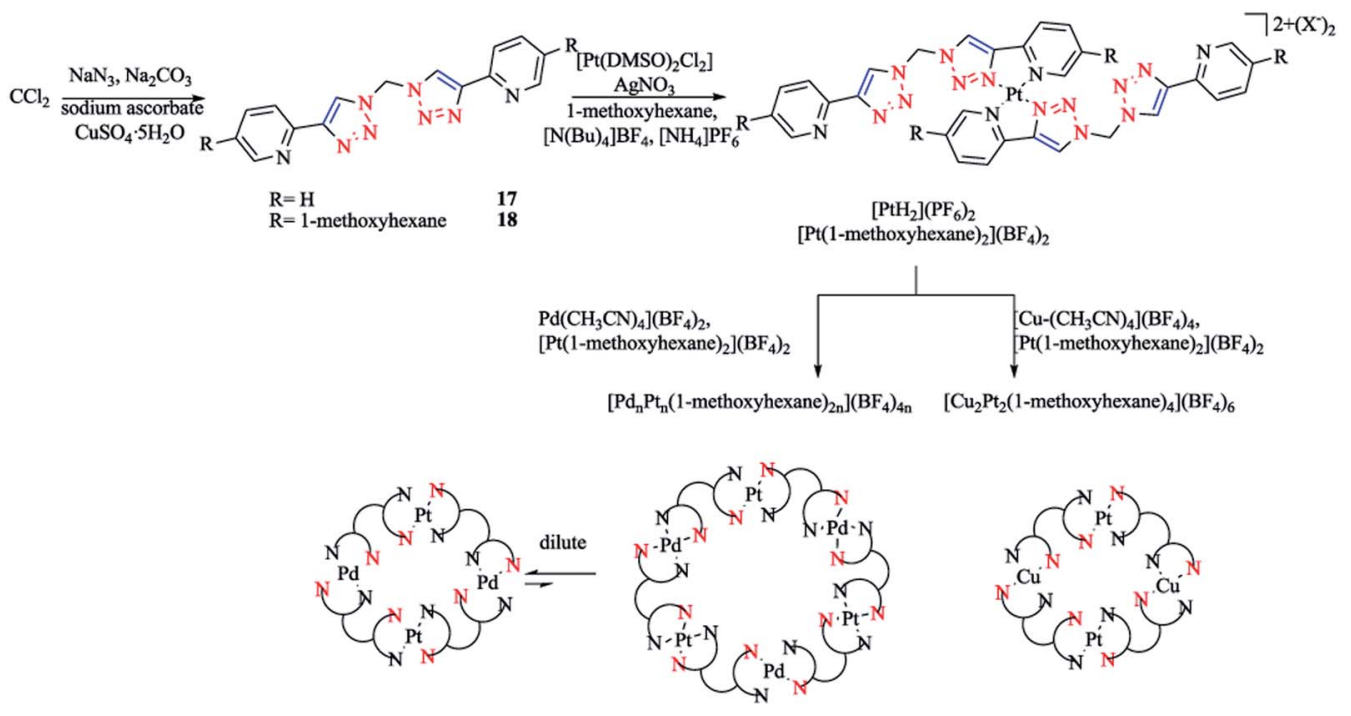

Scheme 12 Synthesis of heterometallic $\left[\mathrm{M}_{n} \mathrm{Pt}_{n}(\mathrm{~L})_{2 n}\right]^{x+}$ macrocycles based on dichloromethane-derivative bis-2-pyridyl-1,2,3-triazole ligands. 
<smiles></smiles>

19

2
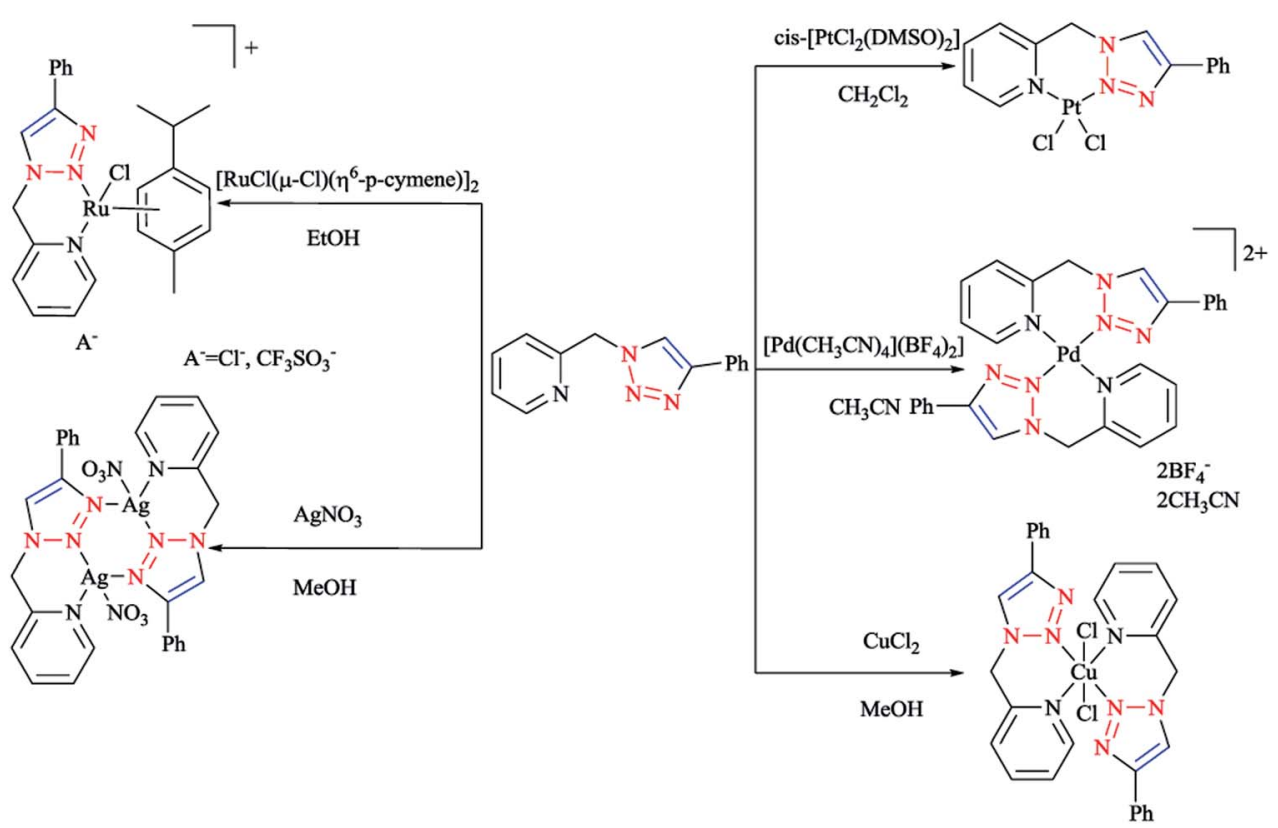

Scheme 13 Syntheses of 1-(2-picolyl)-4-phenyl-1H-1,2,3-triazole ligand and some of the complexes investigated.

were targeted, to reduce the number of degrees of freedom in the ligand architecture. ${ }^{136-138}$

The 1,1-bis(2-pyridyl-1,2,3-triazol-4-yl)methane 17 ligand and 1,1-bis(4-(5-(hexyloxy)pyridin-2-yl)-1H-1,2,3-triazol-1-yl)methane 18 ligand were synthesized through a CuAAC click reaction from sodium azide and dichloromethane(DCM) in a microwave in dimethyl formamide (DMF) up to $110^{\circ} \mathrm{C}$ in the presence of carbonate, leading to the explosive diazide in situ, which then reacts with 2-ethynylpyridine or 2-(2-(trimethylsilyl) ethynyl)-5-(hexyloxy)pyridine. ${ }^{139}$

In the following (Scheme 13), we display the synthesis of a click ligand through a CuAAC one-pot reaction between phenylacetylene
2 and 2-picolylazide 19 and also the coordination of a click ligand to $\mathrm{Pt}^{\mathrm{II}}, \mathrm{Pd}^{\mathrm{II}}, \mathrm{Cu}^{\mathrm{II}}, \mathrm{Ru}^{\mathrm{II}}$, and $\mathrm{Ag}^{\mathrm{I}}$ using $c i s-\left[\mathrm{PtCl}_{2}(\mathrm{DMSO})_{2}\right],\left[\mathrm{Pd}\left(\mathrm{CH}_{3}-\right.\right.$ $\left.\mathrm{CN})_{4}\right]\left(\mathrm{BF}_{4}\right)_{2}, \mathrm{CuCl}_{2},\left[\mathrm{RuCl}(\mu-\mathrm{Cl})\left(\eta^{6}-p \text {-cymene }\right)\right]_{2}$, and $\mathrm{AgNO}_{3}$. In the case of $\left[\mathrm{Pd}\left(\mathrm{CH}_{3} \mathrm{CN}\right)_{4}\right]\left(\mathrm{BF}_{4}\right)_{2}$ and $\mathrm{CuCl}_{2}$, bis-bidentate complexes were obtained, respectively. Synthesis of these two compounds was repeated with a ligand-metal precursor molar ratio of $2: 1$. Other stable products crystallized out from the reaction mixtures and were then isolated by filtration in a $60-82 \%$ yield. ${ }^{99}$

The synthesis of cyclometalating click ligands was investigated in a highly efficient one-pot consecutive process. In this regard, the acetylene derivative was reacted with the organic azide. ${ }^{\mathbf{1 4 0 , 1 4 1}}$ It is important to note that there was no necessity for

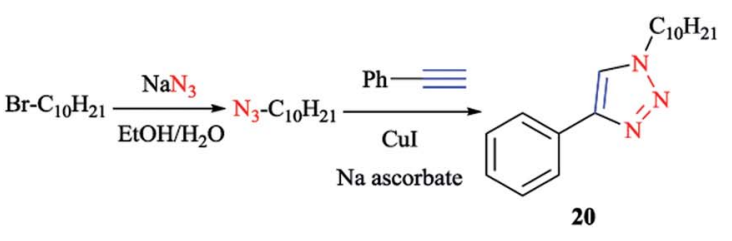

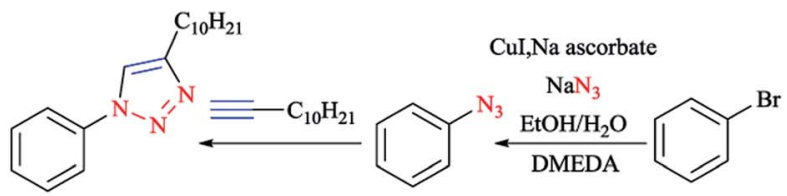

21

Scheme 14 Syntheses of 1 - and 4-decyl-4-phenyl-1H-[1,2,3]triazole ligands. 


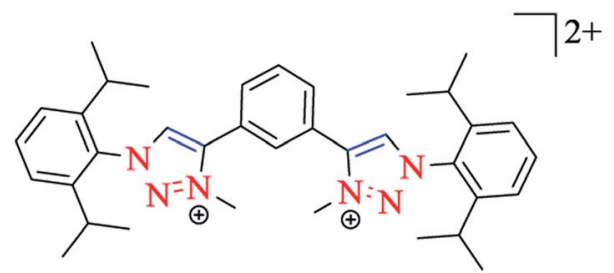

Scheme 15 Structure of the bis-monodentate 1,2,3-triazole-5-ylidene (22) ligand.

any further copper(I) catalyst after the formation of the aryl azide for the click reaction. So, 1-decyl-4-phenyl-1H-[1,2,3]triazole 20 and 4-decyl-1-phenyl-1 $H-[1,2,3]$ triazole 21 were produced as the potential ligands for the formation of iridiu$\mathrm{m}(\mathrm{III})$ complexes in high yields (Scheme 14). ${ }^{114}$

Metallo-macrocycles can be assembled by arranging bis1,2,3-triazol-5-ylidene 22 carbene ligands in conjunction with linear $\mathrm{Ag}(\mathrm{I})$ or $\mathrm{Au}(\mathrm{I})$ ions. Crudden and coworkers produced a $\mathrm{Ag}(\mathrm{I})$ macrocycle from a bis-1,3(1-aryl-1,2,3-triazol-4-yl) benzene ligand (Scheme 15). ${ }^{142}$ An equilibrium mixture of mononuclear $[\mathrm{AgL}]^{+}$and macrocyclic $\left[\mathrm{Ag}_{2} \mathrm{~L}_{2}\right]^{+}$complexes were synthesized by Frutos and Toree by applying a 1,4-xylyl linked steroid substituted bis-1,2,3-triazol-5-ylidene ligand. In order to expand the range of $\mathrm{Au}(\mathrm{I})$ 1,2,3-triazol-5-ylidene catalysts, Crowley and coworkers synthesized a di-Au(I) macrocycle with a 1,3-phenyl linked bis-1,2,3-triazol-5-ylidene ligand. ${ }^{143}$
Furthermore, White and Beer produced four bismonodentate ligands with a 1,3-(5-tert-butyl)phenyl core. ${ }^{144}$ The triazole rings bound via $\mathrm{N} 1$ or $\mathrm{C} 4$ atoms and $\mathrm{C} 4$-connected ligands gave cluster-like compounds consisting of four $\mathrm{Ag}(\mathrm{I})$ cations and four ligands, while three triazole nitrogens were coordinated to each $\mathrm{Ag}(\mathrm{I})$ center and the fourth coordination bond for each metal ion was to water.

Building on their previous Ag(I) metallocycle work, Crowley and coworkers exploited the functional group tolerance of the CuAAC "click" reaction to synthesize a structurally diverse family of bis-triazole ligands. Reaction of a suitable dialkyne with two equivalents of azide gave a range of bis-monodentate ligands with the two triazole groups separated by a linker (either propyl, 1,3-phenyl or 1,4-phenyl units), and substituted with a wide array of benzyl, aryl, and alkyl groups..$^{21,145,146}$

\section{Computational study of electronic energy properties in transition metal complexes of triazole-based ligands}

The coordination of $\mathrm{Ni}(\mathrm{II})$ with the tripodal ligands tpta (tris [(1-phenyl-1H-1,2,3-triazol-4-yl)-methyl]amine) 23, tbta (tris [(1-benzyl-1 $H$-1,2,3-triazol-4-yl)methyl]-amine) 24, and tdta (tris [(1-(2,6-diisopropyl-phenyl)-1H-1,2,3-triazol-4-yl)methyl]amine) 25, and the bidentate ligand pyta (1-(2,6-diisopropylphenyl)-4(2-pyridyl)-1,2,3-triazole) 26 led to the $\left[\mathrm{Ni}\right.$ - $\left.(\mathrm{tpta})_{2}\right]\left(\mathrm{BF}_{4}\right)_{2} \quad \mathbf{2 3}^{\prime}$,

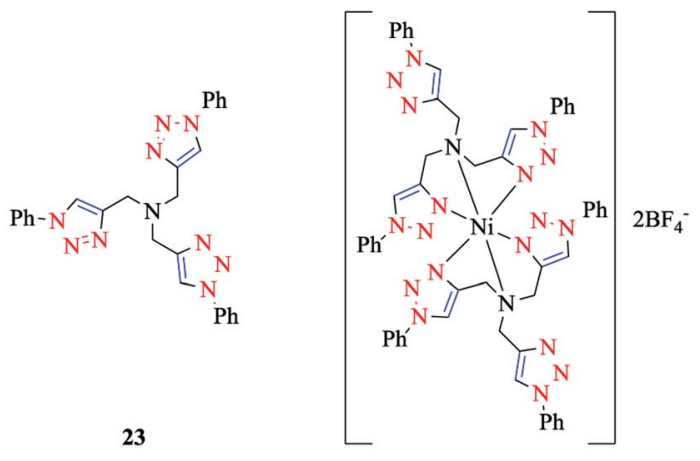

$23^{\prime}$
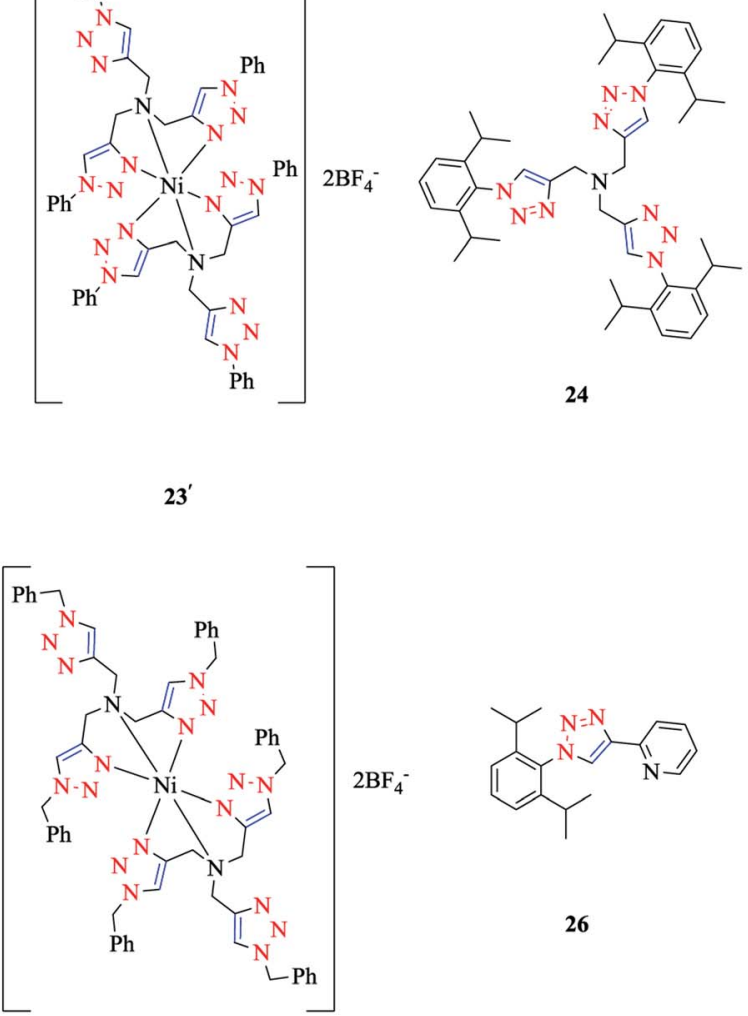

$25^{\prime}$

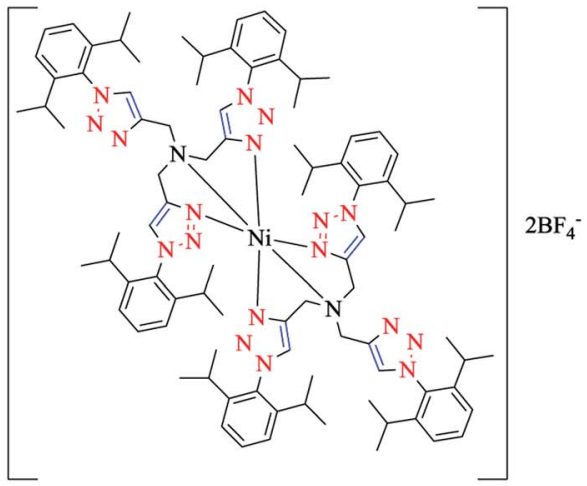

$24^{\prime}$

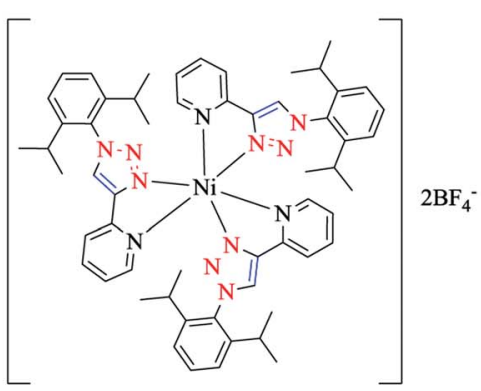

$26^{\prime}$

Scheme 16 tpta, tbta, tdta, and pyta ligands and their corresponding $\mathrm{Ni}(॥)$ complexes. 
$\left[\mathrm{Ni}(\mathrm{tbta})_{2}\right]\left(\mathrm{BF}_{4}\right)_{2} \mathbf{2 4}^{\prime},\left[\mathrm{Ni}(\mathrm{tdta})_{2}\right]\left(\mathrm{BF}_{4}\right)_{2} \mathbf{2 5}^{\prime}$, and $\left[\mathrm{Ni}(\mathrm{pyta})_{3}\right]\left(\mathrm{BF}_{4}\right)_{2}$ 26' complexes (Scheme 16).

In order to obtain a better insight into their absorption spectra, quantum chemistry calculations at the NEVPT2 level of theory ${ }^{147-154}$ were performed. Based on the NEVPT2 calculated values, the electronic transitions in the absorption spectra of complexes $\mathbf{2 3}, \mathbf{2 4}^{\prime}$, and $\mathbf{2 6}^{\prime}$ were assigned (while corresponding calculations for complex $\mathbf{2 5}^{\prime}$ could not be done due to its large size). The energies of the spin-allowed $\mathrm{d}-\mathrm{d}$ transitions of complexes $\mathbf{2 3 ^ { \prime }}, \mathbf{2 4 ^ { \prime }}$, and $\mathbf{2 6}^{\prime}$ were calculated comparatively based on their X-ray and DFT-geometry-optimized structures.

The experimental absorption spectrum of $23^{\prime}$ in $\mathrm{CH}_{3} \mathrm{CN}$ was compared with the NEVPT2 calculated values. All the three main bands were adjusted well with three Gaussian distributions, indicate the three-times-three possible transitions, with the sum of these distributions in reliable agreement with the experimental spectrum.

The absorption spectra of $\mathbf{2 3}^{\prime}, \mathbf{2 4}$, and $\mathbf{2 6}$, which were calculated at the SA-CASSCF/NEVPT2 level of theory in acetonitrile included 24 excited states $(9$ triplets and 15 singlets, which with the triplet ground state resulted in a total of 45 microstates of $\mathrm{d}^{8}$ ). All the triplet states of the absorption spectrum could be attributed to the spin-allowed transitions, while the spin-forbidden transitions were not elucidated.

It should be noted that the excited singlet states can be ascertained by second-order perturbation theory (PT2) and make a minor contribution. In particular, when comparing SACASSCF $^{155}$ with NEVPT2 (ref. 156) approaches, since the dynamic electron correlation is added by the NEVPT2 method, the calculated values of the excited triplet states increase.

Consequently, the zero-field splitting (zfs) parameters $D$ and $E$ are decreased by almost $50 \%$, while zfs qualitatively is inversely proportional to the excited state energies, which can be ascribed as the covalency of the system. The final $D$ values calculated by quasi degenerate perturbation theory (QDPT) ${ }^{157}$ were 2.94 and $3.79 \mathrm{~cm}^{-1}$ for $\mathbf{2 3}^{\prime}$ and $\mathbf{2 4}^{\prime}$ complexes, respectively, which were in reliable agreement with the values obtained by high-frequency and high-field electron paramagnetic resonance HFEPR. ${ }^{158}$

Comparison of QDPT with PT2 approaches revealed that QDPT yielded more accurate results due to the fact that QDPT considers all contributions to the zfs, but this approach does not allow discussing the single contribution of excited states to the total zfs in comparison with PT2.

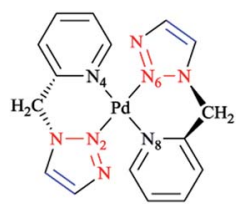

27

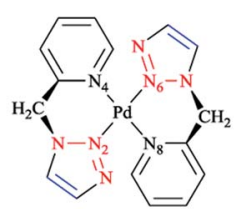

28

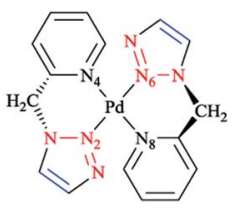

29
Scheme 17 Schematic structures of anti-trans- $\left[\mathrm{Pd}(\mathrm{L})_{2}\right]^{2+}$, syn-trans$\left[\operatorname{Pd}\left(\mathrm{L}_{2}\right]^{2+}\right.$, and anti-cis- $\left[\mathrm{Pd}(\mathrm{L})_{2}\right]^{2+}$ isomers based on the 4-phenyl-1(2-picolyl)-1,2,3-triazole ligand (L).
For complex $\mathbf{2 6}^{\prime}$, the angular overlap model (AOM) parameters ${ }^{159}$ were derived via a least-squares fit to the $\mathrm{V}$ matrices (with a rather small standard deviation) by using the exact structural data of complex $26^{\prime}$ obtained from the X-ray and DFT-optimized structure.

A comparison of the calculated results for the two ligands revealed that $\mathrm{Ni}-\mathrm{N}$ bonding was dominated by $\mathrm{Ni}-\mathrm{N}^{\text {ta }}$ and $\mathrm{Ni}-$ $\mathrm{N}^{\mathrm{py}} \sigma$-antibonding interactions. On the other hand, the parameters $e_{\pi \mathrm{s}}^{\mathrm{py}}=-131 \mathrm{~cm}^{-1}$ and $e_{\pi \mathrm{s}}^{\mathrm{ta}}=-276 \mathrm{~cm}^{-1}$ (attributed to the out-of-plane $\pi$-bonding) had very small and negative values.

In another research study, the interconversion between two boat conformers in a palladium(II) complex of the flexible click chelator $\left(\operatorname{Pd}\left\{(\text { py })_{2} \mathrm{CHNHR}\right\} \mathrm{Cl}_{2}\right)^{160}$ was assessed computationally. The rate constants for the interconversion between the two conformers were calculated. The calculated values for the activation enthalpy and activation entropy (from the Eyring plot) were $13.0 \pm 0.4 \mathrm{kcal} \mathrm{mol}^{-1}$ and $2.7 \pm 1.6 \mathrm{cal} \mathrm{mol}^{-1} \mathrm{~K}^{-1}$, respectively, which were in reliable agreement with other literature results for boat-to-boat inversions in some similar palladocycles. ${ }^{161}$ It should be noted that the low activation entropy can be attributed to a nondissociative isomerization mechanism.

The species involved in equilibrium, including syn- and anticonformers of the trans isomer, namely $\mathbf{2 7}$ and $\mathbf{2 8}$, respectively, and the structure with an anti-cis arrangement 29 (Scheme 17) were investigated via DFT calculations. The calculated geometrical data clearly indicated that the change in the squareplanar core was not considerable when going from the anti (27) to the syn (29) conformer; except the Pd-N2 bond, which was slightly elongated to $0.014 \AA$ A.

Considering the calculated values of the electronic energy as well as the gas phase free energy, isomer $\mathbf{2 8}$ was found to be more stable than 27 by about $1 \mathrm{kcal} \mathrm{mol}^{-1}$, thus predicting the equilibrium was shifted in the direction of 28 .

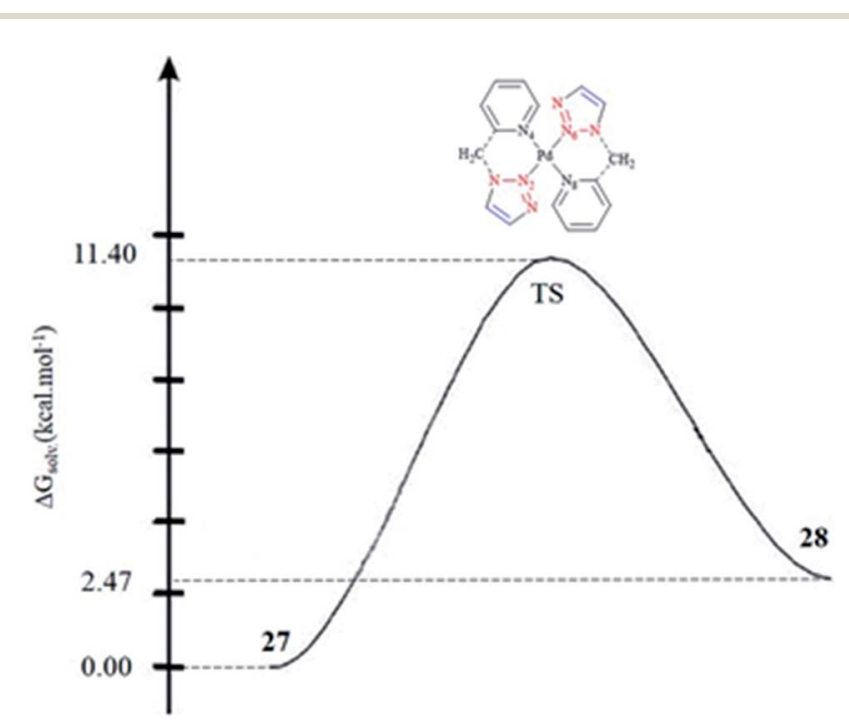

Fig. 1 One-step mechanism for the isomerization of 27 into 28. 
Moreover, the calculated value of steric repulsion, $\mathrm{DE}_{\mathrm{ster}}$, (which was defined as the sum of the Pauli repulsion and electrostatic interaction via the Ziegler-Rauk decomposition framework $\left.{ }^{\mathbf{1 6 2 , 1 6 3}}\right)$ was smaller between ligands in $28\left(\mathrm{DE}_{\mathrm{ster}}=\right.$ $\left.-48.68 \mathrm{kcal} \mathrm{mol}^{-1}\right)$ than in $27\left(\mathrm{DE}_{\text {ster }}=-50.36 \mathrm{kcal} \mathrm{mol}^{-1}\right)$, while the calculated value of the orbital interaction $\left(\mathrm{DE}_{\mathrm{oi}}\right)$ was maintained at about $463 \mathrm{kcal} \mathrm{mol}^{-1}$. This feature could be due to the slightly shorter N4-N6 distance in 27 (3.016 $\AA$ ) than in 28 (3.062 А).

To assess the kinetics of the isomerization procedure theoretically, we focused on the determination of the transition state (TS) connecting 27 and 28 via a one-step mechanism, as illustrated in Fig. 1. It was shown that the calculated activation barrier values and the entropy contributions were in a good agreement with the experimental data. ${ }^{57}$

It was shown that in the following Pd complexes, the calculated electron densities at $\mathrm{Se}, \mathrm{Pd}$, and $\mathrm{N}(3)$ of the triazole ring were higher in complex 16 than in complex 15, mainly due to the strong metal-ligand interaction in complex 16 and its subsequent higher stability and lower reactivity relative to complex 15. ${ }^{37,56,126}$ Moreover, in these complexes, there was a good agreement between the experimentally observed and calculated bond distances and angles. However, some of calculated $\mathrm{Pd}-\mathrm{M}$ bond distances $(\mathrm{M}=\mathrm{S} / \mathrm{Se})$ deviated from the corresponding observed ones. ${ }^{124}$

In another research study, the geometric and electronic structures of ruthenium complexes with bidentate ligands, including bis pyridyl and bis triazole ligands (denoted as bpy and btz ligands, respectively), were investigated computationally (Scheme 18). In the first step, the optimized geometry of the complexes were obtained and then the localization of the $\mathrm{d}_{z^{2}}$-like and $\mathrm{d}_{x^{2}-y^{2}}$-like antibonding $\mathrm{d} \sigma^{*}$ orbitals were assessed to recognize the participating $\mathrm{Ru}-\mathrm{N}$ bonds. In the next step, a pair of stimulated starting geometries was designed by elongation of the main participating $\mathrm{Ru}-\mathrm{N}$ bonds and were then optimized with a spin multiplicity of 3 .

It was shown that the $\mathrm{Ru}-\mathrm{N}$ bond length increases due to the population of $\mathrm{d}_{z^{2}}$-like $\mathrm{d} \sigma^{*}$ orbitals. Moreover, the $\mathrm{d}_{x^{2}-y^{2}}$-like $\mathrm{d} \sigma^{*}$ orbital population leads to the distortion of all three ligands. It was also demonstrated that a metal-ligand orbital overlap could be deducted based on the elongation of both the $\mathrm{Ru}-\mathrm{N}$ bonds of one chelate ligand participating in the $\mathrm{d} \sigma^{*}$ orbital, showing the stabilizing electronic effect. ${ }^{164}$

\section{Structural properties and frontier molecular orbital analysis in the complexation reactions}

\subsection{Ni(II) and $\mathrm{Zn(II)}$ complexes}

The coordination behaviors of the complexes of $\mathrm{Ni}$ (II) with tripodal and bidentate ligands were investigated using X-ray diffraction studies and computational methods, specifically $\left[\mathrm{Ni}(\mathrm{tbta})_{2}\right]\left(\mathrm{BF}_{4}\right)_{2} \mathbf{2 4}^{\prime}$ as a tripodal ligand and $\left[\mathrm{Ni}\left(\mathrm{pyta}_{3}\right)_{3}\right]\left(\mathrm{BF}_{4}\right)_{2} \mathbf{2 6}^{\prime}$ as a bidentate ligand. In the $\left[\mathrm{Ni}(\mathrm{tbta})_{2}\right]\left(\mathrm{BF}_{4}\right)_{2} \mathbf{2 4}^{\prime}$ complex, the $\mathrm{Ni}(\mathrm{II})$ center was coordinated by four triazole $\left(\mathrm{N}^{\mathrm{ta}}\right)$ and two trans

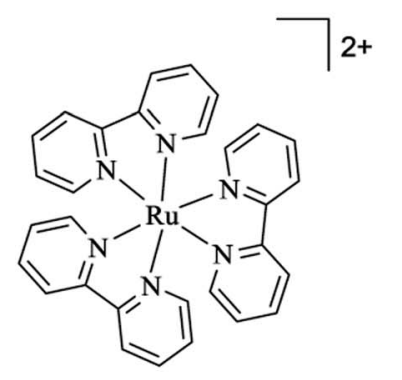

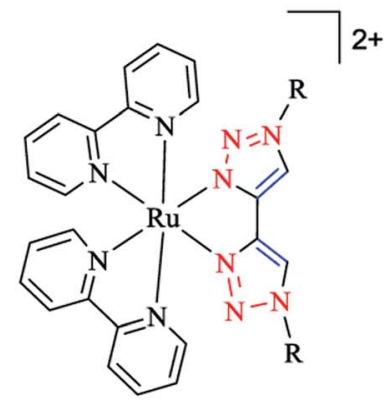

$\left[\mathrm{Ru}(\mathrm{bpy})_{2}(\mathrm{btz})\right]^{2+}$

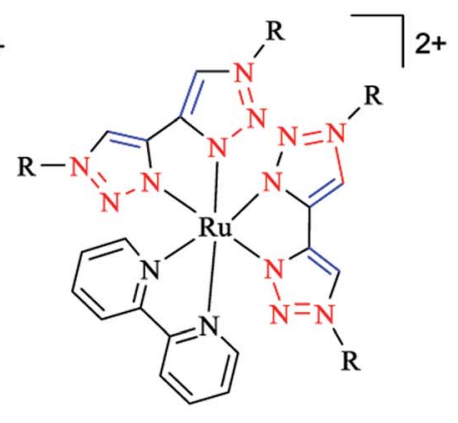

$\left[\mathrm{Ru}(\mathrm{bpy})(\mathrm{btz})_{2}\right]^{2+}$

$\left[\mathrm{Ru}(\mathrm{bpy})_{3}\right]^{2+}$

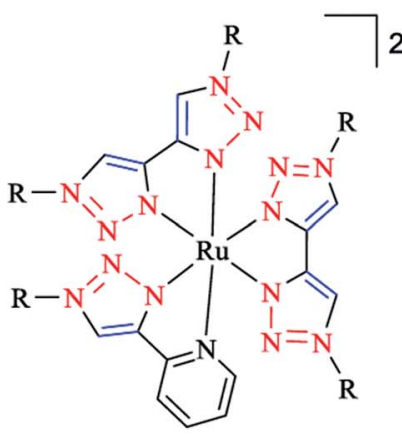

$\left[\mathrm{Ru}(\mathrm{bpy})(\mathrm{btz})_{2}\right]^{2+}$

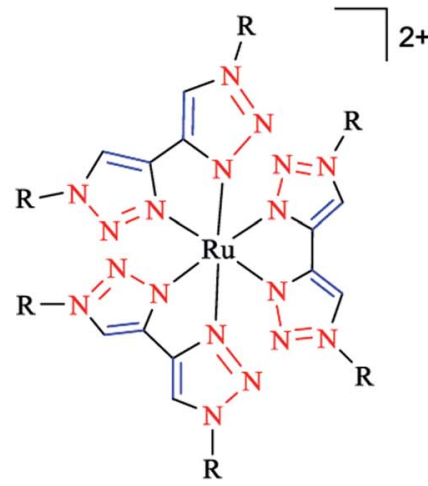

$\left[\mathrm{Ru}(\mathrm{btz})_{3}\right]^{2+}$

Scheme 18 Structures of Ru(I) tris(bidentate) complexes (in experimental studies $\mathrm{R}=$ benzyl, to limit the computational expense in the calculations. $\mathrm{R}$ is simplified to methyl). 
amine $\left(\mathrm{N}^{\mathrm{am}}\right)$ nitrogen donors, in a distorted-octahedral space, while in $\left[\mathrm{Ni}(\text { pyta })_{3}\right]\left(\mathrm{BF}_{4}\right)_{2} \mathbf{2 6}^{\prime}, \mathrm{Ni}$ (II) was coordinated by pyridine $\left(\mathrm{N}^{\mathrm{Py}}\right)$ and triazole $\left(\mathrm{N}^{\mathrm{ta}}\right) \mathrm{N}$-donors in a meridional arrangement.

As could be deduced from the crystal structure of $\left[\mathrm{Ni}(\mathrm{tbta})_{2}\right]\left(\mathrm{BF}_{4}\right)_{2} \mathbf{2 4}^{\prime}$, the nickel center was coordinated by each tbta ligand via the nitrogen atoms of two 1,2,3-triazole rings and the central amine nitrogen donors, while the third triazole ring of the ligand remained uncoordinated. The three nitrogen donors of triazole rings are located at the equatorial coordination position around the nickel center. It should be mentioned that the amine nitrogen atoms are poorer donors than the triazole nitrogen atoms, and this property leads to the larger $\mathrm{Ni}-$ $\mathrm{N}^{\text {am }}$ distances in comparison with the $\mathrm{Ni}-\mathrm{N}^{\text {ta }}$ distances. Furthermore, it was shown that the average values of the axialequatorial angle, denoted by $\alpha$, and distortion angle, denoted by $\delta \alpha$, were significantly distorted from $90^{\circ}$. In the next step, the structural properties of the complexes were reproduced by using DFT geometry optimization in conjunction with a polarized continuum model (COSMO) ${ }^{\mathbf{1 6 5}}$ which showed a good agreement with the X-ray results. ${ }^{55}$

Petitjean and coworkers investigated systematically the synthesis and structural properties of $\mathrm{Fe}$ (II), Ni(II), and $\mathrm{Zn}$ (II) ions with 1,2,3-triazol-4-yl pyridine chelators. They presented the spacer and substitution pattern for the complexation and assessed the various factors affecting the self-assembly procedure and also the stereochemical features of these architectures. $^{\mathbf{1 3 5}}$

In another work, it was reported that the reaction of bis(2-pyridyl-1,2,3-triazole) ligands including 1,3-propyl, 1,4-xylyl, or 2,6-dimethyl naphthalene spacers with Fe(II) or Ni(II) ions led to the production of $\mathrm{M}_{2} \mathrm{~L}_{3}$ cylinders. It should be mentioned that by using several functional groups, a large series of bis(2-pyridyl-1,2,3-triazole) ligands were synthesized via the CuAAC procedure and were then studied in the reaction with $\mathrm{Fe}(\mathrm{II})$, $\mathrm{Ni}(\mathrm{II})$, and $\mathrm{Zn}$ (II) ions. ${ }^{\mathbf{1 3 5 , 1 6 6}}$

In the case of $\mathrm{Zn}(\mathrm{II})$ complexes, the synthesis and structure of the $[2+2]$ macrocycle of $\mathrm{Zn}$ (II) ions with the bis-(4-(2-pyridylthiomethyl)triazolyl) ligand including a pentyl linker were assessed. The zinc(II) ions were coordinated to two N3 triazole nitrogen atoms and two chloride anions in a tetrahedral coordination geometry. It was also demonstrated that the ethyl- and butyl-linked ligands formed $\left[\left(\mathrm{ZnCl}_{2}\right)_{2} \mathrm{~L}\right]$ dinuclear complexes so that each metal ion was coordinated to both a triazole and chelating pyridine..$^{21,167}$

\subsection{Pd(II) and Pt(II) complexes}

The calculated optimized geometry for the $\left[\mathrm{Pd}\left(\eta^{3}-\mathrm{C}_{3} \mathrm{H}_{5}\right)(1-(2-\right.$ (methylthio)ethyl)-4-phenyl-1H-1,2,3-triazole) $]^{+}$(Scheme 19)

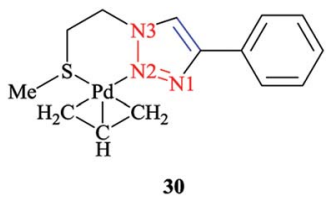

Scheme 19 Structure of the $\left[\mathrm{Pd}\left(\eta^{3}-\mathrm{C}_{3} \mathrm{H}_{5}\right)(1-(2-\right.$ (methylthio)ethyl)-4phenyl-1H-1,2,3-triazole)] ${ }^{+}$complex (30). complex 30 was assessed computationally. The computations were performed at the M06 level of theory, including with the C-PCM solvation model and in the presence of acetone as a solvent, and the results highlighted the binding geometry adopted by the ligand.

Then, a comparison was made between the calculated results and the single-crystal data for the tetrafluoroborate salt of the cationic complex, which demonstrated a reliable confirmation. Moreover, based on the X-ray data, it could be seen that palladium was coordinated to N2 and the sulfur atoms and consequently formed a six-membered ring with the metal center.

The phenyl substituent and the triazole were coplanar, while the angle between N2, Pd, and S was around $95^{\circ}$. Another important structural feature of the complex was that the C-allyl-terminal trans to $\mathrm{S}$ and trans to triazole-N2 deviated from planarity specified by Pd, S, and N2, by $0.180 \AA$ and $0.095 \AA$, respectively. It is important to mention that there was a similar coordination behavior between the triazole species in $\left[\mathrm{Pd}\left(\eta^{3}-\mathrm{C}_{3} \mathrm{H}_{5}\right)(1-(2-(\right.$ methylthio $)$ ethyl)-4-phenyl-1H1,2,3-triazole) $]^{+} \mathbf{3 0}$ with the pyridine-triazole $\mathrm{Pd}(\mathrm{II})$ allyl complex (Scheme 20). ${ }^{\mathbf{9 1 1 6 8}}$ Strictly speaking, coordination of the S-donor moiety of (1-(2-(methylthio)ethyl)-4-phenyl-1H1,2,3-triazole $)$ to the $\left[\operatorname{Pd}\left(\eta^{3}-\mathrm{C}_{3} \mathrm{H}_{5}\right)\right]^{+}$can be evaluated with other neutral bidentate ligands consisting of thioether groups and can generate six-membered rings with the metal center. ${ }^{169-173}$ This coordination feature was assessed

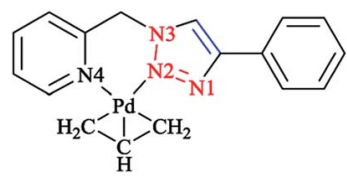

Scheme 20 Structure of the $\left[\mathrm{Pd}\left(\eta^{3}-\mathrm{C}_{3} \mathrm{H}_{5}\right)(2-((4-\right.$ phenyl- $1 \mathrm{H}-1,2,3-$ triazol-1-yl)methyl)-pyridine) $]^{+}$complex.
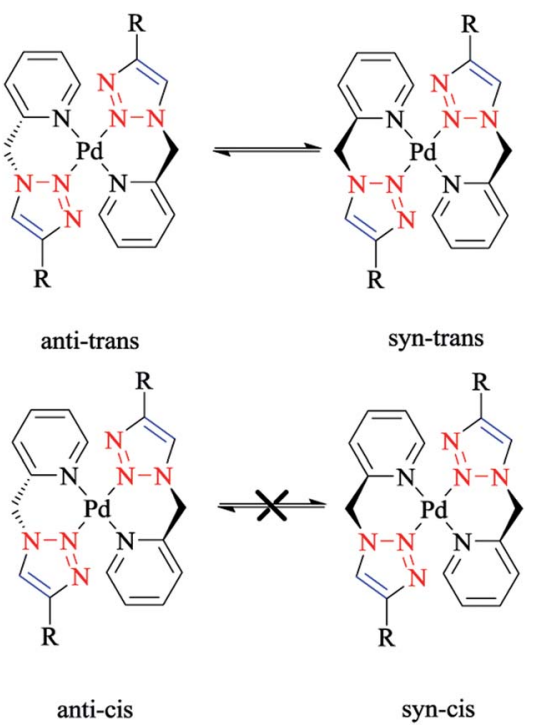

Scheme 21 The solid-state structures under investigation by their molecular drawing $(\mathrm{R}=\mathrm{Ph})$. 
computationally in a number of complexes through adopting starting geometries where the coordination of the triazole fragment occurred through the N1 nitrogen atom. The calculated results demonstrated that, in all cases, the obtained optimized structure was similar to the X-ray structural data, where a Pd-N2 bond was clearly formed. ${ }^{174}$

In another research study, experimental and theoretical DFT studies on the structural properties of $\left[\mathrm{Pd}(\mathrm{L})_{2}\right]\left(\mathrm{BF}_{4}\right)$ $\mathrm{CH}_{3} \mathrm{CN}$ ( $\mathrm{L}=4$-phenyl-1-(2-picolyl)-1,2,3-triazole) as a bischelate complex showed that the central square-planar palladium(II) cation was coordinated by two L substrates in trans position, each through pyridine and triazole N2 nitrogen atoms, generating two six-membered metallacycles. More precisely, anti-trans- $\left[\mathrm{Pd}(\mathrm{L})_{2}\right]^{2+}$ and syn-trans- $\left[\mathrm{Pd}(\mathrm{L})_{2}\right]^{2+}$ were produced as two boat-like conformations, in which the picolyl methylene carbons were anti or syn, respectively, depending on the palladium coordination plane, and could be easily converted to each other in solution (Scheme 21). It should be mentioned that $\left[\mathrm{Pd}(\mathrm{L})_{2}\right]\left(\mathrm{BF}_{4}\right) \mathrm{CH}_{3} \mathrm{CN}$ was synthesized from 4-phenyl-1-(2-picolyl)-1,2,3-triazole (L) and $\left[\mathrm{Pd}\left(\mathrm{CH}_{3} \mathrm{CN}\right)_{4}\right]\left(\mathrm{BF}_{4}\right)_{2}$ in $\mathrm{CH}_{3} \mathrm{CN} .^{99}$

Frontier molecular orbital analysis was also performed for palladium(II) complexes of sulfur-selenium 1,2,3-triazole-based ligands using DFT calculations to rationalize the nature of bonding within these complexes and their reactivity. In both the complexes, the HOMOs were mainly located over $\mathrm{Pd}$ and $\mathrm{Cl}$ atoms and included the interaction of a d orbital of $\mathrm{Pd}(\mathrm{II})$ and a p orbital of chlorine atoms. More precisely, in the HOMO-1 of both complexes' metal d orbitals, p orbitals of a chalcogen donor atom, chlorine atoms, and one of the nitrogen of the triazole ring overlap with each other. Since the high reactivity of a complex may be partially related to a low value for the HOMOLUMO energy gap, among the two complexes, complex 15, which had the lower HOMO-LUMO energy gap, was supposed to be a better catalyst than 16, as was observed experimentally. ${ }^{124}$
In another research study, the chelation properties of some mononuclear bis-bidentate triazole-based complexes (as illustrated in Scheme 22) were reported via X-ray crystallographical analysis. The X-ray structures of Pt and Pd complexes showed a square-planar coordination environment of the central Pt and Pd. The coordination sphere around the platinum atom consisted of two nitrogen atoms of the ligand and two chloride ions in the cis position, while in the palladium mononuclear bisbidentate complex, the palladium ion is trans-chelated by two ligands. There was a close agreement between the bond distances in the coordination sphere of platinum in its complex with those found in the X-ray crystal structure of other squareplanar complexes of $\mathrm{Pt}(\mathrm{II}) \cdot{ }^{175}$ In the crystal geometry of the palladium complex, it was shown that the diagonal bonds are nonequivalent, so that N2-Pd is shorter than N4-Pd. In a copper complex, the metal ion is in a distorted-octahedral coordination environment with two additional chloride ions involved, and the ligands are located in a trans configuration comparable to that of the palladium complex. This displacement of two axial $\mathrm{N} 2$ atoms from the basal plane formed by two pyridine N4 atoms and two chloride ions leads to a pyramidal distortion of the octahedral geometry. In another reported ionic complex of $\left[\mathrm{Cu}(\mathrm{L} 1)_{2}\left(\mathrm{CH}_{3} \mathrm{CN}\right)-\left(\mathrm{ClO}_{4}\right)\right]\left(\mathrm{ClO}_{4}\right),{ }^{176}$ the copper cation displays the square-planar geometry of four nitrogen atoms with $\mathrm{CH}_{3} \mathrm{CN}$ and $\mathrm{ClO}_{4}{ }^{-}$ligands at the axial positions.

In the crystal structure of the ruthenium complex, a threelegged piano-stool geometry with the metal center coordinated by $p$-cymene in an $\eta^{6}$ fashion, a chloride ion, and ligand L1 was observed. The distances between $\mathrm{Ru}(\mathrm{II})$ and the nitrogen atoms of L1 were not equivalent, similarly to $\mathrm{Pt}$ and $\mathrm{Pd}$ complexes.

The X-ray geometry of the Ag complex showed two silver centers bridged by two L1 molecules. Both metal ions in the structure were coordinated by two nitrogen atoms from one L1 ligand (N4 from the pyridine and N2 from the triazole part) and another triazole N1 atom from the second L1 ligand in the

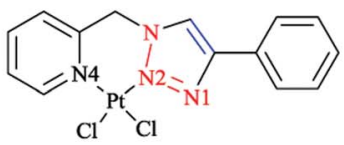

[PtCl2L1]

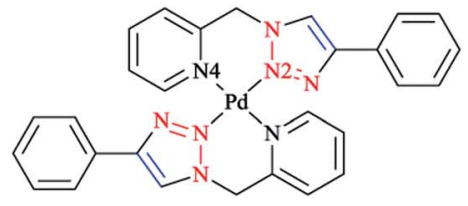

[Pd(L1)2](BF4)2

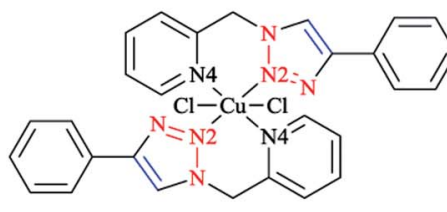

[CuCl2(L1)2]

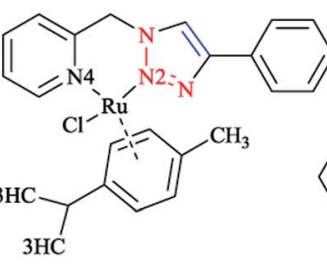

[RuCl( $\eta$ 6-p-cymene)L1]OTf

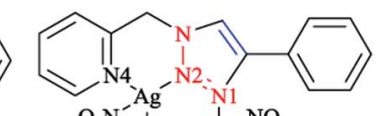

$\mathrm{O}_{3} \mathrm{~N}^{-} \quad$ ।, $\mathrm{NO}_{3}$

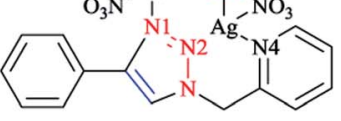

[Ag2(L1)2(NO3)2]

Scheme 22 Structures of $\left[\mathrm{PtCl}_{2} \mathrm{~L} 1\right],\left[\mathrm{Pd}(\mathrm{L} 1)_{2}\right]\left(\mathrm{BF}_{4}\right)_{2},\left[\mathrm{CuCl}_{2}(\mathrm{~L} 1)_{2}\right],\left[\mathrm{RuCl}\left(\eta^{6}-p\right.\right.$-cymene $\left.) \mathrm{L} 1\right] \mathrm{OTf}$ and $\left[\mathrm{Ag}_{2}\left(\mathrm{~L}_{2}\right)_{2}\left(\mathrm{NO}_{3}\right)_{2}\right]$ complexes based on 1-(2picolyl)-4-phenyl-1H-1,2,3-triazole ligand (L1). 
complex. This showed a distorted tetrahedral coordination consisting of the oxygen atom of a nitrate anion coordinated to both silver atoms in a monodentate mode. Alternatively, in the crystal structure of the Ag complex, each silver atom can be displaced from the plane of the coordinating nitrogen atoms and then coordination of the silver atoms can also be assumed to involve a distorted trigonal planar. In the aromatic L1, it was observed that the angle between the plane of the pyridine ring and the plane of the triazole ring was $87.7^{\circ}$ and a distortion was found when ligand was bound to the metal center. Coordination and structural assessments of traditional tetrahedral complexes of $\mathrm{Ag}(\mathrm{I})$ and $\mathrm{Cu}(\mathrm{I})$ with 1,2,3-triazol-4-yl-pyridine click ligands revealed that these complexes can be used as appropriate motifs for the self-assembly of supramolecular architectures. $^{\mathbf{1 7 7}}$

For computational investigation of this series of complexes, in accordance with our elucidations, the complexes with central atoms of copper, palladium, and platinum, $\left[\mathrm{ML}_{n}\left(\mathrm{NH}_{3}\right)_{2}\right]^{2+}(\mathrm{M}=$ $\mathrm{Cu}, \mathrm{Pd}, \mathrm{Pt}$ ), were considered with a coordination number of 4 , while silver complexes $\left[\mathrm{AgL}_{n} \mathrm{NH}_{3}\right]^{+}$were modeled with a coordination number 1 . It is important to notice that the expected $\mathrm{X}$ ray square-planar $(\mathrm{M}=\mathrm{Pd}, \mathrm{Pt})$ and trigonal-planar $(\mathrm{M}=\mathrm{Ag})$ geometries were obtained with a singlet ground state via DFT computations. The natural bond orbital (NBO) analysis affirmed the donation of the in-plane lone pairs of the appropriate nitrogen atoms of the ligand and two ammonia to the empty s and d orbitals of the metal, which decreased the charge localized on the metal. On the other hand, since in $\left[\mathrm{AgL}_{n} \mathrm{NH}_{3}\right]^{+}$ the $d$ orbitals are filled, electron donation occurs only to the $5 \mathrm{~s}$ orbital of the metal, which leads to a weaker metal-ligand interaction. It should be mentioned that these calculated results are in agreement with the observed smallest stabilization energy for $\left[\mathrm{AgL}_{n} \mathrm{NH}_{3}\right]^{+}$complexes.

Frontier molecular orbital analysis demonstrated that the $\mathrm{d}_{z_{2}}$ orbital of the metal $\left(\mathrm{d}_{z_{2}}\right.$ is $\sigma$ interacting in the $D_{4 \mathrm{~h}}$ symmetry) is combined with the high-lying orbitals of the triazole ring that can be observed in this series of complexes. It was also deduced that due to these interactions, the metal d electrons delocalize more efficiently to the $\pi$ system of the ligand and so increase the aromaticity and also the stability of the complexes with the

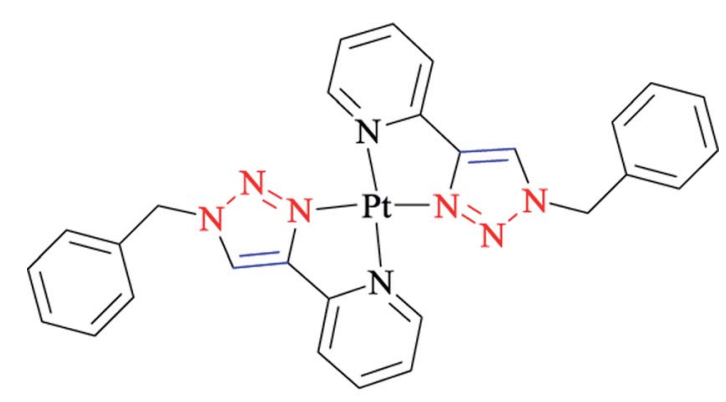

31

Scheme 23 Structure of the $\left[\mathrm{Pt}(\text { Bnpytri })_{2}\right]^{2+}(31)$ complex.

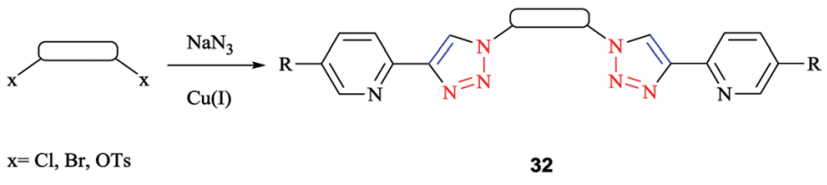

Scheme 24 Formation of the bis-bidentate pyridyl-triazole ligand (32).

ligand. This stabilization effect was confirmed by the secondorder perturbation theory analysis of the Kohn-Sham matrix. ${ }^{99}$

The geometrical and energetic properties of $\left[\mathrm{Pt}(\text { Bnpytri })_{2}\right]^{2+}$ 31 complexes (where Bnpytri = 2-(1-benzyl-1H-1,2,3-triazol-4-yl) pyridine and its schematic structure are illustrated in Scheme 23), and the corresponding palladium(II) analogs were assessed computationally through DFT calculations at the B3LYP/ LanL2DZ/6-31G(d) level of theory and using dimethyl sulfoxide (DMSO) as the solvent. The calculated results of $\left[\mathrm{Pt}(\text { Bnpytri })_{2}\right]^{2+} 26$ complexes revealed that the head-to-tail configuration was significantly favored from a thermodynamic point of view, as was obtained similarly for the corresponding palladium(II) analog. ${ }^{56,125}$ Under special conditions that allow the formation of the thermodynamic product, the head-to-tail configuration would be the dominant form for the $\mathrm{Pt}$ (II) complexes.

Moreover, for tetramer complexes, $\left[\mathrm{Pd}_{2} \mathrm{Pt}_{2}(\mathrm{~L})_{4}\right]^{8+}$ and also $\left[\mathrm{Cu}_{2} \mathrm{Pt}_{2}(\mathrm{~L})_{4}\right]^{6+}$ (Scheme 12), DFT geometry optimization was performed at the B3LYP/LanL2DZ/6-31G(d) level of theory in the presence of nitromethane as the solvent. The $\left[\mathrm{Pd}_{2} \mathrm{Pt}_{2}(\mathrm{~L})_{4}\right]^{8+}$ tetramer complex showed the expected box-like geometry, while optimization for the hexamer (with hexyloxy chains) gave the expected geometry. It was also extracted that applying a labile metal with a tetrahedral geometry might have less scope for the production of larger macrocycles, in addition to closing the $\mathrm{Pt}(\mathrm{II})$ centers and stabilizing the tetramer through platinumplatinum and $\pi$-stacking interactions.

In the case of di-magnetic $\mathrm{Cu}(\mathrm{I})$ and $\mathrm{Ag}(\mathrm{I})\left[\mathrm{M}(\text { Rpytri })_{2}\right]^{+-}$ complexes, the calculated results showed that there was a tendency to adopt a head-to-tail square-planar geometry with bispyridyl-triazoles, ${ }^{\mathbf{1 2 9}, \mathbf{1 3 3}}$ contrary to the primary preference of $\operatorname{Ag}(\mathrm{I})$ for a tetrahedral geometry over a square-planar geometry. ${ }^{178}$

The crystal structure and DFT calculated structural data for $\left[\mathrm{Cu}_{2} \mathrm{Pt}_{2}(\mathrm{~L})_{4}\right]^{6+}$ complexes demonstrated their tetrahedral geometry, ${ }^{129,177,179}$ but only using the asymmetric ligands with orthogonal binding sites in combination with cis-protecting directional bonding strategies at the Pt(II) centers. ${ }^{\mathbf{1 3 9 , 1 8 0 , 1 8 1}}$

A family of bis-(2-pyridyl-1,2,3-triazole) ligands 32 (Scheme 24) were synthesized by employing in situ azide formation conditions and then by methylene-bridging of the bis-(2-pyridyl-

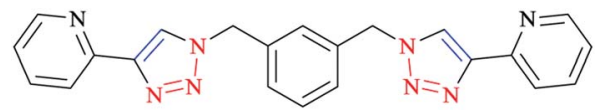

Scheme 25 Structure of the bis-2-pyridyl-1,2,3-triazole ligand (33). 


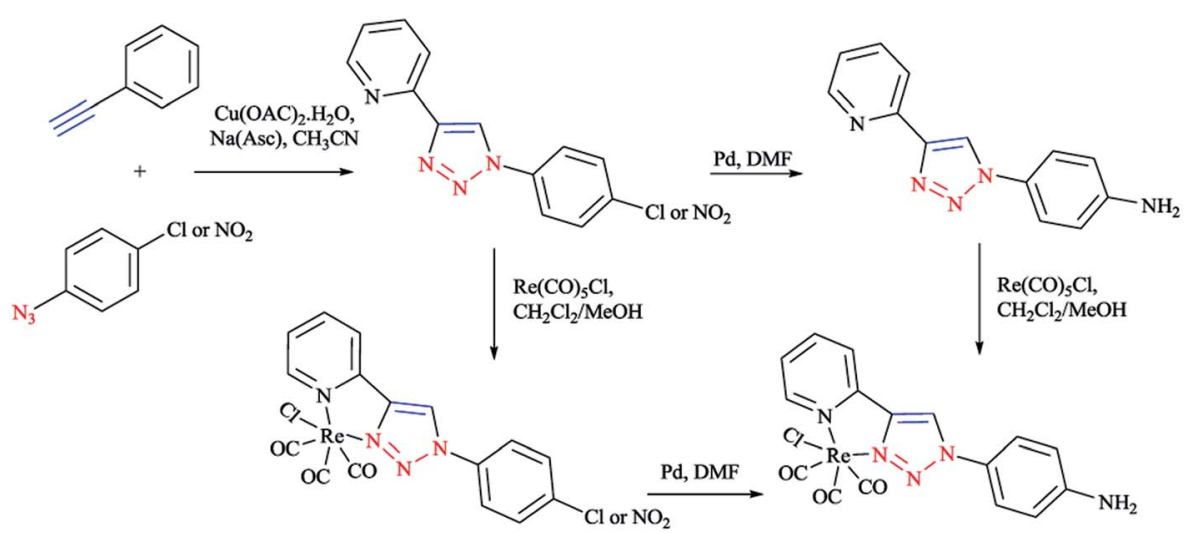

Scheme 26 Production of bidentate 2-pyridyl-1,2,3-triazole ruthenium complexes.

1,2,3-triazole) ligands 32 to produce larger heterometallic macrocycles.

$\left[\mathrm{Pt}(\mathrm{L})_{2}\right]^{2+}$ metallo-ligands showed a square-planar structure with 2-pyridyl-1,2,3-triazole 33 units adopting a head-to-tail arrangement with vacant peripheral binding sites.

In this vein, tetracopper(I) macrocycles were prepared using the bis-(2-pyridyl-1,2,3-triazole)-1,2-xylene ligand so that each pair of copper(I) ions was bridged by two iodides.

Furthermore, $\left[\mathrm{Cu}_{2} \mathrm{~L}_{2}\right]^{4+}$ macrocycles were generated from $\mathrm{Cu}(\mathrm{II})$ ions and bis-2-pyridyl-1,2,3-triazole ligands via embedding a $m$-xylene (1,3-) or 2,7-dimethylnaphthalene spacer unit $^{21,182}$ (Scheme 25).

\section{3 $\operatorname{Re}(\mathrm{I})$ complexes}

In Scheme 26, the production of $\left\{\mathrm{Re}(\mathrm{CO})_{3} \mathrm{Cl}\right\}$ bidentate 2pyridyl-1,2,3-triazole coordination compounds was illustrated via the reaction of the cycloadducts with the commercially available $\left[\mathrm{Re}(\mathrm{CO})_{5} \mathrm{Cl}\right]$.

$\mathrm{X}$-ray diffraction analysis was also performed to identify the structural properties of the aforementioned rhenium complexes and the results compared with the DFT-optimized geometries (via C-PCM computations in methanol solution). In the optimized structures of the complexes, the rhenium ion attains the usual distorted-octahedral coordination. It should be noted that the obtained bond lengths and angles were in the usual range of tricarbonyl rhenium complexes based on bidentate 2-pyridyl1,2,3-triazole derivatives ${ }^{59}$ (Scheme 27).

Policar and coworkers deeply investigated the complexes of $\operatorname{Re}(\mathrm{I})$ centers coordinated with a series of functionalized 1,2,3triazole ligands in an octahedral geometry as noninvasive<smiles></smiles>

, $\mathrm{CO}\left(\mathrm{CH}_{3}\right)_{2}$

Scheme 27 Structure of the $\left[\left(\mathrm{C}_{13} \mathrm{H}_{9} \mathrm{~N}_{5} \mathrm{O}_{2}\right) \mathrm{ReCO} 3 \mathrm{Cl}\right.$ (or $\left.\left.\mathrm{NO}_{2}\right)\right] \cdot \mathrm{CH}_{3}-$ $\mathrm{COCH}_{3}$ complex. imaging probes. In this vein, a series of pyridyl-1,2,3-triazole and quinolinyl-1,2,3-triazole ligands bearing various substituted alkyl side chains were designed and synthesized using click procedures. Furthermore, their photophysical properties were characterized and it was shown that the luminescent properties are enhanced in complexes bearing long alkyl chains. ${ }^{44}$

In some rhenium complexes, the inverse click ligands are generally coordinated to the rhenium(I) center in a bidentate fashion through the pyridyl and triazole nitrogen atoms. In this context, the $\operatorname{Re}(\mathrm{I})$ complexes of the [(4-R-1H-1,2,3-triazol-1-yl) methyl] pyridine ligand series (Scheme 28) were investigated structurally through X-ray crystallography, which showed that all of them were crystallized in the triclinic space group.

As expected, the rhenium metal center forms a distortedoctahedral coordination environment and is coordinated to a chloride and three carbonyl ligands in a facial array. Moreover, due to the presence of a methylene spacer between the triazole and pyridyl groups, a six-membered chelate ring is generated and consequently, the bite angles of the ligands vary little, ranging from $81.98(8)$ to $83.5(3)^{\circ}$. Chelation of the ligand

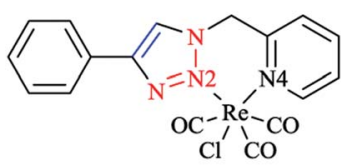

C17.25H13CIN4O3.25Re

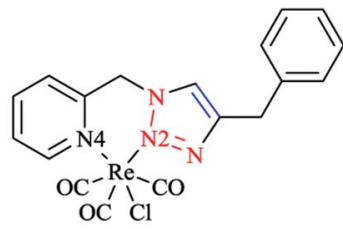

C19H18CIN4O4Re<smiles></smiles>

$\mathrm{C} 22 \mathrm{H} 22 \mathrm{ClN} 8 \mathrm{O} 6 \mathrm{Re}$

Scheme 28 Structures of the $\mathrm{C}_{17.25} \mathrm{H}_{13} \mathrm{CIN}_{4} \mathrm{O}_{3.25} \mathrm{Re}, \mathrm{C}_{19} \mathrm{H}_{18} \mathrm{CIN}_{4} \mathrm{O}_{4} \mathrm{Re}$, and $\mathrm{C}_{22} \mathrm{H}_{22} \mathrm{CIN}_{8} \mathrm{O}_{6}$ Re complexes. 


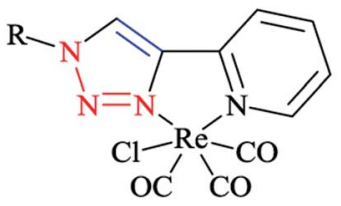

$\mathrm{R}=$ toluene, 1-ethyl-4-methoxybenzene, methyl acetate, 1-(2-methoxyphenyl)-4-propylpiperazine

Scheme 29 Structure of the $\left[(\mathrm{N}-\mathrm{N}) \operatorname{Re}(\mathrm{CO})_{3} \mathrm{Cl}\right]$ regular fivemembered rhenium click complexes.

to the metal center leads to the formation of six-membered rings in boat conformations, with the fold angles between the pyridyl and triazole rings ranging from 111.09 to $114.22^{\circ}$. It has been shown that the triazole ring substituent effect is not considerable on the metric properties of rhenium complexes and so it can be deduced that side-arm substitution leads to little electronic tuning of the ligand. Furthermore, in these [(4R-1H-1,2,3-triazol-1-yl)methyl]pyridine 5 set of ligands, it was found that the $\mathrm{N}^{\mathrm{Py}}$-Re bond length value (2.198(5)-2.218(9) $\AA$ ) is bigger than the $\mathrm{N}_{\text {trz }}-$ Re bonds $(2.155(2)-2.180(7) \AA$ ) that occur in other metal complexes of this ligand set. Further, it was assessed experimentally and computationally ${ }^{56,81,126}$ that metal complexes of the related regular 2-(1-R-1H-1,2,3-triazol-4-yl) pyridine 4 ligands were more stable than those with the [(4-R1H-1,2,3-triazol-1-yl)methyl]pyridine 5 inverse click ligands. Clearly speaking, regardless of whether the triazole is coordinated to the Re center, the obtained values of the Re-N2 $2_{\text {trz }}$ and $\mathrm{Re}-\mathrm{N} 2_{\mathrm{trz}}-\mathrm{N} 4_{\mathrm{py}}$ bond lengths and angles in the entire series of regular five-membered rhenium click complexes ${ }^{63,64,97,183,184}$ (Schemes 27 and 29) were very near to those of inverse sixmembered rhenium click complexes, and this feature has been also studied and confirmed in the $\operatorname{Pd}(\mathrm{II})$ complexes of these ligands. ${ }^{56,95}$

It was observed in the crystal structure of these complexes that double-stranded supramolecular polymers are formed via the many $\mathrm{C}-\mathrm{H} \cdots \mathrm{Cl}$ hydrogen bonds and $\mathrm{CH}-\pi$ or face-to-face $\pi$ stacking interactions. ${ }^{185-188}$ It was also observed that the chloride of one complex bonds to the adjacent complex through the acidic methylene $\mathrm{CH}(\mathrm{Cl} \cdots \mathrm{H}=2.638(2) \AA, \mathrm{Cl} \cdots \mathrm{C}=3.569(7) \AA)$, leading to the formation of a single-stranded linear polymer. A face-to-face $\pi$-stacking interaction (centroid-centroid distance of $3.736 \AA$ ) occurs between the phenyl group and 1,2,3-triazole units on adjacent complexes to produce the double-stranded structure. In addition, $\mathrm{CH}-\pi$ interactions between the benzyl

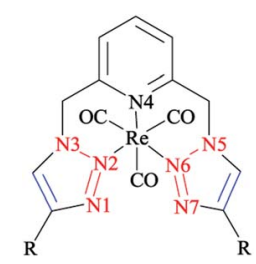

Scheme 30 Structure of the 2,6-bis(4-substituted-1,2,3-triazol-1-ylmethyl)pyridine complexes $\left(\mathrm{R}=\mathrm{Ph}, \mathrm{C}_{3} \mathrm{H}_{7}\right)$.

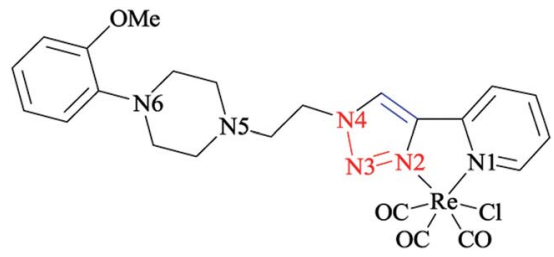

Scheme 31 Structure of the 4-piperazinyl-2-pyridyl-1,2,3-triazole rhenium(I) complex.

substituent methylene hydrogens and the phenyl unit of the adjacent complex were found with $\mathrm{CH}$-centroid distances of 3.032 and $3.122 \AA$. More interestingly, in the caffeinesubstituted complex, the individual complexes are folded into a U-shaped conformation and two complexes interact through $\mathrm{C}-\mathrm{H} \cdots \mathrm{O}$ hydrogen bonds between a carbonyl of the caffeine moiety and an acidic $\mathrm{CH}$ of the pyridyl ring, which consequently leads to a supramolecular cage that is filled with two acetone molecules as the solvent. These face-to-face $\pi$-stacking interactions result in the formation of a slipped stacked polymer with a centroid-centroid distance of $3.381 \AA$ between the caffeine groups.

The structures of 4-n-propyl- and 4-phenyl-substituted fac$\mathrm{Re}(\mathrm{CO})_{3}$ complexes coordinated with the tridentate click ligand (2,6-bis(4-substituted-1,2,3-triazol-1-ylmethyl)pyridine) (Scheme 30) were also investigated via X-ray crystallography and DFT methods. Based on the X-ray and DFT computational results, it was shown that both complexes had the expected facial coordination geometry about distorted-octahedral rhenium(I) centers. More concisely, the $\operatorname{Re}(\mathrm{I})$ cations were coordinated to three carbonyl donors and to the pyridyl and triazoyl nitrogen atoms of the ligands. ${ }^{58}$

In another research study, the complex of rhenium(I) with functionalized 2-pyridyl-1,2,3-triazole derivatives (pyta)-based ligands was crystallized by slow evaporation in dichloromethane/methanol solution and then investigated using the X-ray diffraction method.

A comparative study between the structural features of rhenium(I) complexes of the related pyta derivatives ${ }^{82,133}$ exhibited an anti-arrangement in them adopted by the $\mathrm{N}(1)$ and $\mathrm{N}(2)$ atoms of the triazole and pyridine rings, respectively. In the 1,2,3-triazole ring, the $\mathrm{N}=\mathrm{N}$ bond length of the 1,2,3-triazole

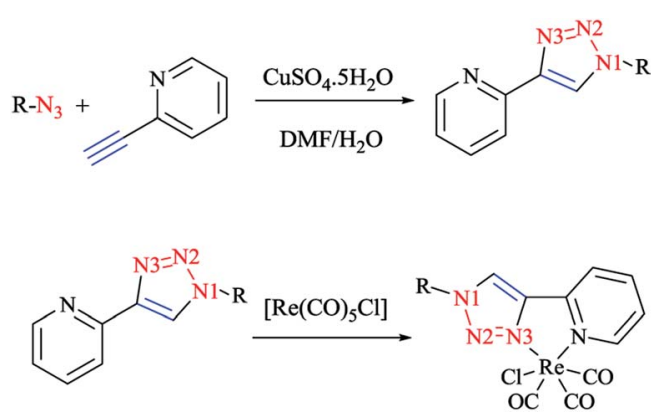

Scheme 32 Syntheses of $\left[\operatorname{Re}(\mathrm{CO})_{3} \mathrm{Cl}\right]$ with bidentate pyridyl-1,2,3triazole click ligands and [(pytri-R)Re(CO) ${ }_{3} \mathrm{Cl}$ complexes. 


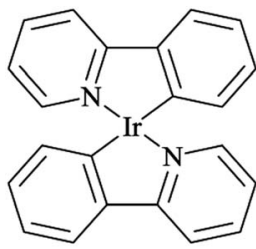

$\operatorname{Ir}(\mathrm{ppy})_{2}$

34

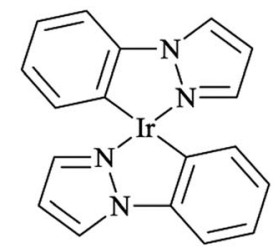

$\operatorname{Ir}(\text { phprz })_{2}$

35

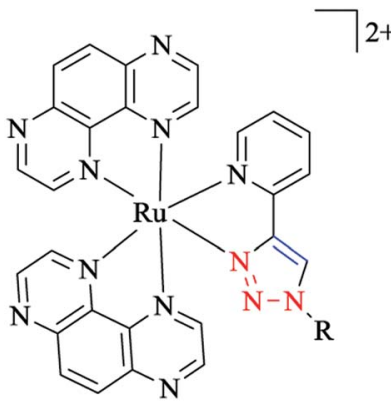

Scheme 33 Structures of the $\operatorname{Ir}(\mathrm{ppy})_{2} \quad$ (34) and $\operatorname{Ir}(\text { phprz })_{2} \quad$ (35) complexes.

ring was decreased and became shorter than the adjacent $\mathrm{N}-\mathrm{C}$ and $\mathrm{N}-\mathrm{N}$ bonds. Moreover, a network of intra-layer hydrogen bonds between the ligands and lattice waters was observed that led to the crystal cohesion. Consequently, the lattice water molecule forms $\mathrm{O}-\mathrm{H} \cdots \mathrm{N}$ bonds with one nitrogen of the piperazinyl moiety $(d(\mathrm{O}-\mathrm{H} \cdots \mathrm{N}(5))=3.013 \AA$, $\mathrm{O}-\mathrm{H}-\mathrm{N}(5)=$ $173.08^{\circ}$ ) (Scheme 31). It was observed that the ethylene bridge leads to a large distance between the (2-methoxyphenyl)piperazine group with the chelating part of the molecule. So, the components near the coordination sphere do not interact through coordination, hydrogen-bonding interaction, or by folding of the pendant arm toward the metal center, which was previously reported in other flexible spacers by Santos' group. ${ }^{189}$ The structural results show that the interaction of the metal center with the bioactive fragments is not considerable and so this suggested a suitable affinity for the serotonin receptors. ${ }^{63}$

Time-dependent DFT (TD-DFT) calculations ${ }^{190}$ on $\operatorname{Re}(\mathrm{I})$ complexes of readily functionalized bidentate pyridyl-1,2,3triazole click ligands (Scheme 32) demonstrated the MLCT nature of the HOMO $\rightarrow$ LUMO transitions (the blue-shift of Re $\rightarrow$ bpy MLCT, which lies at $633 \mathrm{~nm}$ ).

It was also found that the emission from $\mathrm{Re} \rightarrow$ pytri-R MLCT (where $\mathrm{R}=$ benzyl) is blue-shifted at $538 \mathrm{~nm}$ in $\mathrm{CH}_{3} \mathrm{CN}$. It should be mentioned that the electronic role of pytri- $\mathrm{R}$ in communication between the differing emitting centers has also

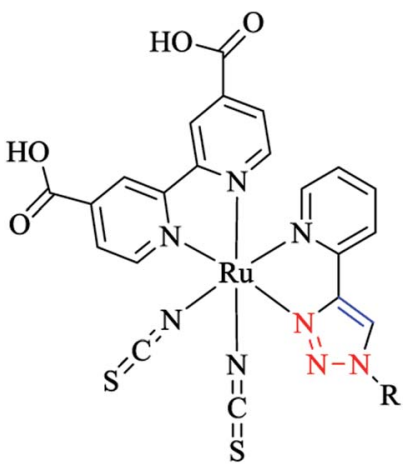

36

Scheme 34 Structure of a ruthenium complex with the (pytri$\mathrm{R})\left(\mathrm{bpy}\left(\mathrm{CO}_{2} \mathrm{H}\right)_{2}\right)(\mathrm{CNS})_{2}$ ligand.

\section{7}

Scheme 35 Structure of a ruthenium complex with the $(\mathrm{TAP})_{2}(\mathrm{pytri}-\mathrm{R})$ ligand.

been studied systematically. ${ }^{88}$ It was reported that $\operatorname{Ir}(\text { ppy })_{2} 34$ and $\operatorname{Ir}(\text { phprz) })_{2} 35$ (where phprz is 1-phenylpyrazole) (Scheme 33) fragments could bind to pytri-R and were then connected via the (N1) $\mathrm{sp}^{2}$ triazole nitrogen to produce dimer and trimer structures. Furthermore, it was shown that the modulation of the linkers through the $\mathrm{N} 1 \mathrm{sp}^{2}$ triazole did not affect the photophysical properties of the individual Ir units.

The coordination behavior of ruthenium ion with (pytri$\mathrm{R})\left(\mathrm{bpy}\left(\mathrm{CO}_{2} \mathrm{H}\right)_{2}\right)(\mathrm{CNS})_{2}$ as a pytri-R based ligand was investigated via DFT analysis ${ }^{85}$ (Scheme 34).

It should be mentioned that these complexes are widely used in dye-sensitized solar cells. DFT computations showed that the LUMO and LUMO+1 of $\left[\mathrm{Ru}(\right.$ pytri-R $)\left(\right.$ bpy $\left.\left.\left(\mathrm{CO}_{2} \mathrm{H}\right)_{2}\right)(\mathrm{CNS})_{2}\right] 36$ were based on the bpy ligand. Moreover, a systematic study of the substituent effects on the ruthenium complexes with substituted pytri-R ligands was performed by Happ et al. ${ }^{87}$ In this respect, the pytri-R ligand was substituted with ethynylphenyl groups at either the 5-pyridyl or N1 triazole positions, and it was shown that substitution of the 5-pyridyl position had a significant effect on the emission properties and increased the emission wavelength from $602 \mathrm{~nm}$ with the 1-ethynyl-4-methoxybenzene substituent to $674 \mathrm{~nm}$ with the 1-ethynyl-4-nitrobenzene substituent. Interestingly, the $\left[\mathrm{Ru}\left(\right.\right.$ pytri-R)(bpy $\left.\left.\left(\mathrm{CO}_{2} \mathrm{H}\right)_{2}\right)(\mathrm{CNS})_{2}\right] \quad 36$ complex substituted by 1-ethynyl-4-nitrobenzene at N1 triazole nitrogen showed the emission wavelength at $610 \mathrm{~nm}$. This behavior revealed that the linkage of the 1-ethynyl-4-nitrobenzene substituent with the triazole insulated the electron-withdrawing power of this substituent from the Ru center.

In another research study, the properties of $\left[\mathrm{Ru}(\mathrm{TAP})_{2}\right.$ (pytri$\mathrm{R})]^{2+} 37$ complexes with a DNA active moiety (where TAP $=1,4,5,8$ tetraazaphenanthracene) were also assessed (Scheme 35). ${ }^{191}$

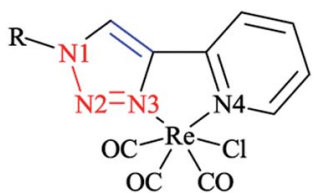

Scheme 36 Structure of the $\mathrm{Re}(\mathrm{CO})_{3} \mathrm{Cl}$ complex series with 2-(1-R$1 H-1,2,3$-triazol-4-yl)pyridine. 
It was demonstrated that the $\mathrm{d}$ and $\mathrm{p}$ orbitals of ruthenium are stabilized at $50 \mathrm{mV}$ relative to $\mathrm{L}=1,10$-phenanthroline, which could be attributed to a poorer overlap between the $\mathrm{d} \pi$ and $\pi^{*}$ (pytri-R) molecular orbitals. Moreover, it was investigated and shown that alkaline and selected first row transition metals have no considerable effect on varying levels of emission intensity and no tuning of the emission frequency. ${ }^{192}$ On the other hand, the $\mathrm{N} 1$ substituent does not shift the emission spectrum for [(pytri-R) $\left.\mathrm{Re}(\mathrm{CO})_{3} \mathrm{Cl}\right]$ complexes. For instance, by using $\mathrm{R}=\left(\mathrm{CH}_{2}\right)_{2} \mathrm{CO}_{2} \mathrm{H}$ and (2-methoxyphenyl) piperazine as substituents in the $\left[(\right.$ pytri- $\left.\mathrm{R}) \mathrm{Re}(\mathrm{CO})_{3} \mathrm{Cl}\right]$ complex, the emission maxima were see to lie at $526 \mathrm{~nm}$ and $522 \mathrm{~nm}$ in DMF/MeOH solution, respectively. ${ }^{63,183}$ DFT calculations on the molecular orbital properties of these systems demonstrated a modest contribution from the N1 substituent in the LUMOs.

Moreover, a series of electronically tuned $\mathrm{fac}-\mathrm{Re}(\mathrm{CO})_{3} \mathrm{Cl} \cdot 2-(1-$ R-1H-1,2,3-triazol-4-yl)pyridine complexes were prepared (Scheme 36). In this systematic study, the substituent effect on the electronic structure of a series of fac-[(pytri-R) $\left.\mathrm{Re}(\mathrm{CO})_{3} \mathrm{Cl}\right]$ complexes was examined. The substituents were chosen so that they could couple conjugatively with the triazole and could insulate it via a $\mathrm{CH}_{2}$ group from such communication. The nature of the lowest energy transition resonance was studied via Raman spectroscopy in conjunction with DFT calculations. The lowest excited state properties were also established using timeresolved emission spectroscopy. Then, the calculated values of a number of bond lengths and angles were compared with X-ray crystallographical data, and it was seen that there was a reliable agreement with the experimental data.

A comparison of the calculated Raman wavenumbers and intensity values with the corresponding experimental data showed a mean absolute deviation (MAD) of $<10 \mathrm{~cm}^{-1}$ for bands between 400 and $1650 \mathrm{~cm}^{-1}$ that had more than $20 \%$ of the maximum band intensity.

The electronic absorption behavior of all the complex series was investigated. The lowest energy transition at approximately $330 \mathrm{~nm}$ was not changed by substitution, regardless of whether was unconjugated or conjugated with the triazole ring.

The band at $330 \mathrm{~nm}$ could be assigned to a metal-ligand charge transfer (MLCT) ${ }^{97}$ as was confirmed by the TD-DFT data. The higher energy MLCT transitions (at $290 \mathrm{~nm}$ ) and additional transitions associated with the ligand (at $275 \mathrm{~nm}$ ) were obtained via TD-DFT computations. It is important to note that DFT methods systematically overestimate the conjugative effects and so, the effect of the conjugated group was predicted computationally to be stronger than the experimental values by up to $0.4 \mathrm{eV} \cdot{ }^{193,194}$

Moreover, it could be observed that conjugated and nonconjugated ligands affect the nature of the MLCT band at $330 \mathrm{~nm}$. Precisely speaking, the acceptor orbitals are localized solely on the triazole species for the unconjugated complexes, while in the case of conjugated complexes, they are spread over the $\mathrm{R}$ substituent in addition to the triazole moiety.

This different behavior can be attributed to the overweighing of the conjugation interactions associated with DFT methods, which can be examined through measuring the resonance Raman spectroscopy.<smiles>CC(C)(C)c1nnn(Cc2ccccn2)p1</smiles>

38

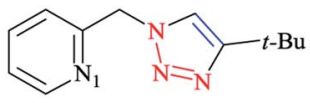

40<smiles>CSc1nnn(Cc2ccccn2)p1</smiles>

39

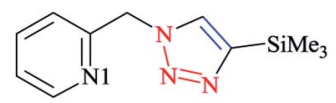

41
Scheme 37 Structures of click-derived chelating phosphorus- and nitrogen-containing heterocycles.

It was shown that different substitution on the triazole ring resulted in different Raman spectra; for instance $\mathrm{NO}_{2}$ substituted complexes showed a distinguished band at $1349 \mathrm{~cm}^{-1}$ attributed to $\mathrm{NO}_{2}$ functionality. ${ }^{195,196}$

A significant aspect was observed in the resonance Raman spectra, which was the identical spectra for the complexes with similar pytri species (bands at 1285, 1571, 1587, and $1625 \mathrm{~cm}^{-1}$ ). It should be stated that DFT normal mode calculations also produced these bands and showed that they are based on the pytri moiety. Small differences in the Raman spectra of the conjugated systems were observed. It should be noticed that the Raman spectra showed pytri modes, which were also observed for non-conjugated systems. Two bands were observed due to the stretching of the R-triazole moiety and an enhancement of the $\mathrm{NO}_{2}$ group ${ }^{\mathbf{1 9 5 , 1 9 6}}$ was present, which was in agreement with the acceptor molecular orbital nature of a nitro functional group.

From the computational viewpoints, the DFT calculated values revealed that the LUMO was nitrobenzene based, and also the TD-DFT computations for the lowest energy transitions demonstrated no or only a minor LUMO character. The calculated results were in confirmation with the resonance Raman data, which indicated an enhancement of nitro vibration, reflecting the role of the nitro group on the electronic transition. ${ }^{64}$

In order to compare the stereoelectronic properties of triazoles with triazaphospholes, $\operatorname{Re}(\mathrm{I})$ complexes containing these

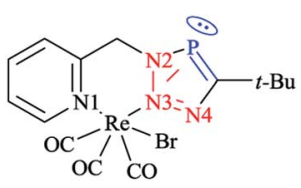

42

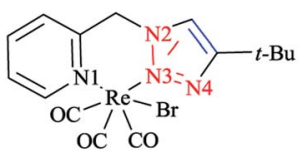

44

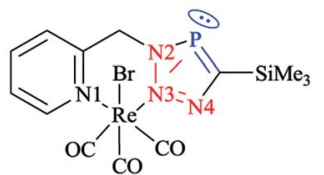

43

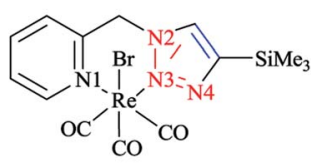

Scheme 38 Syntheses of $\operatorname{Re}($ I) complexes 35-38. 


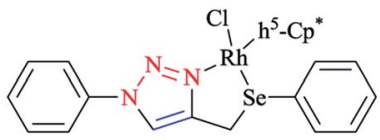

46
47
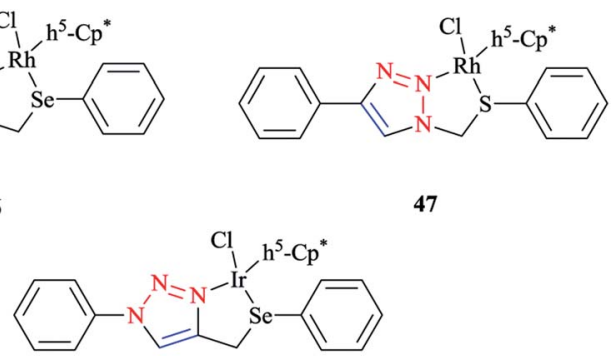

48

Scheme 39 Structures of $\mathrm{Rh}($ III)//I(III) complexes with 1,2,3-triazolebased organochalcogen ligands.

chelating ligands were assessed (Scheme 37). The coordination behavior of the $\mathrm{Re}(\mathrm{I})$ cation with the least nucleophilic nitrogen atom N3 in complexes $\mathbf{3 8 - 4 1}$ is depicted in (Scheme 38).

The crystallographic properties for two complexes of $\left[\mathrm{L}_{2} \mathrm{Re}(\mathrm{CO})_{3} \mathrm{Br}\right]$ were comparatively characterized. The crystal structure revealed that the $\operatorname{Re}(\mathrm{I})$ cation is coordinated to chelating ligands via the $\mathrm{N}(3)$ atom of the triazaphosphole species, rather than via the phosphorus atom. Since, coordination through the $\mathrm{N}(3)$ atom of the triazaphosphole species has not been observed for triazaphospholes before, it can be claimed that this behavior was enforced by the chelating effect of the ligand.

As was observed in the crystal geometry of compounds $\mathbf{4 2}$ and 43 , the nitrogen atoms $\mathrm{N}(3)$ of the triazole units were coordinated to the $\operatorname{Re}(\mathrm{I})$ centers in the facial geometry of complexes 44 and 45, $\left[(40) \operatorname{Re}(\mathrm{CO})_{3} \mathrm{Br}\right]$ and $\left[(41) \operatorname{Re}(\mathrm{CO})_{3} \mathrm{Br}\right]$. Moreover, we can claim that replacing the phosphorus atom in 42 and 43 by an isoelectronic $\mathrm{C}-\mathrm{H}$ group in $\mathbf{4 4}$ and $\mathbf{4 5}$ had no considerable effect on the bite angle $\mathrm{N}(1)-\operatorname{Re}(\mathrm{I})-\mathrm{N}(3)$.

DFT calculations at the B3LYP level of theory ${ }^{54}$ were performed on compound $42(\mathrm{R}=t-\mathrm{Bu})$ to understand the electronic structure of the triazaphospholes. A large coefficient of $\pi$ symmetry at the phosphorus atom was obtained on the LUMO of low-coordinate phosphorus heterocycle compounds, which showed the $\pi$-accepting nature of these systems. In HOMO-1, a large value of the coefficient of $\sigma$ symmetry was obtained at the nitrogen atoms $\mathrm{N} 4$ and $\mathrm{N} 3$ of the heterocycle ring and HOMO-7 clearly indicated the $\pi$-donor properties of triazaphospholes.

It is important to mention that transition metal cation centers coordinate preferentially to the nitrogen atom N3 in triazoles, but in the ligands of $\mathbf{3 8}$ and $\mathbf{3 9}$ this nitrogen atom cannot coordinate via $\sigma$ bonds due to the chelating effects. Furthermore, in the HOMO-4 orbital, similar large coefficients of $\sigma$ symmetry at both the phosphorus atom and nitrogen atom N3 appeared. More importantly, the coordination of a transition metal center with the pyridyl nitrogen and the nitrogen N3 or with the pyridyl nitrogen and the phosphorus via a $\sigma$ coordination mode led to a small energetic difference, and so both coordination modes could be possible. ${ }^{66}$

\subsection{Rh(III) and Ir(III) complexes}

Some 1,2,3-triazole-based organochalcogen ligands and their $\mathrm{Rh}(\mathrm{III} / \mathrm{Ir}(\mathrm{III})$ complexes (Schemes 39 and 40) were synthesized and characterized using elemental analysis, multinuclear NMR, IR, X-ray crystallography, and mass spectral data.

To synthesize the complexes, the chloro bridge cleavage of $\left[\left(\eta^{5}-\mathrm{Cp}^{*}\right) \operatorname{RhCl}(\mu-\mathrm{Cl})\right]_{2} /\left[\left(\eta^{5}-\mathrm{Cp} *\right)-\operatorname{IrCl}(\mu-\mathrm{Cl})\right]_{2}$ occurred, followed by the reaction with 1-benzyl-4-((phenyl-thio/phenylseleno) methyl)-1H-1,2,3-triazole (A/B) or 4-phenyl-1-(phenylthio/phenylseleno)methyl-1H-1,2,3-triazole (C/D) at room temperature. Consequently, rhodium(III) (A1, B1, A2, and B2) and iridium(III) (C1, D1, C2, and D2) half-sandwich complexes were generated and the process was facilitated by anion exchange with $\mathrm{NH}_{4} \mathrm{PF}_{6}$.

The nitrogen of triazole five-membered ring is coordinated to the metal center in all of the complexes. Almost similar X-ray molecular structures were obtained for all the rhodium and iridium complexes, which demonstrated an overall three-legged piano-stool conformation. More clearly, a pseudo-octahedral half-sandwich "piano-stool" disposition of donor atoms is formed around the $\mathrm{Rh} / \mathrm{Ir}$ metal center. The centroid of the $\eta^{5}$ $\mathrm{Cp}^{*}$ ring occupies nearly the center of a triangular face of an octahedron. The coordination sphere is occupied with

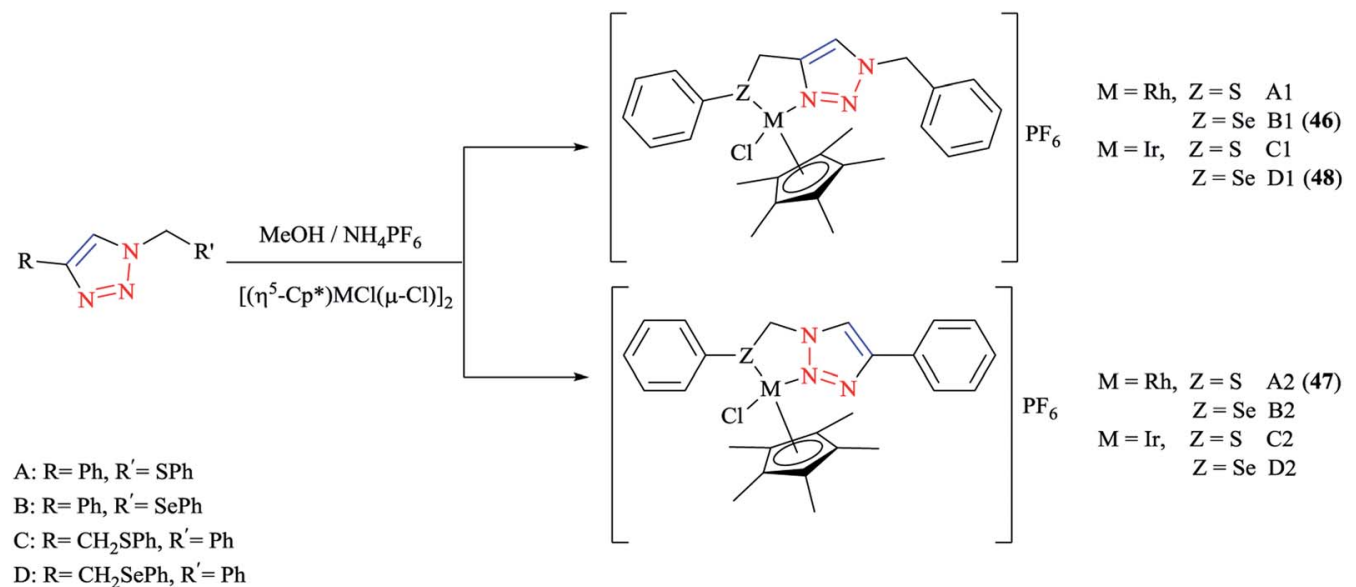

Scheme 40 Syntheses of A-B ligands and A1-D1 and A2-D2 complexes. 
a chlorine donor atom and nitrogen and chalcogen atoms, which form a chelate ring with the metal center.

In comparison with complex 46, the Rh-Se bond length of the half-sandwich complex of $\mathrm{Rh}(\mathrm{III})$ with the ligand 2-(phenylselenomethyl)pyridine was $2.487 \AA$ (ref. 197) and for the complex $\left[\eta^{5}-\mathrm{Cp} * \operatorname{RhCl}\left\{\eta^{2}-\left(\mathrm{SePPh}_{2}\right)_{2} \mathrm{~N}\right\}\right]$ was $2.5266 \AA{ }^{198}$ which were larger than those obtained for the half-sandwich complex of $\mathrm{Rh}$ (III) with the ligand 1,2-dicarba-closo-dodeca-borane-1,2dichalcogen. ${ }^{199}$

In complex 47, the Rh-S bond distance was $2.432 \AA$ and was also greater than the corresponding value for the complexes $\left[\eta^{5}\right.$ $\mathrm{Cp} * \operatorname{RhCl}\left(1,1^{\prime}\right.$-(1,2-ethanediyl)bis(3-methylimidazole-2-thione))] $\mathrm{Cl}$ at $2.3967 \AA$ (ref. 200) and $\left[\eta^{5}-\mathrm{Cp}^{*} \operatorname{RhCl}\{2-(\right.$ phenylthiomethyl) pyridine $\}] \mathrm{PF}_{6}$ at $2.383 \AA$ (ref. 197) and $\left[\eta^{5}-\mathrm{Cp} * \operatorname{RhCl}\left\{\eta^{2}\right.\right.$ $\left.\left.S, P-\mathrm{Ph}_{2} \mathrm{P}(\mathrm{S}) \mathrm{NHPPh}_{2}\right\}\right] \mathrm{BF}_{4}$ at $2.404 \AA{ }^{201}$ Furthermore, in complex 47, the Rh-N bond distance was $2.091 \AA$, which was in reliable agreement with those of $\left[\eta^{5}-\mathrm{Cp} * \mathrm{Rh}\left(2,6-(\text { mesityl })_{2} \mathrm{C}_{6} \mathrm{H}_{3} \mathrm{~S}\right)(\mathrm{bpy})\right]$ $\left[\mathrm{B}\left(3,5-\left(\mathrm{CF}_{3}\right)_{2} \mathrm{C}_{6} \mathrm{H}_{3}\right)_{4}\right] \cdot{ }^{202}$ The obtained bond length values for $\mathrm{Rh}-$ $\mathrm{C}(\mathrm{Cp} *$ centroid $)$ in complexes 46 and $\mathbf{4 7}$ were in the normal range, i.e., $1.784-1.786 \AA^{.201}$

In the case of complex 48 , the Ir-Se bond distance value was $2.4822 \AA$, which was longer than the values obtained for the complex $\left[\eta^{5}-\mathrm{Cp} * \mathrm{Ir}-\left\{\mathrm{Se}_{2} \mathrm{C}_{2}\left(\mathrm{CO}_{2} \mathrm{Me}\right)_{2}\right\}\right](2.3494 \text { and } 2.3520 \AA)^{203}$ and near to the distances reported for $\left[\left(\eta^{5}-\mathrm{Cp} \mathrm{p}^{*}\right) \operatorname{Ir}((2\right.$-arylselenomethyl)pyridine $) \mathrm{Cl}]\left[\mathrm{PF}_{6}\right]$ at $2.453 \AA{ }^{197}\left[\eta^{5}-\mathrm{Cp} * \operatorname{IrCl}\left(\mu-\mathrm{SeCOC}_{6}-\right.\right.$ $\left.\left.\mathrm{H}_{5}\right)\left(\kappa^{2}-\mathrm{SeCOC}_{6} \mathrm{H}_{4}\right) \operatorname{Ir}\left(\eta^{5}-\mathrm{Cp}^{*}\right)\right]$ at $2.445-2.495 \quad \AA{ }^{204}$ and $\left[\eta^{5}\right.$ $\left.\mathrm{Cp} * \operatorname{Ir}\left(\mu^{3}-\mathrm{Se}\right)_{2}\left\{\mathrm{PtTol}-\left(\mathrm{PPh}_{3}\right)\right\}_{2}\right]$ at $2.416-2.422 \AA{ }^{\circ}{ }^{205}$ Moreover, the Ir-N bond distance was $2.094 \AA$, which was very close to the Ir-N bond length in $\left[\left(\eta^{5}-\mathrm{Cp}^{*}\right) \operatorname{Ir}(2\right.$-arylthiopyridyl $)$ pyridineCl $]\left[\mathrm{PF}_{6}\right]$ at $2.099 \AA$ (ref. 197) and shorter than those of Ir complexes of the pyridine-triazole ligand at $2.137 \AA$ (ref. 29) and 2-(1-benzyl- $1 H^{-}$ 1,2,3-triazol-4-yl)pyridine at 2.151-2.159 $\AA^{2006}$ The $\operatorname{Ir}-\mathrm{C}\left(\eta^{5}\right.$ Cp*centroid) bond length in complex 48 was $1.791 \AA$, which was consistent with the Ir-C bond distance in $\left[\left(\eta^{5}-\mathrm{Cp}^{*}\right) \operatorname{Ir}((2\right.$ arylselenomethyl)pyridine) $\mathrm{Cl}]\left[\mathrm{PF}_{6}\right]$ at $1.781 \AA$ and shorter than the reported value for the complex $\left[\left(\eta^{5}-\mathrm{Cp} *\right) \operatorname{Ir}(\mathrm{phpy}) \mathrm{Cl}\right]$ at $1.863 \AA^{.207}$
More interestingly, in complexes $\mathbf{4 6}-\mathbf{4 8}, \mathrm{C}-\mathrm{H} \cdots \mathrm{F}$ secondary interactions and consequent chain-like structures have been found.

Theoretical analysis of the frontier molecular orbitals and charge distribution of complexes A1-D1 and A2-D2 were carried out through DFT approaches. Computational results on N(1)coordinated complexes showed that the HOMOs were essentially located over the metal center and the $\pi$ orbital of the $\mathrm{Cp}^{*}$ ring. Clearly speaking, the HOMO orbitals consist of $d$ orbital of the metal interacting with the $\pi$ orbital of the $\mathrm{Cp}^{*}$ ring and $\mathrm{p}$ orbitals of $\mathrm{N}(1)$ in the triazole ring and chalcogen atom, while in the HOMOs of N(2)-coordinated complexes, the $\pi$ orbital of 4phenyl-1,2,3-triazole interacts with the metal $\mathrm{d}$ orbital and $\pi$ orbital of the $\mathrm{Cp}^{*}$ ring and the $\mathrm{p}$ orbital of the chlorine atom. The HOMO-LUMO energy gap was also investigated to interpret the chemical reactivity of the complexes. The calculated results indicated that the HOMO-LUMO energy gaps of complexes A1, $\mathrm{B} 1, \mathrm{~A} 2$, and $\mathrm{B} 2$ were smaller than those of $\mathrm{C} 1, \mathrm{D} 1, \mathrm{C} 2$, and D2.

It should be stated that the obtained result was in confirmation with the higher reactivity of Rh complexes in comparison to Ir complexes. Moreover, it can be predicted that among the complexes A1, B1, A2, and B2, complexes A2 and B2 could be expected to be more catalytically active than A1 and B1 complexes, and within the Ir complexes, the reactivity of complex D2 should be more than the other three Ir complexes. It should be mentioned that the obtained DFT results were in reliable agreement with the elucidations in terms of the catalytic activities of the various complexes.

From the electronic viewpoint, the coordination strength can be assumed to be a significant parameter in the stability of a complex. In complexes A1-D1, the calculated values of electron density at the coordinated $\mathrm{N}(1)$ of the triazole ring were quite high and so these complexes are more stable electronically, while for the complexes where $\mathrm{N}(2)$ of the triazole ring is involved in the coordination, the calculated electron density on the $\mathrm{N}(2)$ atom and consequently the stability of the complex was reduced. In conclusion, the electronic stability of complexes involving $\mathrm{N}(1)$ in coordination was greater than in those

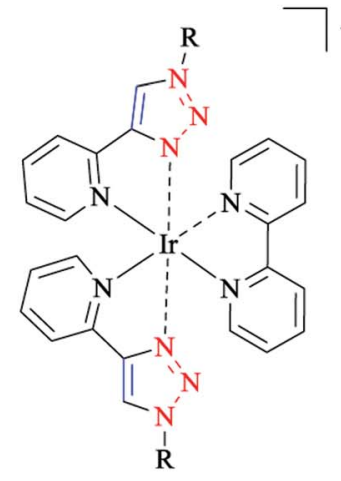

$\left[\operatorname{Ir}(\mathbf{1 9})_{2}(\mathrm{bpy})\right]^{+}$

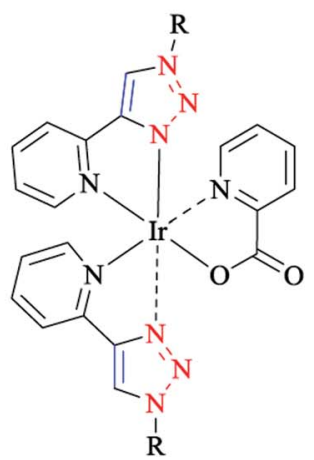

$\left[\operatorname{Ir}(19)_{2}(\right.$ pic $\left.)\right]$<smiles></smiles>

$\left[\operatorname{Ir}(19)_{2}(\mathrm{acac})\right]$ 
involving $\mathrm{N}(2)$ and so their reactivity is less..$^{37,56,126,208}$ It should be noted that the crystallographical structural data for complexes 46, 47, and 48 were in good agreement with the calculated values.

It is important to note that all DFT computations were performed using the B3LYP functional. In the case of Ir and Rh, effective core potential (LANL2DZ) calculations ${ }^{\mathbf{2 0 9}-212}$ were applied for core electrons, while for other elements, the 6$311 \mathrm{G}^{* *}$ basis set were used.

The initial geometry coordinates were directly specified as a single-crystal X-ray structure. In order to establish the stationary points as the minima, frequency calculations were carried out at the end of the geometry optimization process and the molecular orbital properties were calculated with respect to the optimized coordinates using the same level of theory and the same basis set. ${ }^{213}$

The frontier molecular orbital analysis of iridium(III) complexes with phenyl- $1 H$-[1,2,3]triazoles showed that for all the complexes, the HOMO corresponded to the $5 \mathrm{~d}_{x y}$-orbital, while the LUMO was a $\pi^{*}$-orbital. In the case of $\left[\operatorname{Ir}(\mathbf{1 9})_{2}(\mathrm{bpy})\right]^{+}$ 49, a $\pi$-orbital of the cyclometalating ligand was intercalated within the occupied 5d-orbitals. Interestingly, this antibonding orbital was located on the ancillary ligand in the case of $\left[\operatorname{Ir}(\mathbf{1 9})_{2}(\mathrm{bpy})\right]^{+} 49$ and $\left[\operatorname{Ir}(\mathbf{1 9})_{2}(\right.$ pic $\left.)\right] 50$, but was on the cyclometalating ligand in the case of $\left[\operatorname{Ir}(\mathbf{1 9})_{2}\right.$ (acac)] 51 (schematic structures of the iridium(III) complexes are displayed in Scheme 41).

Since the strong ligand field effect of the phenyl anion ligand increased the gap between the $t_{2 g}$ and $e_{g}$ orbitals, the $e_{g}$ orbitals of $\operatorname{Ir}(\mathrm{III})$ were strongly destabilized in these complexes. The calculations demonstrated that the substituents on the cyclometalating ligands as well as on the ancillary ligand destabilized the HOMO and stabilized the LUMO, and so decreased the HOMO-LUMO energy gap.

The calculated values of the LUMO levels and the theoretical band gaps $E_{\mathrm{g}}$ showed particularly an overestimation compared to the corresponding experimental data. It should be mentioned that the relative change in the complex series was in

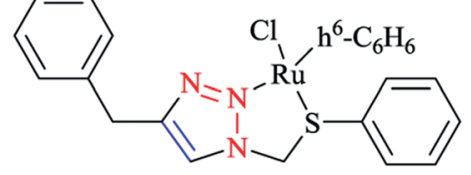

52

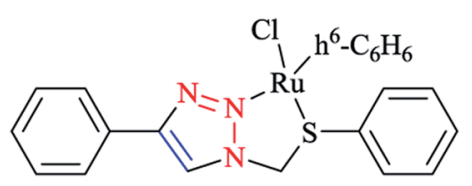

agreement with the LUMO energies and the HOMO-LUMO energy gaps $\left(E_{\mathrm{g}}^{\mathrm{acac}}>E_{\mathrm{g}}^{\mathrm{pic}}>E_{\mathrm{g}}^{\mathrm{bpy}}\right)$.

The calculated results for $\left[\operatorname{Ir}(\mathbf{1 9})_{2}(\right.$ acac $\left.)\right] 51$ could be used to evaluate the influence of the cyclometalating ligand on the HOMO-LUMO gap. Apparently, 1,2,3-triazole ligands increase the energy gap in comparison with the ppy ligand-based complex, which can be attributed to the stabilization of HOMO and destabilization of LUMO, and so can be caused by the increased $\pi$-acceptor ability of the 1,2,3-triazole moiety. Moreover, back-bonding effects for receiving electron density in the $\pi^{*}$-orbitals of the ligand-centered $\pi$-system stabilized the occupied $t_{2 g}$ orbitals of the iridium complexes. On the other hand, it also destabilized the unoccupied $\pi^{*}$-orbitals of the ligands including the LUMO level.

Computational frontier orbitals assessment on the effect of the ancillary ligand (bpy, acac, pic) led to the following results: first, a larger band gap was obtained for the neutral compounds in comparison to the cationic $\left[\operatorname{Ir}(19)_{2}(\mathrm{bpy})\right]^{+} 49$ complex and Ir(III) complexes. More precisely, the HOMO energies were stabilized in the cationic compound in comparison to in the neutral complexes. However, the LUMO was considerably more stabilized than the HOMO, and so the HOMO-LUMO energy gap was reduced. Second, it was shown that the major differences between the neutral compounds (i.e., $\left[\operatorname{Ir}(\mathbf{1 9})_{2}(\mathrm{pic})\right] \mathbf{5 0}$ and $\left.\left[\operatorname{Ir}(\mathbf{1 9})_{2}(\mathrm{acac})\right] \mathrm{51}\right)$ were mainly due to the LUMO energies rather than the HOMO energies through a comparison between the neutral compounds (i.e., $\left[\operatorname{Ir}(\mathbf{1 9})_{2}(\right.$ pic $\left.)\right] 50$ and $\left[\operatorname{Ir}(\mathbf{1 9})_{2}(\right.$ acac $\left.\left.)\right] \mathbf{5 1}\right)$. As mentioned earlier, both LUMOs showed a $\pi *$-character, but were located on the cyclometalating and on the ancillary ligand, respectively. For the $\operatorname{In}\left[\operatorname{Ir}(\mathbf{1 9})_{2}(\right.$ pic $\left.)\right] \mathbf{5 0}$ complex, the LUMO $\left(\pi_{\text {anc }}^{*}\right)$ on the ancillary ligand was stabilized with respect to the $\pi^{*}$ and orbital in $\left[\operatorname{Ir}(\mathbf{1 9})_{2}(\right.$ acac $\left.)\right]$ 51, which had higher energy values than the $\pi^{*}$-orbital of the cyclometalating ligands. ${ }^{114}$

\subsection{Ru(II) complexes}

Next, we report the crystallographical assessments of some ruthenium complexes of click-generated 1,2,3-triazole-based organosulfur-selenium ligands (Schemes 42 and 43).

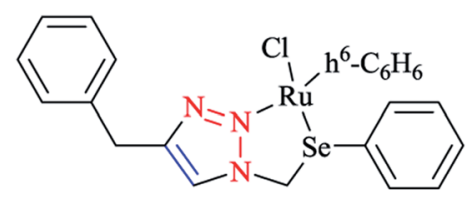

53

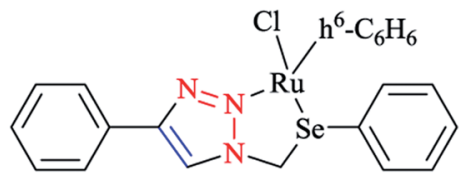

Scheme 42 Structures of Ru(॥) complexes with 1,2,3-triazole-based organosulfur/selenium ligands. 


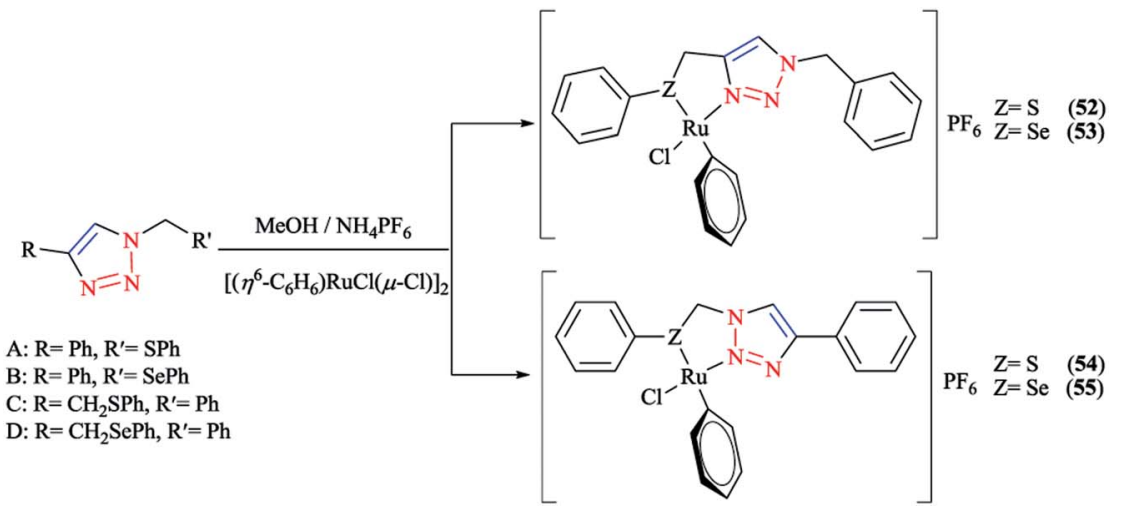

Scheme 43 Syntheses of A-D ligands and complexes 52-55.

A pseudo-octahedral half-sandwich "piano-stool" disposition of donor atoms occurs around the $\mathrm{Ru}$ metal center in complexes 52-55. More precisely, one face of an octahedron in all four complexes was occupied with a benzene ring and a chelate ring is formed with nitrogen and chalcogen atoms around the metal center, while a chlorine donor atom completes the coordination sphere. Overall, a three-legged piano-stool conformation was observed in the X-ray crystal structure.

The $\mathrm{Ru}-\mathrm{S}$ bond lengths were obtained as $2.3847 \AA$ in complex 52 and $2.3893 \AA$ in complex $\mathbf{5 4}$, which are consistent with each other.
On the other hand, the Ru-Se bond distance in complex $\mathbf{5 3}$ was obtained as $2.497 \AA$, which was longer than that of complex 55 at $2.4859 \AA$, but was similar with the values for $\left[\left(\eta^{6}-\mathrm{C}_{6} \mathrm{H}_{6}\right)\right.$ $\operatorname{RuCl}(N-\{2$-(phenylseleno)ethyl $\}$ pyrrolidine $)]^{+}$at $2.480 \AA$ and for $\left[\left(\eta^{6}-\mathrm{C}_{6} \mathrm{H}_{6}\right) \mathrm{Ru}\left(2-\mathrm{MeSC}_{6} \mathrm{H}_{4} \mathrm{CH}=\mathrm{NCH}_{2} \mathrm{CH}_{2} \mathrm{SeC}_{6} \mathrm{H}_{5}\right)\right]^{2+}$ at $2.4848 \AA$. However, the $\mathrm{Ru}-\mathrm{Se}$ bond length for $[\mathrm{RuCp}(\mathrm{CO})(\mathrm{C}=\mathrm{CPh})(\mu-\mathrm{Se})$ $\left.\mathrm{ZrCp}_{2}\right]$ at $2.494 \AA$ was in confirmation with that of complex 53. In complexes 52-55, the $\mathrm{Ru}-\mathrm{N}$ bond lengths varied in a narrow range $(2.072-2.101 \AA)$ and were similar with the reported $\mathrm{Ru}-\mathrm{N}$ bond distance for $[\mathrm{Ru}(2,6-\mathrm{bis}(1-\mathrm{benzyl}-1,2,3$-triazol-4-yl) pyridine $\left.)_{2}\right]\left(\mathrm{PF}_{6}\right)_{2}$ at $2.050 \AA$ (ref. 214) and $\left[\left(\eta^{6}-\mathrm{C}_{6} \mathrm{H}_{6}\right)\right.$ $\left.\mathrm{Ru}\left(2-\mathrm{MeSC}_{6} \mathrm{H}_{4} \mathrm{CH}=\mathrm{N}-\mathrm{CH}_{2} \mathrm{CH}_{2} \mathrm{SC}_{6} \mathrm{H}_{5}\right)\right]^{2+}$ at $2.073 \AA$. In

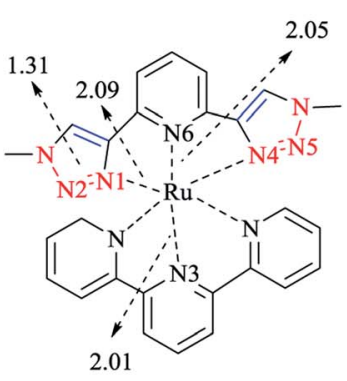

RuNNN

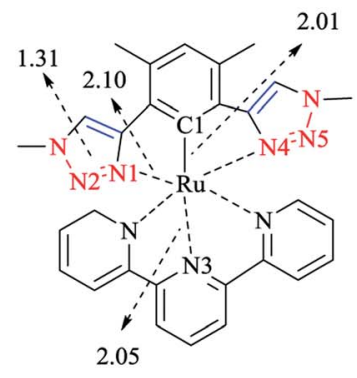

RuNCN

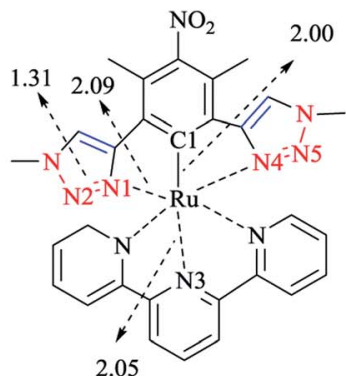

$\mathrm{RuNCN}-\mathrm{NO}_{2}$

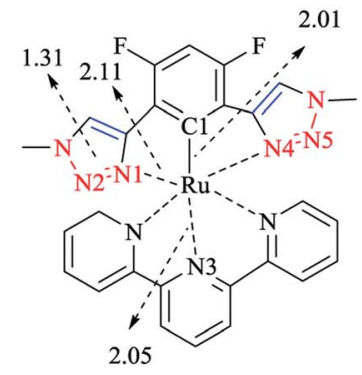

RuNCN-F

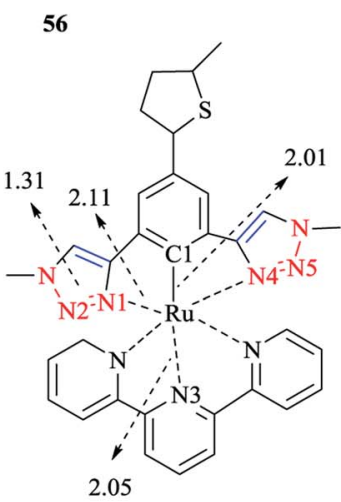

RuNCN-Tph
57
58

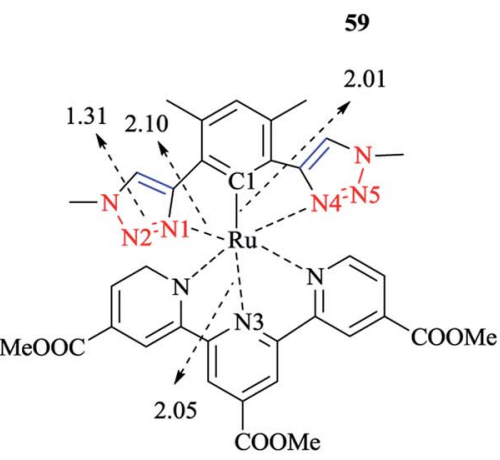

RuNCN-(COOMe $)_{3}$

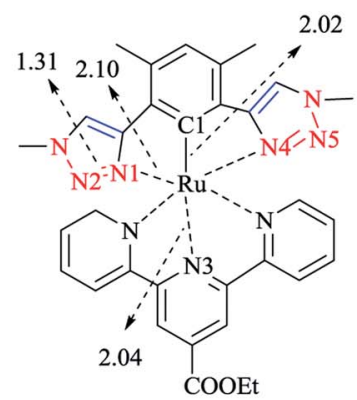

RuNCN-COOEt

Scheme 44 Structures of Ru(॥) complexes with some selected calculated bond distances $(\AA)$ 
addition, the $\mathrm{Ru}-\mathrm{C}$ bond lengths of 2.154-2.22 $\mathrm{A}$ and the $\mathrm{C}-\mathrm{Ru}-$ $\mathrm{C}$ bond angles of complexes 52-55 were in the normal range. ${ }^{215-217}$ The $\mathrm{PF}_{6}$-groups were involved in $\mathrm{C}-\mathrm{H} \cdots \mathrm{F}$ secondary interactions in all the complexes 52-55.

From the computational viewpoint, the cases of $\mathrm{Ru}-\mathrm{Cl}, \mathrm{Ru}-$ $\mathrm{N}$, and $\mathrm{Ru}-\mathrm{C}$ (centroid) showed an excellent agreement between the DFT calculated and experimental bond distances values. Furthermore, the X-ray values of the bond angles were very close to the calculated ones.

In the next step, DFT calculations were performed to assess qualitatively the optimized geometries, frontier orbitals, and charge distribution of complexes 52-55. In complexes 52 and 53, the HOMOs are positioned primarily over the $\mathrm{Ru}$ and $\mathrm{Cl}$ atoms and include the orbital of $\mathrm{Ru}(\mathrm{II})$ interacting with a $\pi$ orbital of the $\eta^{6}$-benzene ring, a $p$ orbital of the triazole nitrogen, and a chalcogen atom. In complexes 54 and 55, the HOMOs constitute a $\pi$ orbital of 4-phenyl-1,2,3-triazole and a d orbital of the metal. However, the d orbital of Ru(II) interacts with the $\pi$ orbital of the $\eta^{6}$-benzene ring, the p orbital of triazole nitrogen, and a chalcogen donor atom in HOMO-1.

DFT calculations indicated that the HOMO-LUMO energy gaps in complexes $\mathbf{5 4}$ and $\mathbf{5 5}$ were lower than those of $\mathbf{5 2}$ and 53, which corresponds to the higher reactivity of complexes $\mathbf{5 4}$ and 55.

It is important to note that in complexes $\mathbf{5 4}$ and $\mathbf{5 5}$, there is $\mathrm{N}(2)$ coordinating moiety, which can be attributed to the low energy gaps. On the other hand, the calculated electron densities of the coordinated N(1) triazole ring in complexes 52 and 53 were higher than the calculated value for $\mathrm{N}(2)$ in complexes 54 and 55. This electronic feature can be interpreted as due to a strong coordination between $\mathrm{N}(1)$ of triazole and $\mathrm{Ru}$ in complexes 52 and 53, which leads to greater electronic stability in comparison with $\mathbf{5 4}$ and $\mathbf{5 5 .}{ }^{37}$

In another work, the crystal structure of $\mathrm{Ru}(\mathrm{II})$ complexes with $\mathrm{NNN}, \mathrm{NCN}, \mathrm{NCN}-\mathrm{NO}_{2}, \mathrm{NCN}-\mathrm{F}$, and $\mathrm{NCN}-\mathrm{Tph}$ ligands were determined via the X-ray diffraction method and some considerable changes were observed attributed to the packing effects, such as a strong distortion within RuNCN-F.

In the RuNCN-Tph complex 60, the thiophene-phenyl torsion angle was obtained as $30.78^{\circ}$, which confirmed the calculated results. This feature led to the partial extension of conjugation into the thiophene ring. It was shown that when a dative $\mathrm{Ru}-\mathrm{N}$ bond of the poly-pyridyl-type complex RuNNN was replaced with a covalent organometallic $\mathrm{Ru}-\mathrm{C} 1$ bond in RuNCN complex 57, the bond distance was reduced from 2.02 to
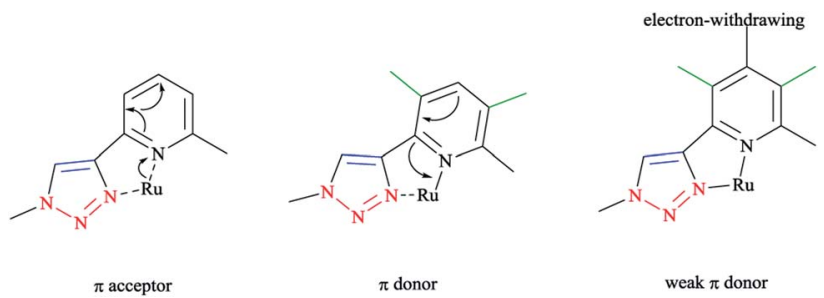

Scheme 45 Schematic of the electronic features of the cyclometalation and an electron-withdrawing group.

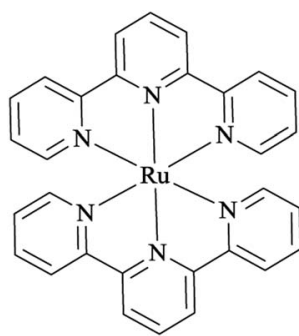

$\left[\mathrm{Ru}\left(\mathrm{tpy}_{2}\right)_{2}\left(\mathrm{PF}_{6}\right)_{2}\right.$

63

Scheme 46 Structure of $\left[R u(t p y)_{2}\right]\left(\mathrm{PF}_{6}\right)_{2}$ complex.

$1.98 \AA$ A. This behavior could be mainly attributed to s donation and additional $\mathrm{p}$ donation as well as by electrostatic interactions with the anionic, aromatic carbon donor. Moreover, the triazole $\mathrm{N}-\mathrm{Ru}$ bond length was increased due to the decrease in the orbital overlap by the small bite angle, while, a trans influence occurs and the opposed $\mathrm{Ru}-\mathrm{N}$ bond distance is increased to $2.01 \AA$ based on the considerable electron-donation ability of the carbanion. More interestingly, the outer pyridine $\mathrm{N}-\mathrm{Ru}$ bonds were shortened, which could be ascribed to the $\mathrm{p}$ back donation from the electron-rich $\mathrm{Ru}(\mathrm{II})$ metal center (Schemes 44 and 45).

Further, the bond length of the $\mathrm{N}-\mathrm{N}$ double bond in the triazole ring was increased due to the increasing $\mathrm{p}$ back donation into the $\pi^{*}$ orbitals. By the substitution of $\mathrm{NO}_{2}$ as an electron-withdrawing group, it was indicated that the cyclometalation process was affected less than by installing a $\mathrm{CN}$ withdrawing moiety in the RuNCN complex 57.

Another important structural feature is the dihedral angle with the central phenyl ring (as illustrated in Scheme 44), which has a $51.88 \mathrm{X}$-ray determined value and 51.68 calculated value and can lead to a strong decrease in the $\pi$-donation ability of the cyclometalating carbanion in the para position, whereby consequently, the $\mathrm{Ru}-\mathrm{C} 1$ bond is elongated to $2.00 \AA$.

In the case of the RuNCN-F complex 59, it was found that substitution of the fluorine atom as a strong s-accepting group with a moderate p-donation character, in the meta position, has a not considerable effect on the carbanion and so results in a very short $\mathrm{Ru}-\mathrm{C} 1$ bond of $1.98 \AA$. Moreover, it should be mentioned that a decrease in the bond length of the triazole N2-N3 double bond arises from the fluoro and nitro substituent effect, which causes a reduction of the $\mathrm{p}$ back electron-donation ability of the carbanion. Strictly speaking, the fluorine substituent essentially affects the $\sigma$ donation and indirectly reduces the energy of the p system as an inductive effect. This occurs while the $\mathrm{NO}_{2}$ group polarizes the $\mathrm{p}$ system additionally and so lowers its p-donation character via a mesomeric effect. It was also demonstrated for the RuNCN-F complex 59 that the HOMO is stabilized and located on $\mathrm{Ru}$ (II) metal center and also covers the fluoro-substituted cyclometalating phenyl ring. This occurs while an additional LUMO stabilization occurs in RuNCN- $\mathrm{NO}_{2}$ complex 58 since the LUMO is located on the opposed tpy 
ligand and so this can be related to the effect of the aromatic $\mathrm{p}$ system and $\mathrm{d}$ orbitals of $\mathrm{Ru}(\mathrm{II}){ }^{\mathbf{1 1 6}}$

In another report, the electronic properties of ruthenium(II) complexes with 2,6-bis(1,2,3-triazol-4-yl)pyridine 7 ligands were assessed using DFT calculations. The calculations showed that the highest occupied molecular orbital (HOMO) of the complexes included a metal d orbital and $\pi$ orbitals located on the triazolate rings, which were in confirmation with the electron-rich $\pi$ system of the anionic ring. ${ }^{218-220}$ Based on the electron repulsion between the anionic ligand and the metal center, the HOMO is strongly destabilized in comparison to polypyridyl complexes such as $\left[\mathrm{Ru}(\mathrm{tpy})_{2}\right]\left(\mathrm{PF}_{6}\right)_{2} 63$ (Scheme 46). For complexes with terpyridine ligands, the lowest unoccupied molecular orbital (LUMO) is mainly composed of $\pi^{*}$ orbitals of the ligand. Considering the electron-withdrawing groups, the HOMO and, in particular, the LUMO are stabilized due to the electron-withdrawing effect, leading to a significantly smaller HOMO-LUMO gap. A similar effect on the frontier orbitals energies was observed using $-\mathrm{COOH}$ anchoring groups. In contrast, for a deprotonated complex, the HOMO and LUMO of the complex are destabilized and the HOMO-LUMO gap slightly increased, which is attributed to the electron-donating effect of the-COO-groups.

There was good confirmation between the calculated electronic excitations and the experimental UV-vis absorption spectrum. The lowest energy absorption was a pure HOMOLUMO transition, which could be assigned to a metal-to-ligand charge transfer (MLCT) with some ligand-to-ligand chargetransfer (LLCT) character. ${ }^{117}$

\section{Conclusions}

In summary, 1,2,3-triazole-based ligands synthesized via CuAAC click reaction are introduced as diverse biological and pharmaceutical compounds and also their complexes with transition metals were widely applied as efficient catalysts in chemical reactions and reported here. The coordination properties of $\mathrm{Ni}$, $\mathrm{Pd}, \mathrm{Pt}, \mathrm{Re}, \mathrm{Rh}, \mathrm{Ru}$, and Ir transition metal complexes with a series of triazole-based click ligands were investigated via computational chemistry approaches by the calculation of their structural properties, electronic energies, and by frontier molecular orbital analysis. More clearly, in the aforementioned metal complexes of triazoles- and triazaphospholes-based ligands, their X-ray crystal structure, FT-IR and NMR spectroscopic features, metal-to-ligand charge transfer, trans and cis chelation modes, and emission properties were computationally assessed via comparison with the experimental data, which showed reliable agreement.

\section{Conflicts of interest}

There are no conflicts to declare.

\section{Acknowledgements}

The authors gratefully acknowledge Alzahra University Research Council. Tayebeh Hosseinnejad is also thankful to
Iran National Science Foundation (INSF) for partial financial support.

\section{Notes and references}

1 R. Huisgen, Angew. Chem., 1963, 75, 604-637.

2 R. Huisgen, Angew. Chem., Int. Ed. Engl., 1963, 2, 633-645.

3 H. C. Kolb, M. Finn and K. B. Sharpless, Angew. Chem., Int. Ed., 2001, 40, 2004-2021.

4 V. K. Tiwari, B. B. Mishra, K. B. Mishra, N. Mishra, A. S. Singh and X. Chen, Chem. Rev., 2016, 116, 3086-3240.

5 M. M Heravi, M. Tamimi, H. Yahyavi and T. Hosseinnejad, Curr. Org. Chem., 2016, 20, 1591-1647.

6 J. Lauko, P. H. Kouwer and A. E. Rowan, J. Heterocycl. Chem., 2017, 54, 1677-1699.

7 B. Schulze and U. S. Schubert, Chem. Soc. Rev., 2014, 43, 2522-2571.

8 H. Struthers, T. L. Mindt and R. Schibli, Dalton Trans., 2010, 39, 675-696.

9 L. Liang and D. Astruc, Coord. Chem. Rev., 2011, 255, 29332945.

10 J. E. Hein and V. V. Fokin, Chem. Soc. Rev., 2010, 39, 13021315.

11 H. C. Kolb and K. B. Sharpless, Drug Discovery Today, 2003, 8, 1128-1137.

12 A. H. Kategaonkar, P. V. Shinde, A. H. Kategaonkar, S. K. Pasale, B. B. Shingate and M. S. Shingare, Eur. J. Med. Chem., 2010, 45, 3142-3146.

13 S. Demirci, S. Basoglu, A. Bozdereci and N. Demirbas, Med. Chem. Res., 2013, 22, 4930-4945.

14 W. S. Horne, C. D. Stout and M. R. Ghadiri, J. Am. Chem. Soc., 2003, 125, 9372-9376.

15 W. S. Horne, M. K. Yadav, C. D. Stout and M. R. Ghadiri, J. Am. Chem. Soc., 2004, 126, 15366-15367.

16 M. H. Palmer, R. H. Findlay and A. J. Gaskell, J. Chem. Soc., Perkin Trans. 2, 1974, 420-428.

17 R. Alvarez, S. Velazquez, A. San-Felix, S. Aquaro, E. D. Clercq, C.-F. Perno, A. Karlsson, J. Balzarini and M. J. Camarasa, J. Med. Chem., 1994, 37, 4185-4194.

18 L. L. Brockunier, E. R. Parmee, H. O. Ok, M. R. Candelore, M. A. Cascieri, L. F. Colwell, L. Deng, W. P. Feeney, M. J. Forrest and G. J. Hom, Bioorg. Med. Chem. Lett., 2000, 10, 2111-2114.

19 M. J. Genin, D. A. Allwine, D. J. Anderson, M. R. Barbachyn, D. E. Emmert, S. A. Garmon, D. R. Graber, K. C. Grega, J. B. Hester and D. K. Hutchinson, J. Med. Chem., 2000, 43, 953-970.

20 D. R. Buckle and C. J. Rockell, J. Chem. Soc., Perkin Trans. 1, 1982, 627-630.

21 R. A. Vasdev, D. Preston and J. D. Crowley, Dalton Trans., 2017, 46, 2402-2414.

22 Q. V. van Hilst, N. R. Lagesse, D. Preston and J. D. Crowley, Dalton Trans., 2018, 47, 997-1002.

23 S. C. Hockey, G. J. Barbante, P. S. Francis, J. M. Altimari, P. Yoganantharajah, Y. Gibert and L. C. Henderson, Eur. J. Med. Chem., 2016, 109, 305-313. 
24 S. Löber, P. Rodriguez-Loaiza and P. Gmeiner, Org. Lett., 2003, 5, 1753-1755.

25 J. P. Collman, N. K. Devaraj and C. E. Chidsey, Langmuir, 2004, 20, 1051-1053.

26 D. D. Díaz, S. Punna, P. Holzer, A. K. Mcpherson, K. B. Sharpless, V. V. Fokin and M. Finn, J. Polym. Sci., Part A: Polym. Chem., 2004, 42, 4392-4403.

27 A. Kumar, G. K. Rao, S. Kumar and A. K. Singh, Dalton Trans., 2013, 42, 5200-5223.

28 F. Saleem, G. K. Rao, P. Singh and A. K. Singh, Organometallics, 2013, 32, 387-395.

29 M. Felici, P. Contreras-Carballada, Y. Vida, J. M. Smits, R. J. Nolte, L. De Cola, R. M. Williams and M. C. Feiters, Chem.-Eur. J., 2009, 15, 13124-13134.

30 H. Yang, L. Li, L. Wan, Z. Zhou and S. Yang, Inorg. Chem. Commun., 2010, 13, 1387-1390.

31 S. Ladouceur, D. Fortin and E. Zysman-Colman, Inorg. Chem., 2011, 50, 11514-11526.

32 M. Felici, P. Contreras-Carballada, J. Smits and R. Nolte, Molecules, 2010, 15, 2039.

33 C. Hua, K. Q. Vuong, M. Bhadbhade and B. A. Messerle, Organometallics, 2012, 31, 1790-1800.

34 N. V. Dubrovina, L. Domke, I. A. Shuklov, A. Spannenberg, R. Franke, A. Villinger and A. Börner, Tetrahedron, 2013, 69, 8809-8817.

35 D. C. Goldstein, J. R. Peterson, Y. Y. Cheng, R. G. Clady, T. W. Schmidt and P. Thordarson, Molecules, 2013, 18, 8959-8975.

36 K. Q. Vuong, M. G. Timerbulatova, M. B. Peterson, M. Bhadbhade and B. A. Messerle, Dalton Trans., 2013, 42, 14298-14308.

37 F. Saleem, G. K. Rao, A. Kumar, G. Mukherjee and A. K. Singh, Organometallics, 2013, 32, 3595-3603.

38 M. Schuster, M. Botoshansky and M. Gandelman, Angew. Chem., Int. Ed., 2008, 47, 4555-4558.

39 H. Struthers, B. Spingler, T. L. Mindt and R. Schibli, Chem.Eur. J., 2008, 14, 6173-6183.

40 E. M. Schuster, G. Nisnevich, M. Botoshansky and M. Gandelman, Organometallics, 2009, 28, 5025-5031.

41 E. M. Schuster, M. Botoshansky and M. Gandelman, Organometallics, 2009, 28, 7001-7005.

42 H. V. Ching, X. Wang, M. He, N. Perujo Holland, R. Guillot, C. Slim, S. Griveau, H. C. Bertrand, C. Policar and F. Bedioui, Inorg. Chem., 2017, 56, 2966-2976.

43 S. Hostachy, C. Policar and N. Delsuc, Coord. Chem. Rev., 2017, 351, 172-188.

44 H. C. Bertrand, S. Clède, R. Guillot, F. Lambert and C. Policar, Inorg. Chem., 2014, 53, 6204-6223.

45 A. Dazzi and C. Policar, in Biointerface characterization by advanced IR spectroscopy, Elsevier, 2011, pp. 245-278.

46 M. G. Fraser, A. G. Blackman, G. I. Irwin, C. P. Easton and K. C. Gordon, Inorg. Chem., 2010, 49, 5180-5189.

47 S. L. Howell, K. C. Gordon and J. J. McGarvey, J. Phys. Chem. A, 2005, 109, 2948-2956.

48 S. L. Howell, B. J. Matthewson, M. I. Polson, A. K. Burrell and K. C. Gordon, Inorg. Chem., 2004, 43, 2876-2887.
49 B. J. Matthewson, A. Flood, M. I. J. Polson, C. Armstrong, D. L. Phillips and K. C. Gordon, Bull. Chem. Soc. Jpn., 2002, 75, 933-942.

50 A. Y. Hirakawa and M. Tsuboi, Science, 1975, 188, 359-361.

51 R. J. Clark and T. J. Dines, Angew. Chem., Int. Ed. Engl., 1986, 25, 131-158.

52 A. Flood, R. B. Girling, K. C. Gordon, R. E. Hester, J. N. Moore and M. I. Polson, J. Raman Spectrosc., 2002, 33, 434-442.

53 A. D. Becke, J. Chem. Phys., 1993, 98, 1372-1377.

54 C. Lee, W. Yang and R. G. Parr, Phys. Rev. B: Condens. Matter Mater. Phys., 1988, 37, 785.

55 D. Schweinfurth, J. Krzystek, I. Schapiro, S. Demeshko, J. Klein, J. Telser, A. Ozarowski, C.-Y. Su, F. Meyer and M. Atanasov, Inorg. Chem., 2013, 52, 6880-6892.

56 K. J. Kilpin, E. L. Gavey, C. J. McAdam, C. B. Anderson, S. J. Lind, C. C. Keep, K. C. Gordon and J. D. Crowley, Inorg. Chem., 2011, 50, 6334-6346.

57 B. Pinter, A. Demšar, D. Urankar, F. De Proft and J. Košmrlj, Polyhedron, 2011, 30, 2368-2373.

58 C. B. Anderson, A. B. Elliott, J. E. Lewis, C. J. McAdam, K. C. Gordon and J. D. Crowley, Dalton Trans., 2012, 41, 14625-14632.

59 M. Wolff, L. Munoz, A. François, C. Carrayon, A. Seridi, N. Saffon, C. Picard, B. Machura and E. Benoist, Dalton Trans., 2013, 42, 7019-7031.

60 D. Schweinfurth, L. Hettmanczyk, L. Suntrup and B. Sarkar, Z. Anorg. Allg. Chem., 2017, 643, 553-561.

61 P. A. Scattergood, A. Sinopoli and P. I. Elliott, Coord. Chem. Rev., 2017, 350, 136-154.

62 P. A. Scattergood and P. I. Elliott, Dalton Trans., 2017, 46, 16343-16356.

63 A. Seridi, M. Wolff, A. Boulay, N. Saffon, Y. Coulais, C. Picard, B. Machura and E. Benoist, Inorg. Chem. Commun., 2011, 14, 238-242.

64 T. Y. Kim, A. B. Elliott, K. J. Shaffer, C. J. McAdam, K. C. Gordon and J. D. Crowley, Polyhedron, 2013, 52, 1391-1398.

65 J. P. Byrne, J. A. Kitchen and T. Gunnlaugsson, Chem. Soc. Rev., 2014, 43, 5302-5325.

66 J. A. Sklorz, S. Hoof, M. G. Sommer, F. Weißer, M. Weber, J. Wiecko, B. Sarkar and C. Müller, Organometallics, 2014, 33, 511-516.

67 F. Ebrahimpour-Malamir, T. Hosseinnejad, R. Mirsafaei and M. M. Heravi, Appl. Organomet. Chem., 2017, DOI: 10.1002/aoc.3913.

68 T. Baie Lashaki, H. A. Oskooie, T. Hosseinnejad and M. M. Heravi, J. Coord. Chem., 2017, 1-20.

69 T. Hossiennejad, M. Daraie, M. M. Heravi and N. N. Tajoddin, J. Inorg. Organomet. Polym. Mater., 2017, 1-10.

70 R. Mirsafaei, M. M. Heravi, T. Hosseinnejad and S. Ahmadi, Appl. Organomet. Chem., 2016, 10, 823-830.

71 R. Mirsafaei, M. M. Heravi, S. Ahmadi and T. Hosseinnejad, Chem. Pap., 2016, 70, 418-429.

72 T. Hosseinnejad and M. Dinyari, Comput. Theor. Chem., 2015, 1071, 53-60. 
73 R. Mirsafaei, M. M. Heravi, S. Ahmadi, M. H. Moslemin and T. Hosseinnejad, J. Mol. Catal. A: Chem., 2015, 402, 100-108.

74 T. Hosseinnejad, M. M. Heravi and R. Firouzi, J. Mol. Model., 2013, 19, 951-961.

75 M. M. Heravi, T. Hosseinnejad and N. Nazari, Can. J. Chem., 2017, 95, 530-536.

76 T. Hosseinnejad, B. Fattahi and M. M. Heravi, J. Mol. Model., 2015, 21, 264.

77 M. Meldal and C. W. Tornøe, Chem. Rev., 2008, 108, 29523015.

78 P. Wu and V. V. Fokin, Aldrichimica Acta, 2007, 40, 7-17.

79 J. D. Crowley and D. A. McMorran, in Click Triazoles, Springer, 2012, pp. 31-83.

80 D. Schweinfurth, N. Deibel, F. Weisser and B. Sarkar, Nachr. Chem., 2011, 59, 937-941.

81 P. M. Guha, H. Phan, J. S. Kinyon, W. S. Brotherton, K. Sreenath, J. T. Simmons, Z. Wang, R. J. Clark, N. S. Dalal and M. Shatruk, Inorg. Chem., 2012, 51, 34653477.

82 D. Schweinfurth, R. Pattacini, S. Strobel and B. Sarkar, Dalton Trans., 2009, 9291-9297.

83 M. Felici, P. Contreras-Carballada, J. M. Smits, R. J. Nolte, R. M. Williams, L. De Cola and M. C. Feiters, Molecules, 2010, 15, 2039-2059.

84 S. Zanarini, M. Felici, G. Valenti, M. Marcaccio, L. Prodi, S. Bonacchi, P. Contreras-Carballada, R. M. Williams, M. C. Feiters and R. J. Nolte, Chem.-Eur. J., 2011, 17, 4640-4647.

85 I. Stengel, A. Mishra, N. Pootrakulchote, S.-J. Moon, S. M. Zakeeruddin, M. Grätzel and P. Bäuerle, J. Mater. Chem., 2011, 21, 3726-3734.

86 S. Liu, P. Müller, M. K. Takase and T. M. Swager, Inorg. Chem., 2011, 50, 7598-7609.

87 B. Happ, D. Escudero, M. D. Hager, C. Friebe, A. Winter, H. Görls, E. Altuntas, L. González and U. S. Schubert, J. Org. Chem., 2010, 75, 4025-4038.

88 M. Juríček, M. Felici, P. Contreras-Carballada, J. Lauko, S. R. Bou, P. H. Kouwer, A. M. Brouwer and A. E. Rowan, J. Mater. Chem., 2011, 21, 2104-2111.

89 M. Juríček, P. H. Kouwer and A. E. Rowan, Chem. Commun., 2011, 47, 8740-8749.

90 G. Zhang, Y. Wang, X. Wen, C. Ding and Y. Li, Chem. Commun., 2012, 48, 2979-2981.

91 E. Amadio, M. Bertoldini, A. Scrivanti, G. Chessa, V. Beghetto, U. Matteoli, R. Bertani and A. Dolmella, Inorg. Chim. Acta, 2011, 370, 388-393.

92 A. D'Amora, L. Fanfoni, D. Cozzula, N. Guidolin, E. Zangrando, F. Felluga, S. Gladiali, F. Benedetti and B. Milani, Organometallics, 2010, 29, 4472-4485.

93 I. Bratsos, D. Urankar, E. Zangrando, P. Genova-Kalou, J. Košmrlj, E. Alessio and I. Turel, Dalton Trans., 2011, 40, 5188-5199.

94 D. Urankar, A. Pevec, I. Turel and J. Košmrlj, Cryst. Growth Des., 2010, 10, 4920-4927.

95 C. B. Anderson, A. B. Elliott, C. J. McAdam, K. C. Gordon and J. D. Crowley, Organometallics, 2013, 32, 788-797.
96 B. Happ, C. Friebe, A. Winter, M. D. Hager, R. Hoogenboom and U. S. Schubert, Chem.-Asian J., 2009, 4, 154-163.

97 M. Obata, A. Kitamura, A. Mori, C. Kameyama, J. A. Czaplewska, R. Tanaka, I. Kinoshita, T. Kusumoto, H. Hashimoto and M. Harada, Dalton Trans., 2008, 32923300.

98 D. Schweinfurth, C.-Y. Su, S.-C. Wei, P. Braunstein and B. Sarkar, Dalton Trans., 2012, 41, 12984-12990.

99 D. Urankar, B. Pinter, A. Pevec, F. De Proft, I. Turel and J. Košmrlj, Inorg. Chem., 2010, 49, 4820-4829.

100 S. L. Choong, A. Nafady, A. Stasch, A. M. Bond and C. Jones, Dalton Trans., 2013, 42, 7775-7780.

101 S. V. Chapyshev, Synlett, 2009, 1-8.

102 S. Chapyshev, U. Bergsträßer and M. Regitz, Chem. Heterocycl. Compd., 1996, 32, 59-64.

103 S. L. Choong, C. Jones and A. Stasch, Dalton Trans., 2010, 39, 5774-5776.

104 C. Pardin, I. Roy, W. D. Lubell and J. W. Keillor, Chem. Biol. Drug Des., 2008, 72, 189-196.

105 G. Becker, G. Gresser and W. Uhl, Z. Naturforsch., B: Anorg. Chem., Org. Chem., 1981, 36, 16-19.

106 J. G. Cordaro, D. Stein, H. Rüegger and H. Grützmacher, Angew. Chem., Int. Ed., 2006, 45, 6159-6162.

107 H. C. Kolb, M. Finn and K. B. Sharpless, Angew. Chem., 2001, 113, 2056-2075.

108 Y. Li, J. C. Huffman and A. H. Flood, Chem. Commun., 2007, 2692-2694.

109 R. M. Meudtner, M. Ostermeier, R. Goddard, C. Limberg and S. Hecht, Chem.-Eur. J., 2007, 13, 9834-9840.

110 M. Ostermeier, M. A. Berlin, R. M. Meudtner, S. Demeshko, F. Meyer, C. Limberg and S. Hecht, Chem.-Eur. J., 2010, 16, 10202-10213.

111 B. Schulze, D. Escudero, C. Friebe, R. Siebert, H. Görls, U. Köhn, E. Altuntas, A. Baumgaertel, M. D. Hager and A. Winter, Chem.-Eur. J., 2011, 17, 5494-5498.

112 M. Beley, J. P. Collin, R. Louis, B. Metz and J. P. Sauvage, J. Am. Chem. Soc., 1991, 113, 8521-8522.

113 J. G. Williams, Chem. Soc. Rev., 2009, 38, 1783-1801.

114 B. Beyer, C. Ulbricht, D. Escudero, C. Friebe, A. Winter, L. González and U. S. Schubert, Organometallics, 2009, 28, 5478-5488.

115 A. J. Wilkinson, H. Puschmann, J. A. Howard, C. E. Foster and J. G. Williams, Inorg. Chem., 2006, 45, 8685-8699.

116 B. Schulze, D. Escudero, C. Friebe, R. Siebert, H. Görls, S. Sinn, M. Thomas, S. Mai, J. Popp and B. Dietzek, Chem.-Eur. J., 2012, 18, 4010-4025.

117 S. Sinn, B. Schulze, C. Friebe, D. G. Brown, M. Jäger, J. Kübel, B. Dietzek, C. P. Berlinguette and U. S. Schubert, Inorg. Chem., 2014, 53, 1637-1645.

118 S. K. Vellas, J. E. Lewis, M. Shankar, A. Sagatova, J. D. Tyndall, B. C. Monk, C. M. Fitchett, L. R. Hanton and J. D. Crowley, Molecules, 2013, 18, 6383-6407.

119 S. V. Kumar, W. K. Lo, H. J. Brooks and J. D. Crowley, Inorg. Chim. Acta, 2015, 425, 1-6.

120 R. A. Vasdev, D. Preston, S. Ø. Scottwell, H. J. Brooks, J. D. Crowley and M. P. Schramm, Molecules, 2016, 21, 1548. 
121 S. V. Kumar, W. K. Lo, H. J. Brooks, L. R. Hanton and J. D. Crowley, Aust. J. Chem., 2016, 69, 489-498.

122 B. J. Pages, J. Sakoff, J. Gilbert, Y. Zhang, F. Li, D. Preston, J. D. Crowley and J. R. Aldrich-Wright, J. Inorg. Biochem., 2016, 165, 92-99.

123 S. Jindabot, K. Teerachanan, P. Thongkam, S. Kiatisevi, T. Khamnaen, P. Phiriyawirut, S. Charoenchaidet, T. Sooksimuang, P. Kongsaeree and P. Sangtrirutnugul, J. Organomet. Chem., 2014, 750, 35-40.

124 F. Saleem, G. Rao, A. Kumar, S. Kumar, M. P. Singh and A. K. Singh, RSC Adv., 2014, 4, 56102-56111.

125 W. K. Lo, G. S. Huff, J. R. Cubanski, A. D. Kennedy, C. J. McAdam, D. A. McMorran, K. C. Gordon and J. D. Crowley, Inorg. Chem., 2015, 54, 1572-1587.

126 K. J. Kilpin and J. D. Crowley, Polyhedron, 2010, 29, 31113117.

127 D. Schweinfurth, S. Strobel and B. Sarkar, Inorg. Chim. Acta, 2011, 374, 253-260.

128 S. Yano, H. Ohi, M. Ashizaki, M. Obata, Y. Mikata, R. Tanaka, T. Nishioka, I. Kinoshita, Y. Sugai and I. Okura, Chem. Biodiversity, 2012, 9, 1903-1915.

129 E. P. McCarney, C. S. Hawes, S. Blasco and T. Gunnlaugsson, Dalton Trans., 2016, 45, 10209-10221.

130 M. Krikorian, S. Liu and T. M. Swager, J. Am. Chem. Soc., 2014, 136, 2952-2955.

131 D. Sooksawat, S. J. Pike, A. M. Slawin and P. J. Lusby, Chem. Commun., 2013, 49, 11077-11079.

132 M. Prabhath, J. Romanova, R. J. Curry, S. R. P. Silva and P. D. Jarowski, Angew. Chem., Int. Ed., 2015, 54, 7949-7953.

133 J. D. Crowley and P. H. Bandeen, Dalton Trans., 2010, 39, 612-623.

134 J. D. Crowley, P. H. Bandeen and L. R. Hanton, Polyhedron, 2010, 29, 70-83.

135 N. Wu, C. F. Melan, K. A. Stevenson, O. Fleischel, H. Guo, F. Habib, R. J. Holmberg, M. Murugesu, N. J. Mosey and H. Nierengarten, Dalton Trans., 2015, 44, 14991-15005.

136 C. Ducani, A. Leczkowska, N. J. Hodges and M. J. Hannon, Angew. Chem., Int. Ed., 2010, 49, 8942-8945.

137 Y. Parajó, J. Malina, I. Meistermann, G. J. Clarkson, M. Pascu, A. Rodger, M. J. Hannon and P. Lincoln, Dalton Trans., 2009, 4868-4874.

138 S. Phongtongpasuk, S. Paulus, J. Schnabl, R. K. Sigel, B. Spingler, M. J. Hannon and E. Freisinger, Angew. Chem., Int. Ed., 2013, 52, 11513-11516.

139 D. Preston, R. A. Tucker, A. L. Garden and J. D. Crowley, Inorg. Chem., 2016, 55, 8928-8934.

140 Y. Ju, D. Kumar and R. S. Varma, J. Org. Chem., 2006, 71, 6697-6700.

141 J. Andersen, U. Madsen, F. Björkling and X. Liang, Synlett, 2005, 2209-2213.

142 E. C. Keske, O. V. Zenkina, R. Wang and C. M. Crudden, Organometallics, 2011, 31, 456-461.

143 K. J. Kilpin, U. S. Paul, A.-L. Lee and J. D. Crowley, Chem. Commun., 2011, 47, 328-330.

144 N. G. White and P. D. Beer, Supramol. Chem., 2012, 24, 473480.
145 S. Ø. Scott, E. L. Gavey, S. J. Lind, K. C. Gordon and J. D. Crowley, Dalton Trans., 2011, 40, 12117-12124.

146 J. D. Crowley and E. L. Gavey, Dalton Trans., 2010, 39, 40354037.

147 M. Atanasov, J. M. Zadrozny, J. R. Long and F. Neese, Chem. Sci., 2013, 4, 139-156.

148 M. Atanasov, P. Comba, S. Helmle, D. Müller and F. Neese, Inorg. Chem., 2012, 51, 12324-12335.

149 F. Neese, Wiley Interdiscip. Rev.: Comput. Mol. Sci., 2012, 2, 73-78.

150 C. Angeli, R. Cimiraglia and J.-P. Malrieu, Chem. Phys. Lett., 2001, 350, 297-305.

151 C. Angeli, R. Cimiraglia, S. Evangelisti, T. Leininger and J.-P. Malrieu, J. Chem. Phys., 2001, 114, 10252-10264.

152 C. Angeli, R. Cimiraglia and J.-P. Malrieu, J. Chem. Phys., 2002, 117, 9138-9153.

153 C. Angeli, S. Borini, M. Cestari and R. Cimiraglia, J. Chem. Phys., 2004, 121, 4043-4049.

154 C. Angeli, B. Bories, A. Cavallini and R. Cimiraglia, J. Chem. Phys., 2006, 124, 054108.

155 B. O. Roos, Advances in Chemical Physics: Ab Initio Methods in Quantum Chemistry Part 2, John Wiley \& Sons, 2007, pp. 399-445.

156 S. Guo, M. A. Watson, W. Hu, Q. Sun and G. K.-L. Chan, J. Chem. Theory Comput., 2016, 12, 1583-1591.

157 H. Nakano, R. Uchiyama and K. Hirao, J. Comput. Chem., 2002, 23, 1166-1175.

158 J. Telser, J. Krzystek and A. Ozarowski, J. Biol. Inorg Chem., 2014, 19, 297-318.

159 P. E. Hoggard, Angular overlap model parameters, Springer, 2004, pp. 37-57.

160 J. J. Wilson, J. Fedoce Lopes and S. J. Lippard, Inorg. Chem., 2010, 49, 5303-5315.

161 V. A. Polyakov and A. D. Ryabov, J. Chem. Soc., Dalton Trans., 1986, 589-593.

162 T. Ziegler and A. Rauk, Inorg. Chem., 1979, 18, 1558-1565.

163 T. Ziegler and A. Rauk, Inorg. Chem., 1979, 18, 1755-1759.

164 I. M. Dixon, J.-L. Heully, F. Alary and P. I. Elliott, Phys. Chem. Chem. Phys., 2017, 19, 27765-27778.

165 A. Klamt and G. Schüürmann, J. Chem. Soc., Perkin Trans. 2, 1993, 799-805.

166 K. A. Stevenson, C. F. Melan, O. Fleischel, R. Wang and A. Petitjean, Cryst. Growth Des., 2012, 12, 5169-5173.

167 L. Jiang, Z. Wang, S.-Q. Bai and T. A. Hor, CrystEngComm, 2013, 15, 10451-10458.

168 E. Amadio, A. Scrivanti, G. Chessa, U. Matteoli, V. Beghetto, M. Bertoldini, M. Rancan, A. Dolmella, A. Venzo and R. Bertani, J. Organomet. Chem., 2012, 716, 193-200.

169 J. Herrmann, P. S. Pregosin, R. Salzmann and A. Albinati, Organometallics, 1995, 14, 3311-3318.

170 P. Barbaro, A. Currao, J. Herrmann, R. Nesper, P. S. Pregosin and R. Salzmann, Organometallics, 1996, 15, 1879-1888.

171 M. Gómez, S. Jansat, G. Muller, M. A. Maestro and J. Mahía, Organometallics, 2002, 21, 1077-1087.

172 A. Ros, D. Monge, M. Alcarazo, E. Álvarez, J. M. Lassaletta and R. Fernández, Organometallics, 2006, 25, 6039-6046. 
173 S. J. Roseblade, A. Ros, D. Monge, M. Alcarazo, E. Álvarez, J. M. Lassaletta and R. Fernández, Organometallics, 2007, 26, 2570-2578.

174 E. Amadio, A. Scrivanti, M. Bortoluzzi, M. Bertoldini, V. Beghetto, U. Matteoli and G. Chessa, Inorg. Chim. Acta, 2013, 405, 188-195.

175 A. Maisonial, P. Serafin, M. Traïkia, E. Debiton, V. Thery, D. J. Aitken, P. Lemoine, B. Viossat and A. Gautier, Eur. J. Inorg. Chem., 2008, 298-305.

176 W. S. Brotherton, H. A. Michaels, J. T. Simmons, R. J. Clark, N. S. Dalal and L. Zhu, Org. Lett., 2009, 11, 4954-4957.

177 O. Fleischel, N. Wu and A. Petitjean, Chem. Commun., 2010, 46, 8454-8456.

178 A. G. Young and L. R. Hanton, Coord. Chem. Rev., 2008, 252, 1346-1386.

179 P. Thongkam, S. Jindabot, S. Prabpai, P. Kongsaeree, T. Wititsuwannakul, P. Surawatanawong and P. Sangtrirutnugul, RSC Adv., 2015, 5, 55847-55855.

180 C. Schouwey, M. Papmeyer, R. Scopelliti and K. Severin, Dalton Trans., 2015, 44, 2252-2258.

181 M. L. Saha, Z. Zhou and P. J. Stang, Chem.-Asian J., 2016, 11, 2662-2666.

182 U. R. Pokharel, F. R. Fronczek and A. W. Maverick, Dalton Trans., 2013, 42, 14064-14067.

183 A. Boulay, A. Seridi, C. Zedde, S. Ladeira, C. Picard, L. Maron and E. Benoist, Eur. J. Inorg. Chem., 2010, 50585062 .

184 S. Clède, F. Lambert, C. Sandt, Z. Gueroui, M. Réfrégiers, M.-A. Plamont, P. Dumas, A. Vessières and C. Policar, Chem. Commun., 2012, 48, 7729-7731.

185 L. Wei, S. R. Banerjee, M. K. Levadala, J. Babich and J. Zubieta, Inorg. Chim. Acta, 2004, 357, 1499-1516.

186 T. Tabeya, M. Abe, A. Mitani, K. Tsuge and Y. Sasaki, J. Nucl. Radiochem. Sci., 2005, 6, 157-159.

187 R. Díaz, A. Francois and B. Loeb, Polyhedron, 2011, 30, 697701.

188 S. Wanniarachchi, B. J. Liddle, J. Toussaint, S. V. Lindeman, B. Bennett and J. R. Gardinier, Dalton Trans., 2010, 39, 3167-3169.

189 E. Palma, J. D. Correia, Â. Domingos, I. Santos, R. Alberto and H. Spies, J. Organomet. Chem., 2004, 689, 4811-4819.

190 E. Runge and E. K. Gross, Phys. Rev. Lett., 1984, 52, 997.

191 A. Mattiuzzi, I. Jabin, C. Moucheron and A. Kirsch-De Mesmaeker, Dalton Trans., 2011, 40, 7395-7402.

192 D. Schweinfurth, K. I. Hardcastle and U. H. Bunz, Chem. Commun., 2008, 2203-2205.

193 T. M. Clarke, K. C. Gordon, D. L. Officer, S. B. Hall, G. E. Collis and A. K. Burrell, J. Phys. Chem. A, 2003, 107, 11505-11516.

194 T. M. Clarke, K. C. Gordon, D. L. Officer and D. K. Grant, J. Phys. Chem. A, 2005, 109, 1961-1973.

195 M. R. Waterland and K. C. Gordon, J. Raman Spectrosc., 2000, 31, 243-253.
196 M. R. Waterland, K. C. Gordon, J. J. McGarvey and P. M. Jayaweera, J. Chem. Soc., Dalton Trans., 1998, 609-616. 197 O. Prakash, P. Singh, G. Mukherjee and A. K. Singh, Organometallics, 2012, 31, 3379-3388.

198 M. Valderrama, R. Contreras, M. P. Lamata, F. Viguri, D. Carmona, F. J. Lahoz, S. Elipe and L. A. Oro, J. Organomet. Chem., 2000, 607, 3-11.

199 M. Herberhold, H. Yan, W. Milius and B. Wrackmeyer, Organometallics, 2000, 19, 4289-4294.

200 W.-G. Jia, Y.-B. Huang, Y.-J. Lin and G.-X. Jin, Dalton Trans., 2008, 5612-5620.

201 E. Simón-Manso, M. Valderrama, P. Gantzel and C. P. Kubiak, J. Organomet. Chem., 2002, 651, 90-97.

202 M. Sakamoto, Y. Ohki and K. Tatsumi, Organometallics, 2010, 29, 1761-1770.

203 S. Nagao, H. Seino, T. Okada, Y. Mizobe and M. Hidai, J. Chem. Soc., Dalton Trans., 2000, 3546-3553.

204 L. B. Kumbhare, A. P. Wadawale, V. K. Jain, M. Sieger and W. Kaim, Inorg. Chem. Commun., 2010, 13, 475-478.

205 T. Nakagawa, H. Seino and Y. Mizobe, Organometallics, 2010, 29, 2254-2259.

206 R. Lalrempuia, H. Müller-Bunz and M. Albrecht, Angew. Chem., Int. Ed., 2011, 50, 9969-9972.

207 Z. Liu, L. Salassa, A. Habtemariam, A. M. Pizarro, G. J. Clarkson and P. J. Sadler, Inorg. Chem., 2011, 50, 5777-5783.

208 A. Bastero, D. Font and M. A. Pericàs, J. Org. Chem., 2007, 72, 2460-2468.

209 T. H. Dunning Jr and P. J. Hay, in Methods of electronic structure theory, Springer, 1977, pp. 1-27.

210 P. J. Hay and W. R. Wadt, J. Chem. Phys., 1985, 82, 270-283. 211 P. J. Hay and W. R. Wadt, J. Chem. Phys., 1985, 82, 299-310. 212 W. R. Wadt and P. J. Hay, J. Chem. Phys., 1985, 82, 284-298. 213 F. Saleem, G. K. Rao, A. Kumar, G. Mukherjee and A. K. Singh, Organometallics, 2014, 33, 2341-2351.

214 C. Zhang, X. Shen, R. Sakai, M. Gottschaldt, U. S. Schubert, S. Hirohara, M. Tanihara, S. Yano, M. Obata and N. Xiao, J. Polym. Sci., Part A: Polym. Chem., 2011, 49, 746-753.

215 S. J. Ahmed, M. I. Hyder, S. E. Kabir, M. A. Miah, A. J. Deeming and E. Nordlander, J. Organomet. Chem., 2006, 691, 309-322.

216 A. K. Singh, M. Kadarkaraisamy, M. Mishra, J. Sooriyakumar, J. Drake, M. Hursthouse, M. Light and J. P. Jasinski, Inorg. Chim. Acta, 2001, 320, 133-140.

217 H. Mishra and R. Mukherjee, J. Organomet. Chem., 2006, 691, 3545-3555.

218 C.-W. Hsu, S.-T. Ho, K.-L. Wu, Y. Chi, S.-H. Liu and P.-T. Chou, Energy Environ. Sci., 2012, 5, 7549-7554.

219 K.-L. Wu, H.-C. Hsu, K. Chen, Y. Chi, M.-W. Chung, W.-H. Liu and P.-T. Chou, Chem. Commun., 2010, 46, 5124-5126.

220 P. G. Bomben, K. C. Robson, B. D. Koivisto and C. P. Berlinguette, Coord. Chem. Rev., 2012, 256, 1438-1450. 